\title{
SMART DC WALL OUTLET DESIGN WITH IMPROVED LOAD VOLTAGE DETECTION
}

\author{
A Thesis \\ presented to \\ the Faculty of California Polytechnic State University, \\ San Luis Obispo
}

In Partial Fulfillment

of the Requirements of the Degree of Joint Bachelor of Science and Master of Science in Electrical Engineering

by

Patrick Donovon Granieri

June 2019 
(C) 2019

Patrick Donovon Granieri

ALL RIGHTS RESERVED

ii 
TITLE:

AUTHOR:

DATE SUBMITTED:

COMMITTEE CHAIR:

COMMITTEE MEMBER:

COMMITTEE MEMBER:
Smart DC Wall Outlet Design and Load Voltage Detection

Patrick Donovon Granieri

June 2019

Taufik, Ph.D.

Professor of Electrical Engineering

Tina Smilkstein, Ph.D.

Associate Professor of Electrical

Engineering

Majid Poshtan, Ph.D.

Associate Professor of Electrical

Engineering 


\begin{abstract}
Smart DC Wall Outlet Design with Improved Load Voltage Detection Patrick Donovon Granieri
\end{abstract}

A standard home in the United States has access to the $120 \mathrm{~V}$ AC power grid for use with home appliances. Many electronics used at home are powered by a DC power supply, which loses energy in the conversion from AC power. The DC House project avoids any conversion between AC and DC by storing energy in batteries as DC power and supplying it directly to DC appliances. While AC systems feature a standardized output voltage, no such standard exists for DC systems. The Smart DC Wall Outlet solves this by automatically adjusting its output voltage to meet any required DC load voltage. A hardware solution was developed using a microcontroller in tandem with a DC to DC Buck converter to monitor trends in the output current and set the output voltage accordingly. The Smart DC Wall Outlet features two 100W output channels that were able to correctly identify the required output voltage of five out of seven test devices. Results indicate that it is possible to generalize the turn on characteristics of DC devices, but that other solutions may find more success. 


\section{ACKNOWLEDGMENTS}

I would like to thank my advisor Dr. Taufik for showing me the true utility of power electronics. I would also like to thank my mother and my sister, Barbara and Rebecca Granieri, along with the rest of my family for helping me through university and encouraging me every step of the way. Last, but not least, I would like to thank my friends for being my support when I was in need. Without these people, none of this would have been possible. 


\section{TABLE OF CONTENTS}

Page

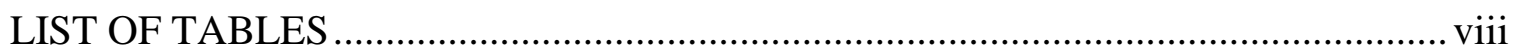

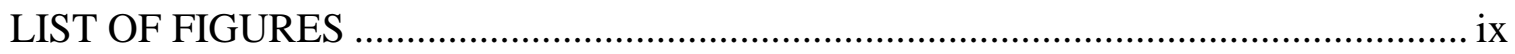

\section{CHAPTER}

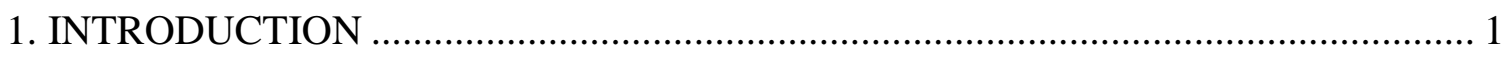

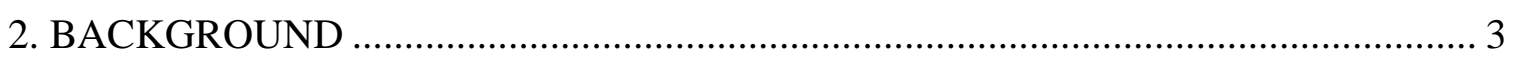

2.1. The Need for a Variable DC Wall Outlet ................................................................. 3

2.2. DC to DC Voltage Converters ……………….............................................. 3

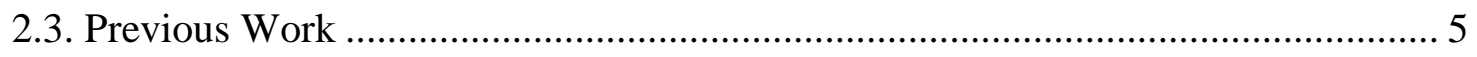

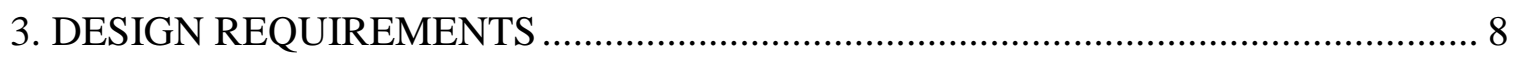

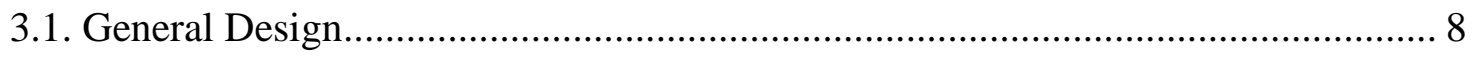

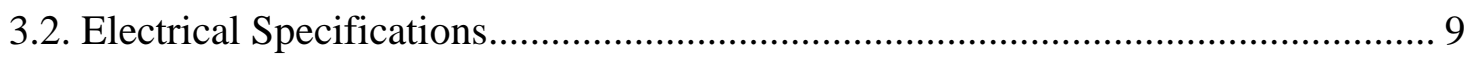

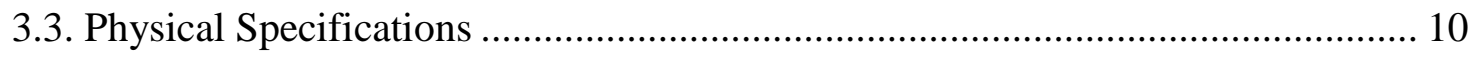

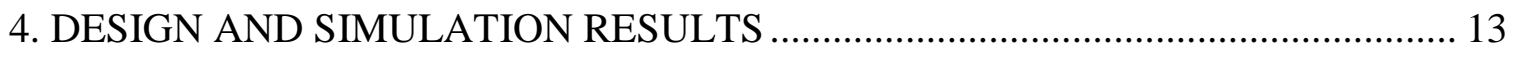

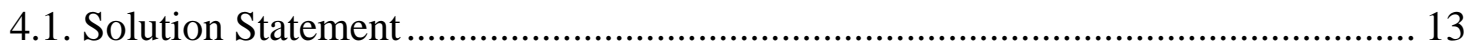

4.2. Primary and Secondary Buck Controller Selection ............................................... 13

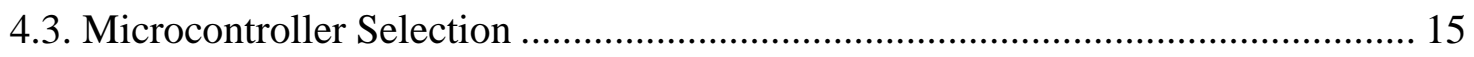

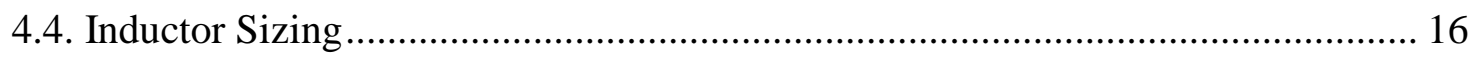

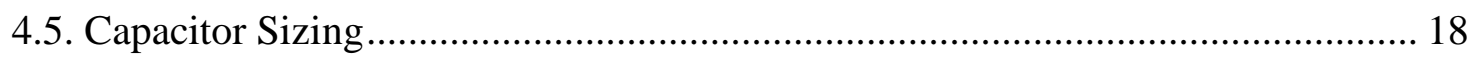

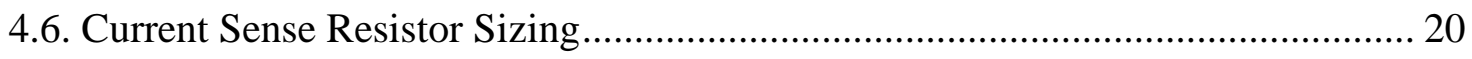

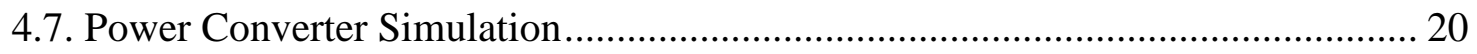




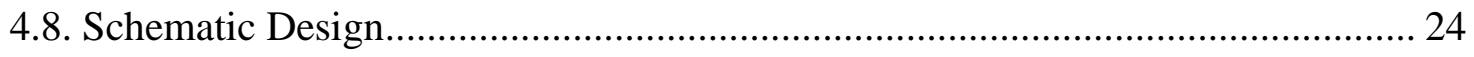

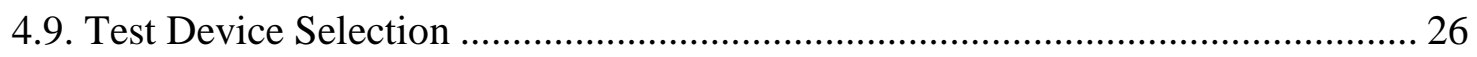

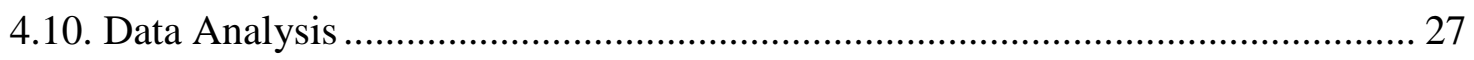

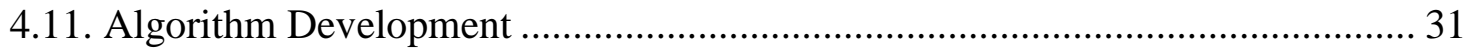

5. HARDWARE CONSTRUCTION AND TESTING RESULTS .................................. 35

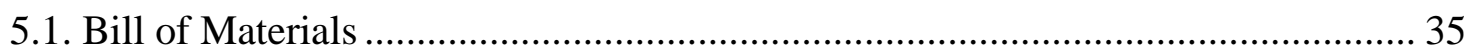

5.2. PCB Layout and Fabrication............................................................................... 37

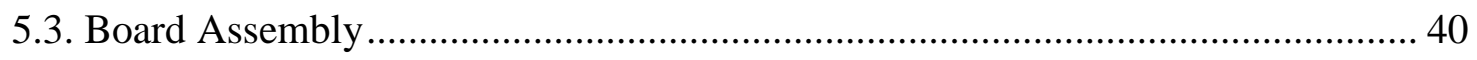

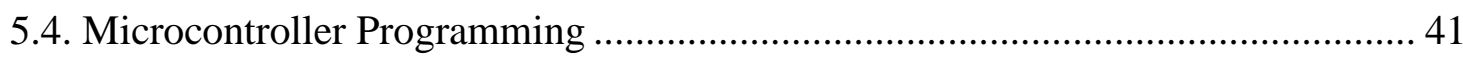

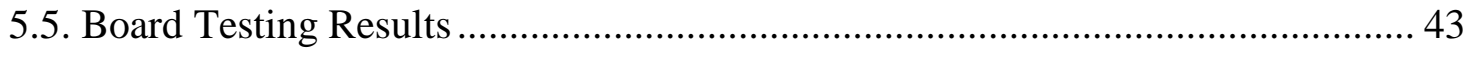

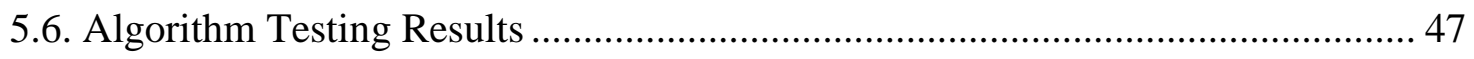

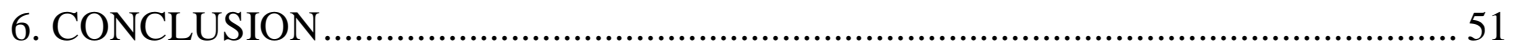

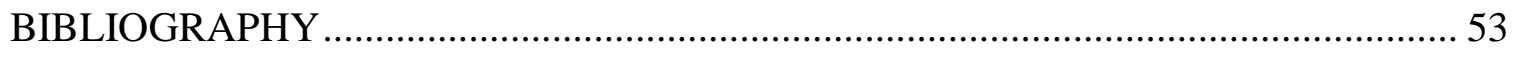

APPENDICES

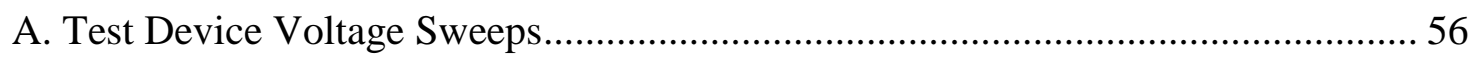

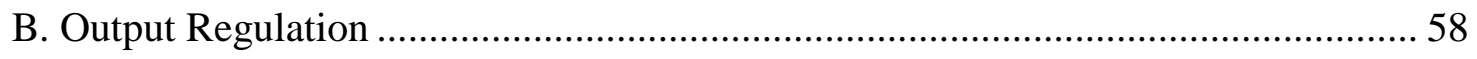

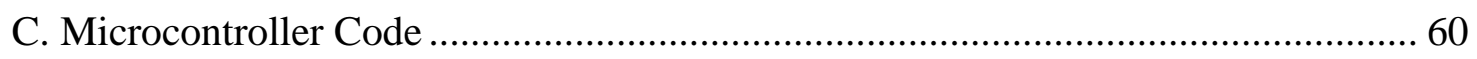




\section{LIST OF TABLES}

Table $\quad$ Page

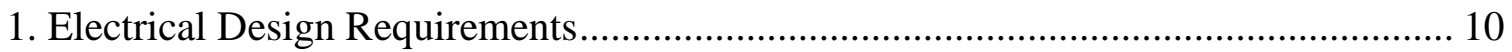

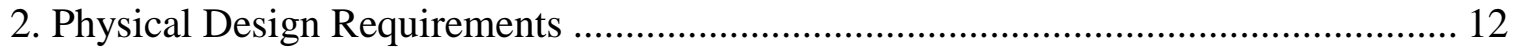

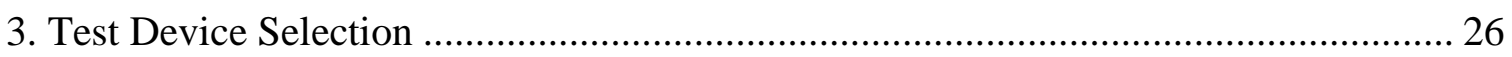

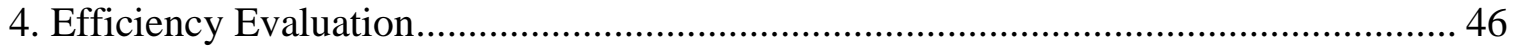

5. Output Voltage Percent Error Evaluation ............................................................. 46

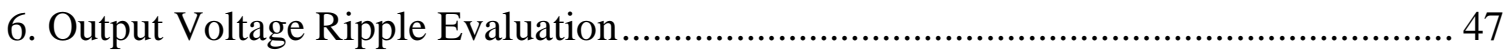




\section{LIST OF FIGURES}

Figure

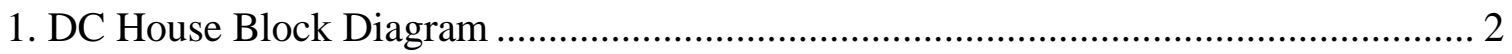

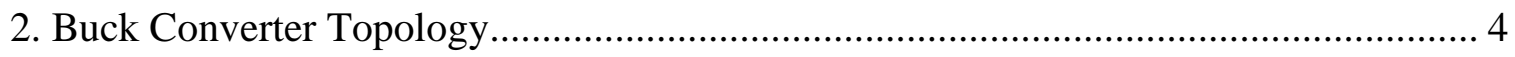

3. Potentiometer Value vs. Output Voltage [9] ...................................................... 7

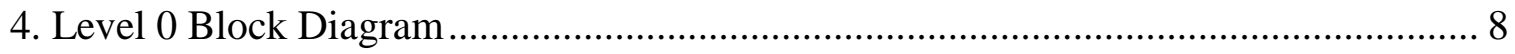

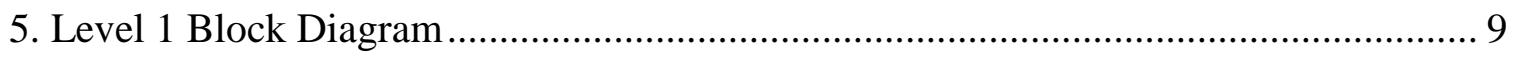

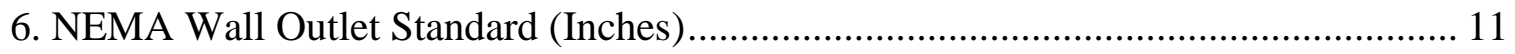

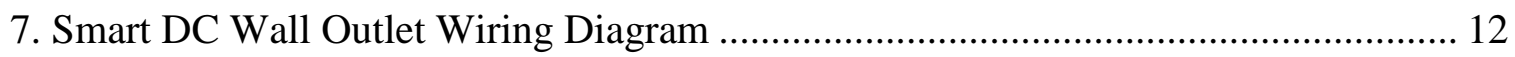

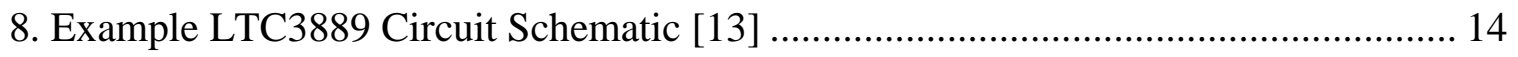

9. Example LT8619-5 Circuit Schematic [15] ....................................................... 15

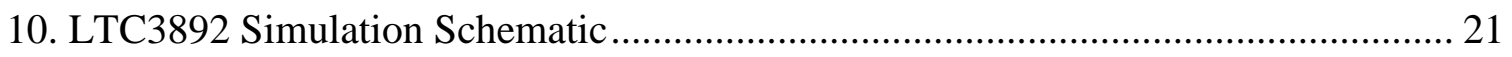

11. Simulated Output Voltage of 3V, Load Current of 250mA................................... 22

12. Simulated Output Voltage of 3V, Load Current of 6A......................................... 22

13. Simulated Output Voltage of 36V, Load Current of 250mA.................................. 23

14. Simulated Output Voltage of 36V, Load Current of 2.78A.................................... 23

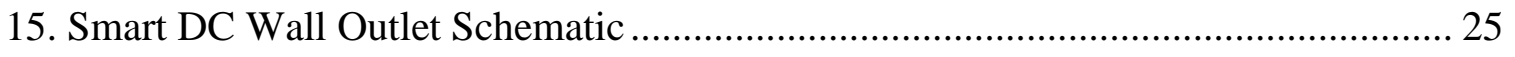

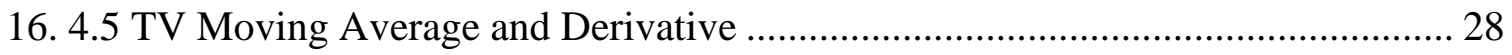

17. 5V Radio Moving Average and Derivative ..................................................... 28

18. 5V Raspberry Pi Moving Average and Derivative ............................................ 28

19. 5V Android Moving Average and Derivative ................................................ 28

20. 5V Windows Phone Moving Average and Derivative ....................................... 29

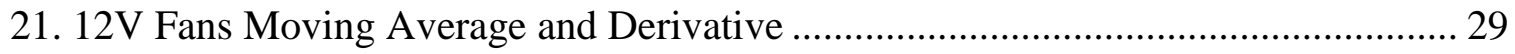


22. 15V Speakers Moving Average and Derivative

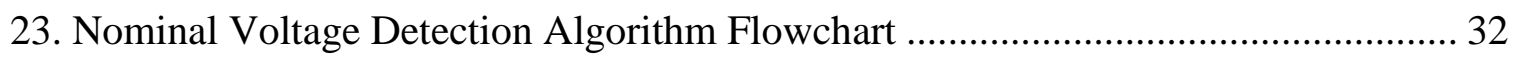

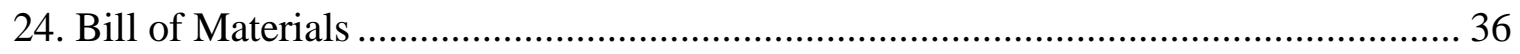

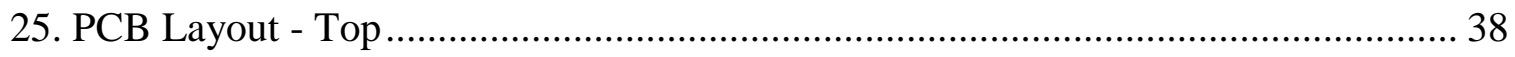

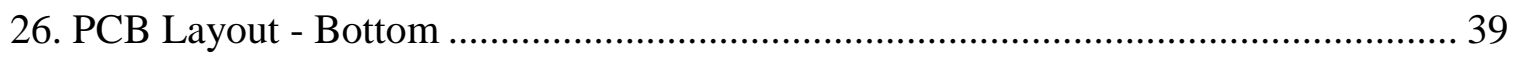

27. Fully Assembled Smart DC Wall Outlet .................................................................. 41

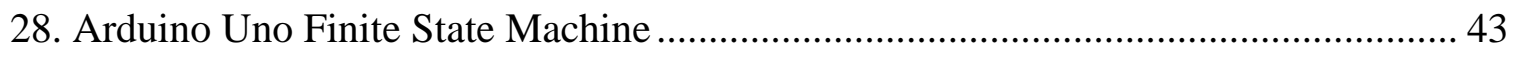

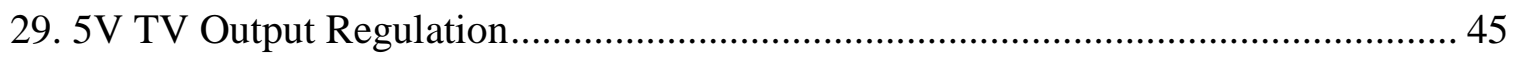

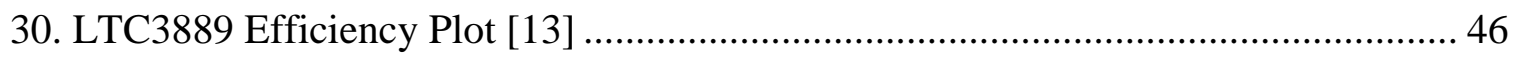

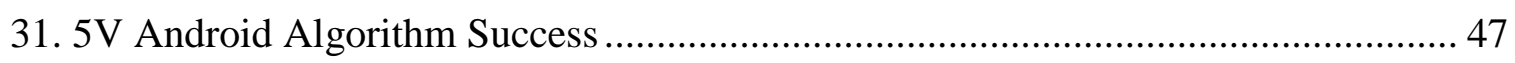

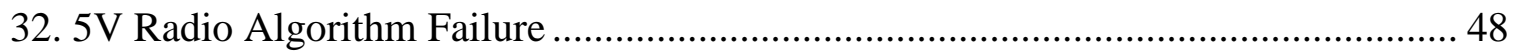

33. 5V Radio Experimental Current Draw ………………........................................ 49

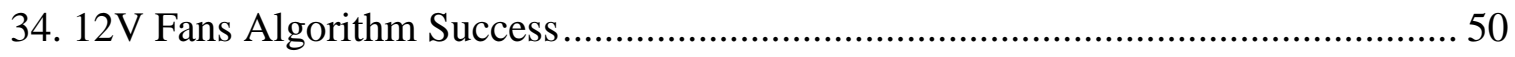

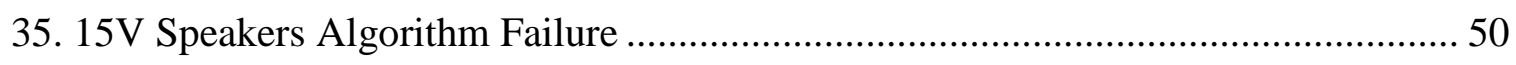

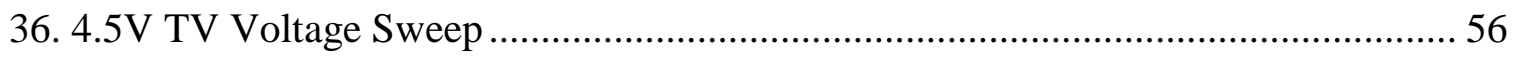

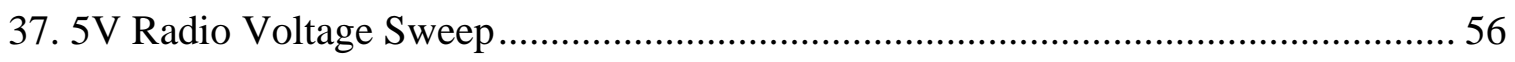

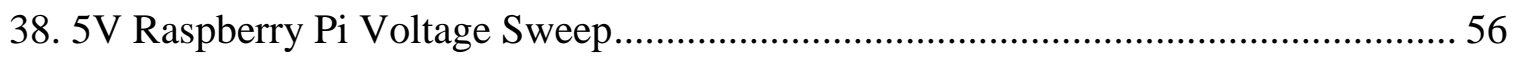

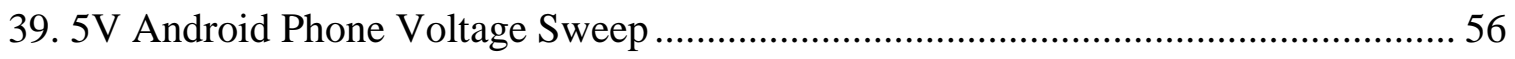

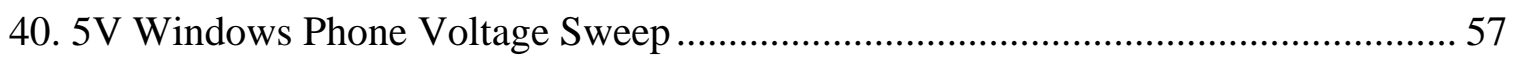

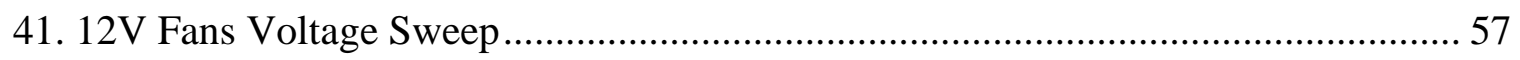

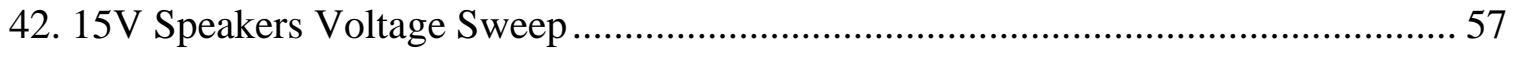

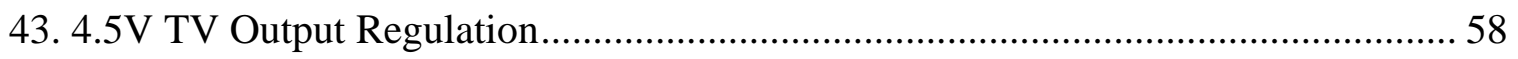

44. 5V Radio Output Regulation ........................................................................... 58 
45. 5V Raspberry Pi Output Regulation .................................................................... 58

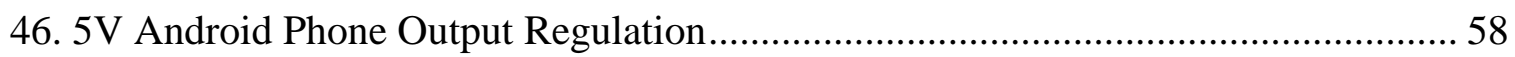

47. 5V Windows Phone Output Regulation................................................................ 59

48. 12V Fans Output Regulation .......................................................................... 59

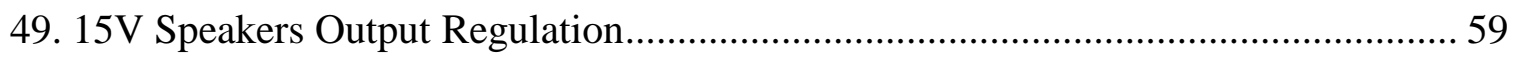




\section{INTRODUCTION}

Electric power distribution became a necessity in the late 1870's with the advent of arc lamp street lighting systems [1], eventually leading to the rise of electric lighting, climate control and other home appliances available to the modern American home. High voltage alternating current (AC) systems were developed to distribute power to these arc lamp street lights and low voltage direct current (DC) systems were developed to deliver power to indoor incandescent lights. While both forms of power distribution are used in different applications, AC systems were ultimately favored as the primary transmission method due to the existence of the transformer. To reduce the power losses in the transmission lines, power distribution systems try to minimize the amount of current being transmitted through the inherent resistance of the transmission lines. By using transformers, AC systems could step-up and step-down the transmission voltage as needed to minimize the current being transmitted over long distances. DC systems had no alternative to the transformer at the time, leading to a maximum transmission range of less than two miles [2]. As a result, AC power distribution became the standard in the United States and the rest of the world.

While AC systems are used to distribute power across long distances, many devices in the home do not use AC to power their internal circuitry. Whether it be a computer, a television, an LED light or a smartphone, these devices accept the AC voltage from a wall socket and rectify it to a safe DC voltage that the device can use. This rectification comes at a price, as there is always some power lost in the process. Additionally, any device that uses a transformer in the rectification process will 
continually draw power from the wall socket even when not in use. Some devices like game consoles and cable boxes waste upwards of 20 watts when not in use [3]. By distributing power with a DC system instead of AC, these inefficiencies could be eliminated.

The DC House Project is a humanitarian effort that focuses on creating a small, independent electrical grid that is entirely powered by DC [4]. All power for the system is generated locally using renewable methods, including DC water turbines, DC wind turbines and solar panels. The power is then stored on-site using batteries, preventing the losses incurred by transmitting the power over long distances. Figure 1 presents a simplified illustration of the DC House Project [5]. This system allows for people who live in rural areas without easy access to a centralized power grid to generate their own power independent of the state or utility companies. By removing the unnecessary conversions from $\mathrm{DC}$ to $\mathrm{AC}$, then $\mathrm{AC}$ back to $\mathrm{DC}$, the system is made more efficient and can run longer on a single battery charge.

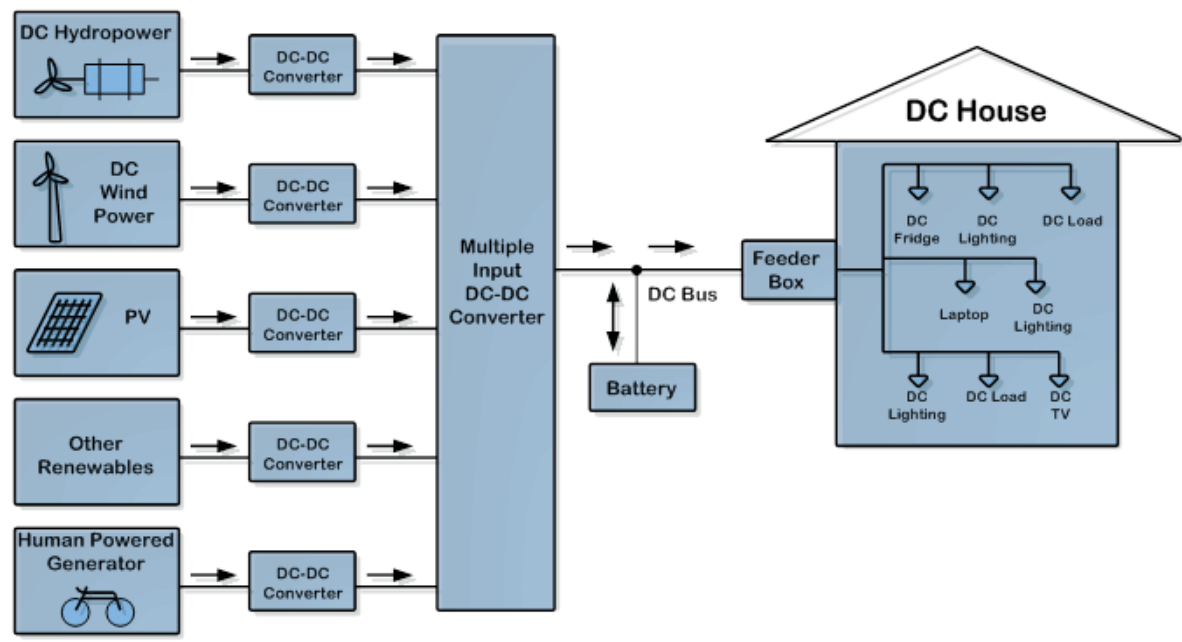

Figure 1: DC House Block Diagram 


\section{BACKGROUND}

\subsection{The Need for a Variable DC Wall Outlet}

One of the aims of the DC House Project is to provide power to DC devices with the same convenience as their AC alternatives. While AC powered devices operate with a wide range of internal voltage levels, they all accept the same input voltage of $120 \mathrm{~V}_{\mathrm{rms}}$ AC in the United States. AC devices benefit from a standardized wall outlet in every country, but there exists no such standard for DC devices. Some DC devices operate using dry cell batteries, accepting input voltages of $9 \mathrm{~V}$ or in increments of $1.5 \mathrm{~V}$ (e.g., $1.5 \mathrm{~V}, 3 \mathrm{~V}, 4.5 \mathrm{~V}$, etc.). Others accept $12 \mathrm{~V}$ from car batteries or even $5 \mathrm{~V}$ from USB chargers like those used by smartphones. As there is no standard for what voltage a DC device should use as its input, the DC House must be able to accommodate all these input voltages. Installing a separate wall socket for each input voltage would be inefficient, as there are so many possible values that the number of sockets needed would be impractical. A DC wall outlet with a variable voltage setting would be a much more appropriate solution.

\subsection{DC to DC Voltage Converters}

The primary reason that $\mathrm{AC}$ power distribution systems were favored over DC systems was due to the existence of the transformer, allowing AC systems to easily change their transmission voltage. DC power systems had no easy method of doing this in the late 1800 's, but with the rise of transistors and integrated circuits alternatives have emerged. Known as DC to DC converters, these systems accept a DC voltage as an input 
and change it to another voltage with minimal power loss. There are multiple topologies of DC to DC converters that allow for stepping up or stepping down an input voltage. The DC House Project features a 48V power rail inside the house, so the wall socket being designed in this paper will focus on an architecture that steps down the input voltage as most loads require an input voltage less than $48 \mathrm{~V}$. The Buck converter is an example of a DC to DC converter that transfers power from the input to the output while decreasing the voltage level. The power stage of a Buck converter is shown in Figure 2.

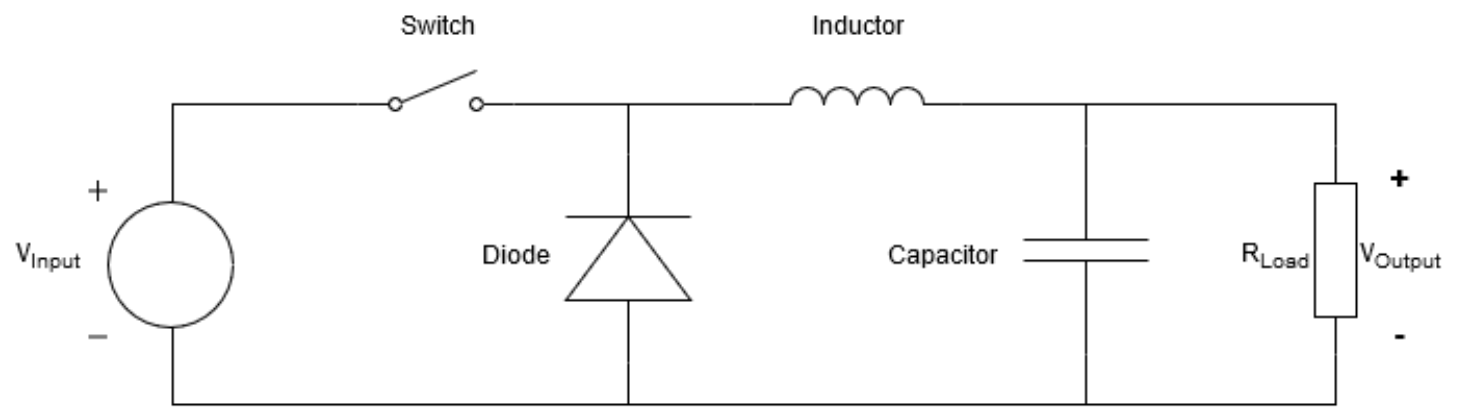

Figure 2: Buck Converter Topology

The Buck converter controls the voltage across the output by rapidly charging and discharging the inductor. The voltage across an inductor is proportional to the change in the current over time, as shown in Equation 2-1 [6].

$$
V=L \frac{d i}{d t}
$$

The switch, usually implemented as a MOSFET, is connected to a controller which monitors the voltage at the output. When the switch is closed by the controller a voltage is induced across the inductor, causing it to conduct more and more current. This current must go through the capacitor and the parallel resistive load, causing the output voltage to 
go up with the increasing current. When the switch is opened by the controller the input source is disconnected from the circuit, causing the inductor to release the energy that it collected while the switch was closed. The polarity of the voltage across the inductor flips during this period, causing the current through the inductor and the voltage across the output to steadily decrease. The controller uses a feedback network connected to the output to determine when to close or open the switch as necessary to maintain a desired voltage level.

This is a simplistic model of a Buck converter that assumes ideal components are being used. As a more robust model, a capacitor would be attached in parallel to the input source. This would aid in maintaining the input voltage at a constant level, as the Buck converter draws large transients of current from the input and the capacitor helps to filter these out. Furthermore, the diode in use in this model will be a source of power loss when conducting due to its $\sim 0.7 \mathrm{~V}$ forward voltage drop. This can be replaced with another MOSFET that is synchronously turned on and off by the controller, as it is more power efficient in high current applications.

\subsection{Previous Work}

The Smart DC Wall Plug project began with the Senior Project of Michael Detmers and Tyler Blauvelt [7]. Their design was based on a different DC to DC converter topology (a Flyback Converter) and featured a single channel with a maximum power output of $80 \mathrm{~W}$. The DC to DC converter allowed for four discrete output voltages of $5 \mathrm{~V}, 12 \mathrm{~V}, 19 \mathrm{~V}$ and $24 \mathrm{~V}$ for different appliances. In order to select which output voltage 
was desired the user needed to manually select a pin. This was undesirable, as selecting the wrong pin on accident could destroy the load device and potentially harm the user.

Edward Sibal continued work on the Smart DC Wall Plug with his proof of concept thesis [8]. This research effort pushed for automating the wall outlet voltage selection, removing the need for the user to select a voltage for the load device. This DC to DC converter used a Buck topology and implemented a microcontroller with a digital potentiometer to vary the output voltage. The voltage of the load device was determined by increasing the output voltage until a spike in the current was detected, upon which the final voltage was set. This method was able to turn on the load device in most cases, but the determined voltage was likely to be significantly below the device's nominal voltage. This would result in higher current draw than normal, causing unnecessary power losses. Kevin Mendoza focused on improving the project by condensing all the components onto one board and attempted to improve the voltage finding algorithm [9]. While still using the Buck converter, microcontroller and digital potentiometer setup, the new algorithm focused on passing a current threshold at a reference voltage and setting the voltage based on the amount of current being drawn. This method limited the output voltage to only $3 \mathrm{~V}, 6 \mathrm{~V}$ and $12 \mathrm{~V}$, and required a user input to start the process. The algorithm lacked flexibility and was only able to correctly determine the nominal voltage for a small range of devices.

The most recent improvement on the project was implemented by Richard Liu to expand the output voltage range and make the output more accurate [10]. The output range was significantly increased, allowing for output loads from $3 \mathrm{~V}$ to $36 \mathrm{~V}$ in discrete steps. In the previous two implementations, the use of a digital potentiometer to adjust the 
output voltage resulted in an inverse relationship between the two. This made the output voltage quite sensitive to small steps in the resistance in the higher voltage ranges, as seen in the upper left corner of Figure 3. To help make the output in the higher voltage range more accurate, Liu added a separate current source that could compensate for the lack of resolution. The algorithm for detecting the load's nominal voltage was not changed, and instead assumed that the output voltage had already been detected.

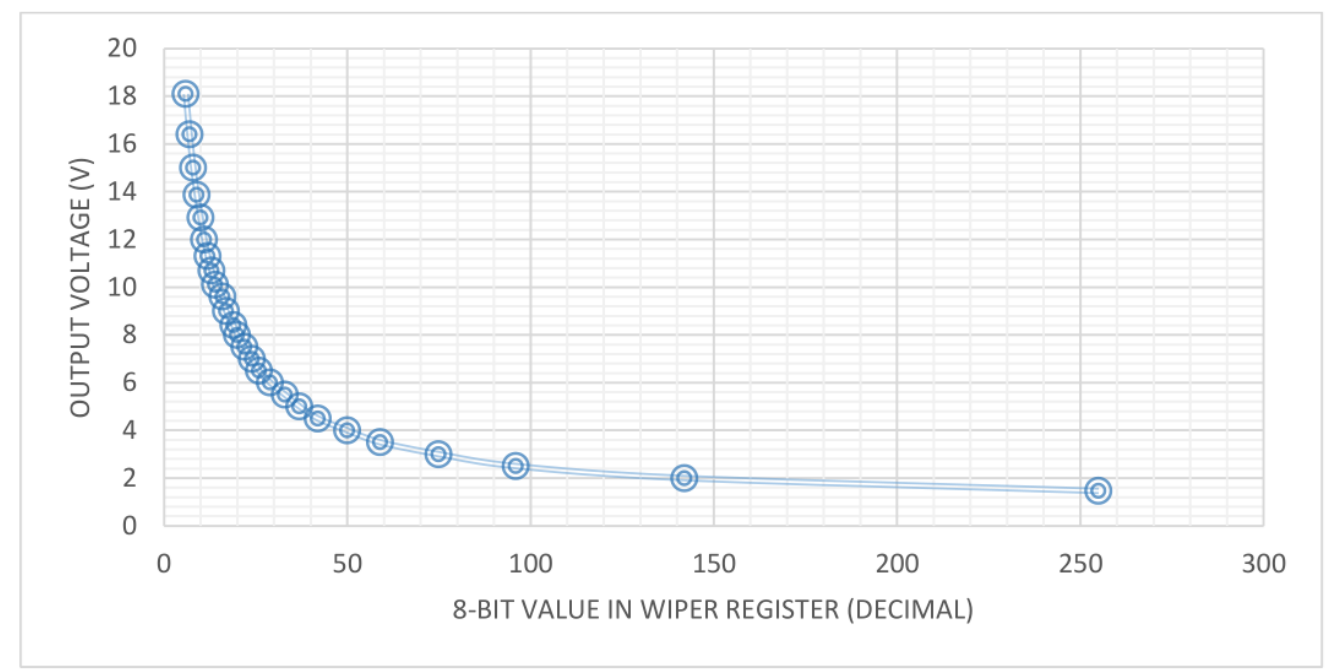

Figure 3: Potentiometer Value vs. Output Voltage [9]

The goal for this thesis is to improve the algorithm for detecting the load's nominal voltage, along with investigating an easier method of changing the output voltage. Potential DC loads will be grouped into different profiles based on their current and voltage characteristics, allowing for an algorithm that can better predict the nominal voltage. The digital potentiometer and current source will be removed from the feedback network and the microcontroller will instead communicate directly with the Buck controller to adjust the output as necessary. 


\section{DESIGN REQUIREMENTS}

\subsection{General Design}

The Smart DC Wall Outlet functions as a multiple input, multiple output system. It accepts the $48 \mathrm{~V}$ line voltage from the DC House battery as an input, as well as the voltage and current characteristics of the loads plugged into each channel of the outlet. The system then outputs the calculated voltage level on the appropriate channel. A simplified diagram of the system is shown in Figure 4.

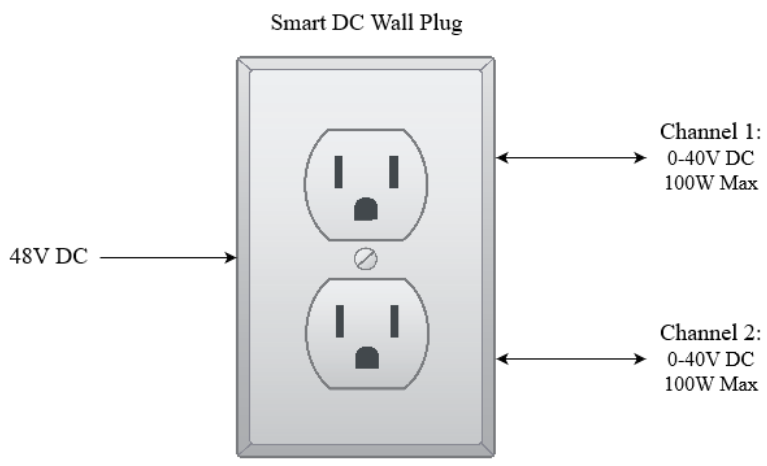

Figure 4: Level 0 Block Diagram

A more detailed view of the system can be seen in Figure 5 with the power path indicated by the bold arrows. Fuses are located at the $48 \mathrm{~V}$ input to the system along with both the outputs to protect the internal circuitry and any loads from a potential fault condition. The Primary DC to DC Converter will accept the power from the $48 \mathrm{~V}$ input and generate an appropriate voltage on both output channels. To adjust for any errors in the output, the Primary DC to DC Converter monitors the voltage and current in use by the loads. The Secondary DC to DC Converter is a fixed output step-down converter that takes the $48 \mathrm{~V}$ 
input and produces a 5V source that can power the Microcontroller. The Microcontroller communicates with the Primary DC to DC Converter to gather information about the voltage and current needs of the loads. Using this information, it calculates the load's nominal voltage and commands the Primary DC to DC Converter to adjust each output channel accordingly.

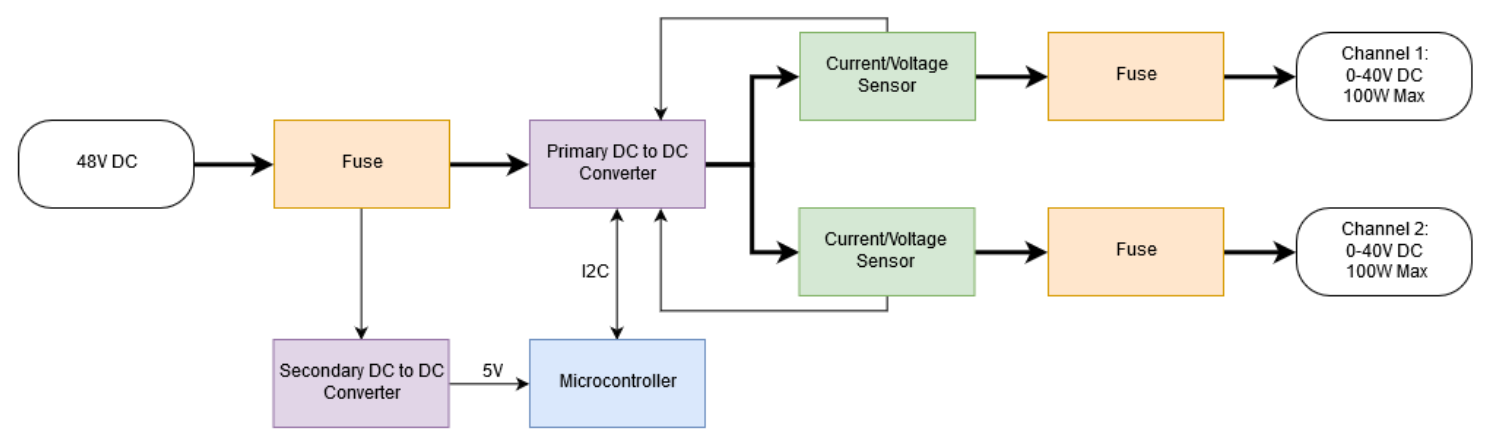

Figure 5: Level 1 Block Diagram

\subsection{Electrical Specifications}

The electrical requirements of the Smart DC Wall Outlet are dictated by the DC House specifications and the most common needs of available DC powered devices. The DC House supplies a $48 \mathrm{~V}$ power rail, so that will be used as the input to the smart outlet. The output voltage range must be able to cover a wide range of devices, and studies were done in previous iterations of the project to find a suitable range. Sibal [8] and Liu [10] found that many DC devices were between $3 \mathrm{~V}$ and $24 \mathrm{~V}$; to allow for some extra flexibility, the output range of this project will be from $1 \mathrm{~V}$ to $40 \mathrm{~V}$. The output power on each channel will be set to $100 \mathrm{~W}$ to accommodate the USB-C maximum of $5 \mathrm{~A}$ at $20 \mathrm{~V}$ [11]. The maximum load current will be set to $6 \mathrm{~A}$ to prevent unnecessarily wide trace 
widths on the printed circuit board, and the minimum load current will be set to $0.25 \mathrm{~A}$ to maintain adequate efficiency and ensure proper operation of the Primary DC to DC Converter. The target efficiency of the system will be $85 \%$ at full load, though this will likely suffer under low current applications. The maximum output voltage ripple will be set to $2.5 \%$, and the voltage error will be within $2.5 \%$ of the nominal setting. This is to protect load devices from overvoltage conditions. These electrical requirements are shown in Table 1.

Table 1: Electrical Design Requirements

\begin{tabular}{c|c} 
Category & Requirement \\
\hline Input Voltage & $48 \mathrm{~V}$ \\
\hline Output Voltage Range Per Channel & $1-40 \mathrm{~V}$ \\
\hline Output Current Range Per Channel & $0.25-6 \mathrm{~A}$ \\
\hline Maximum Power Per Channel & $100 \mathrm{~W}$ \\
\hline Efficiency at Full Load & $\geq 85 \%$ \\
\hline Output Voltage Ripple & $\leq 2.5 \%$ \\
\hline Steady State Voltage Error & $\leq 2.5 \%$
\end{tabular}

\subsection{Physical Specifications}

The Smart DC Wall Outlet project is designed to use the size and form factor of the standard wall outlet in the United States. This is defined by the NEMA standard for a duplex wall outlet, as shown in Figure 6 [12]. The maximum size of the final system is set by the size of this faceplate, which has dimensions of 3.12 " by 4.87 ". 


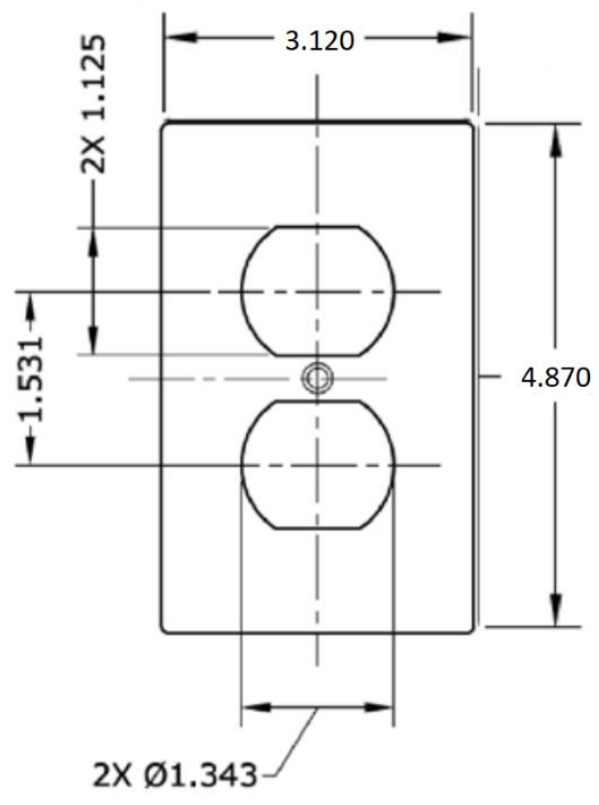

Figure 6: NEMA Wall Outlet Standard (Inches)

Additionally, the system must output power to the same plugs used by this system. In a traditional AC configuration, one prong is used for the hot wire, one is use for the neutral wire, and one is used for ground. DC systems only require a positive supply wire and a ground wire, so the third prong is redundant. In this setup, the DC supply wire will be wired to the hot prong, and the ground wire will be connected to both the neutral and the ground prongs of the receptacle. This configuration is better illustrated in Figure 7 [10]. All physical requirements are listed in Table 2. 


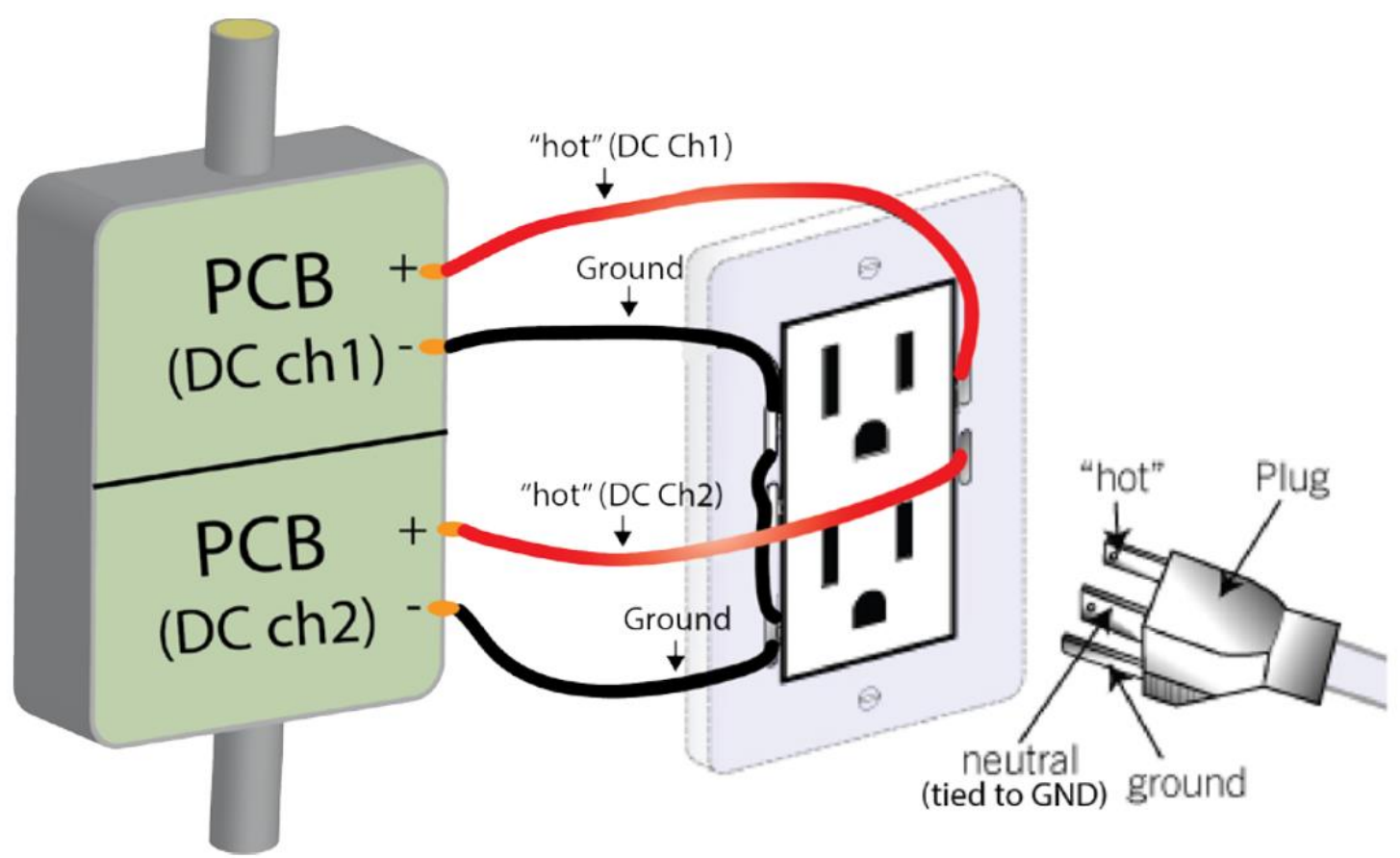

Figure 7: Smart DC Wall Outlet Wiring Diagram

Table 2: Physical Design Requirements

\begin{tabular}{c|c} 
Category & Requirement \\
\hline $\begin{array}{c}\text { Maximum } \\
\text { Width }\end{array}$ & $3.12 \%$ \\
\hline $\begin{array}{c}\text { Maximum } \\
\text { Height }\end{array}$ & $4.87 ”$ \\
\hline Form & $\begin{array}{c}\text { NEMA Duplex } \\
\text { Wactor }\end{array}$ \\
\end{tabular}




\section{DESIGN AND SIMULATION RESULTS}

\subsection{Solution Statement}

The two primary functions of the Smart Wall Plug project are to detect the optimal supply voltage for each load and to deliver that voltage efficiently. The output voltage for both channels is provided by the hardware of the system, featuring two individual Buck converter topologies as outlined in Figure 2 and a Buck controller integrated circuit (IC) to manage them. The algorithm for detecting the nominal voltage of the loads is implemented in software on a microcontroller. This microcontroller can communicate with the Buck controller IC, allowing it to set the output voltages and request the output current measurements for both channels.

\subsection{Primary and Secondary Buck Controller Selection}

The primary Buck controller is one of the most essential pieces of hardware in this build, and its selection should be taken with great care. The input and output range of the controller must at minimum accommodate the specifications listed in Table 1. In addition, a digital communication interface is desired to reduce the total number of components required on the board. The LTC3889 is a 60V Dual Output Step-Down Controller that fits these requirements [13]. It features an input voltage range from $5 \mathrm{~V}$ to $60 \mathrm{~V}$, and two independent output channels ranging from $0 \mathrm{~V}$ to $40 \mathrm{~V}$ with a $10 \mathrm{mV}$ resolution. The controller uses a version of the Inter-Integrated Circuit (I2C) serial communication protocol known as the Power Management Bus (PMBus), which allows a microcontroller to digitally set target output voltages and monitor telemetry [14]. The 
controller's digital architecture aligns with one of this project's main goals of reducing the complexity involved in changing the output. An example application circuit can be seen in Figure 8. This IC can use a switching frequency ranging from $85 \mathrm{kHz}$ to $500 \mathrm{kHz}$, where higher switching frequencies allow for smaller inductors and capacitors at the cost of power efficiency. The smart DC wall outlet uses a switching frequency of $f_{\text {osc }}=300 \mathrm{kHz}$ to reduce the physical space needed by components while still maintaining a respectable efficiency.

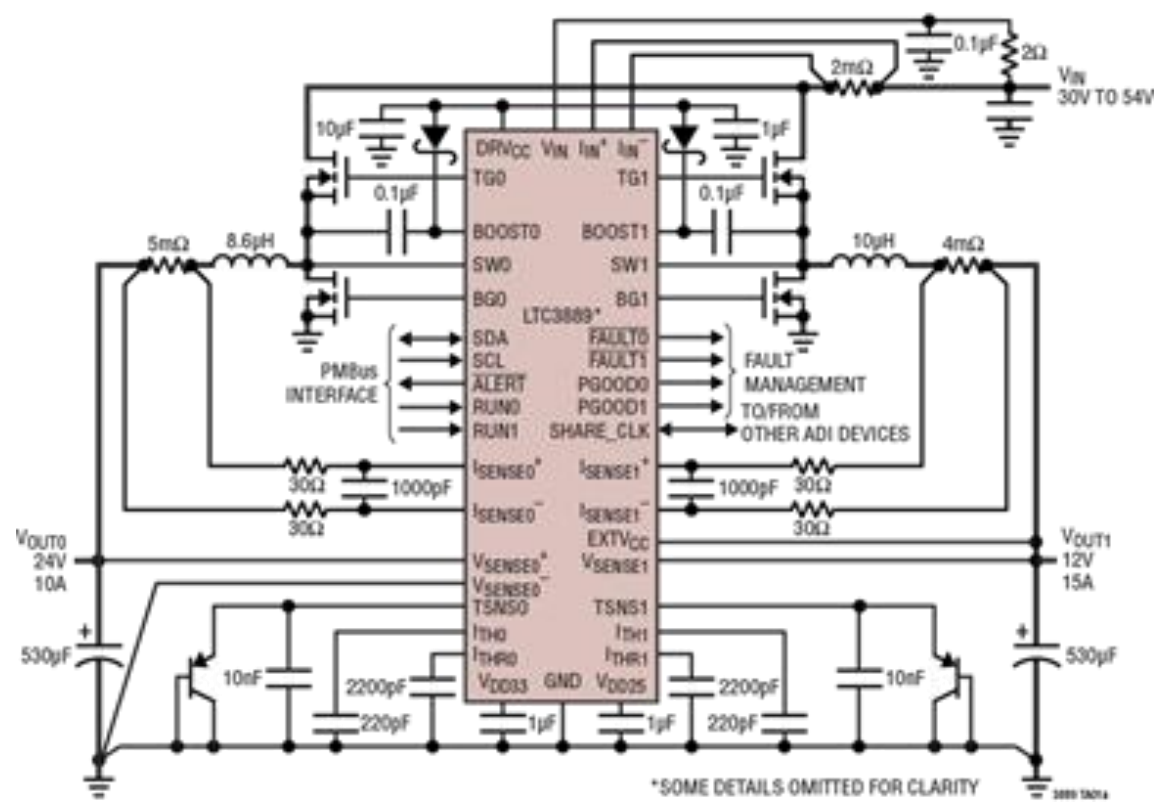

Figure 8: Example LTC3889 Circuit Schematic [13]

While the primary Buck controller manages the output voltage to the wall plug, some components require their own low voltage power supply on the board. Microcontrollers and status LEDs typically operate off a 5V supply, and the LTC3889 features an external power input that can use a 5V supply to increase the efficiency of its internal LDO regulators. A prospective Buck regulator would need to accept a $48 \mathrm{~V}$ input 
voltage, output $5 \mathrm{~V}$, and be able to supply at least $250 \mathrm{~mA}$ conservatively assuming $100 \mathrm{~mA}$ for the microcontroller, $100 \mathrm{~mA}$ for the LTC 3889 and 50mA for three status LEDs. The LT8619-5 is a 60V, 1.2A Synchronous Monolithic Buck Regulator with a fixed output of 5V that meets these specifications [15]. Since this chip features internal switching components fewer parts are needed to operate the IC, as can be seen in Figure 9. The LT8619-5 can use a switching frequency anywhere between $300 \mathrm{kHz}$ and $2.2 \mathrm{MHz}$. This chip was configured to use a switching frequency of $1.4 \mathrm{MHz}$ to minimize the size needed by the inductors and capacitors, as the efficiency of this regulator is not as important as the primary Buck converter.

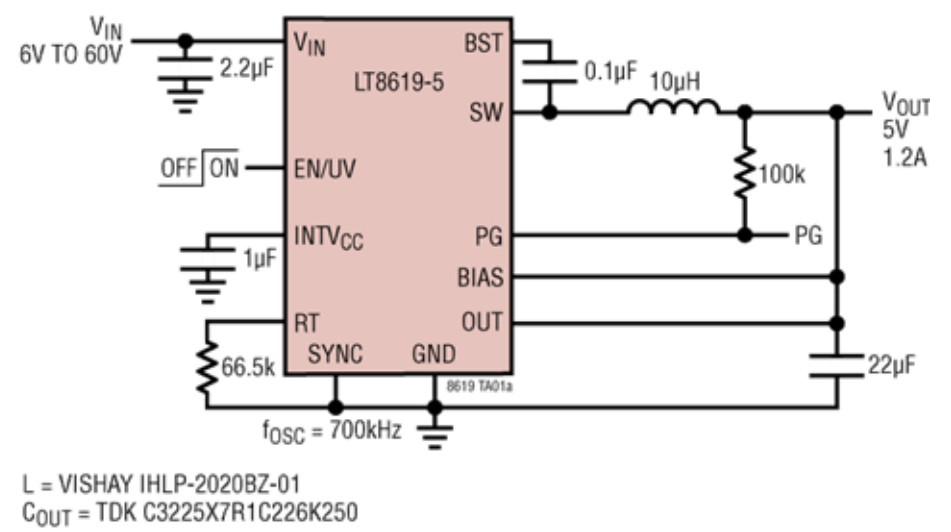

Figure 9: Example LT8619-5 Circuit Schematic [15]

\subsection{Microcontroller Selection}

The microcontroller used in this project must be able to read and write to the numerous digital ports on both the LTC3889 and the LT8619-5, along with controlling three status LEDs. The LTC3889 requires two ports for use with the I2C-based PMBus system, along with seven general purpose input/output (GPIO) pins. The LT8619-5 
requires one GPIO pin to be monitored, and the three status LEDs will require one GPIO pin each to turn them on and off individually. In total, the microcontroller will need 11 GPIO pins and two pins for use with I2C. The microcontroller must also feature a relatively quick internal clock to process calculations on floating point numbers, enough memory to store the load voltage detection algorithm, and fit within the physical constraints listed in Table 2.

The ATmega328P on the Arduino Uno board was chosen to be the microcontroller for use in the smart DC wall outlet. The Uno features 20 GPIO pins, two pins with dedicated hardware for processing I2C connections, $2 \mathrm{~KB}$ of SRAM and $32 \mathrm{~KB}$ of Flash Memory [16]. The microcontroller uses a modest internal clock speed of $16 \mathrm{MHz}$ for calculations, and its dimensions measure 2.7in by 2.1in. Beyond meeting these requirements, the ease of use and financial cost were carefully considered. As this microcontroller was purchased for a separate project, it was essentially free to use compared to similar microcontrollers that cost more than $\$ 30$. In addition, the Arduino IDE provides a quick setup and rapid prototyping which can be invaluable when working under a deadline.

\subsection{Inductor Sizing}

The primary energy storing device used in the Buck DC to DC converter is the inductor. The smart DC wall outlet features two individual buck converters generating the output voltages of the system, as well as a third Buck converter providing $5 \mathrm{~V}$ as an internal supply. A practical method for determining the critical inductance for each inductor is by specifying a desired ripple current, $\Delta i_{L}$ [3]. From Figure $2, \Delta i_{L}$ can be 
calculated when the high side switch is conducting using Equation 2-1 for the voltage across an inductor.

$$
\frac{d i_{L}}{d t}=\frac{V_{i n}-V_{o u t}}{L}
$$

By using discrete time instead of continuous time for this calculation, the ripple current can be related to the inductance, frequency of oscillation and duty cycle of the system.

$$
\frac{d i_{L}}{d t} \approx \frac{\Delta i_{L}}{\Delta t_{\text {on }}}=\frac{\Delta i_{L}}{T * D}=\frac{\Delta i_{L} * f_{\text {osc }}}{D} \rightarrow \Delta i_{L}=\frac{V_{\text {in }}-V_{\text {out }}}{L * f_{\text {osc }}} * D
$$

In Equation 4-2, $\mathrm{T}$ represents the period of oscillation for the switch, $f_{o s c}$ represents the frequency of oscillation for the switch, and D represents the duty cycle percentage of the switch during that period. As shown in [3], the steady-state duty cycle of a buck converter can be related to the input and output voltage.

$$
D=\frac{V_{\text {out }}}{V_{\text {in }}}
$$

This substitution gives us the final equation for calculating the ripple current in the inductor of a Buck converter, which can be rearranged to calculate the critical inductance:

$$
\Delta i_{L}=\frac{V_{\text {out }} *\left(V_{\text {in }}-V_{\text {out }}\right)}{V_{\text {in }} * L * f_{\text {osc }}} \rightarrow L=\frac{V_{\text {out }} *\left(V_{\text {in }}-V_{\text {out }}\right)}{V_{\text {in }} * \Delta i_{L} * f_{\text {osc }}}
$$

Using Equation 4-4, the worst-case condition for the primary Buck converter inductors is calculated when the output voltage is $V_{\text {out }}=24 \mathrm{~V}$, or half the input voltage of $V_{\text {in }}=48 \mathrm{~V}$.

The maximum average current at this output voltage is $4.2 \mathrm{~A}$, as limited by the maximum power specification of $100 \mathrm{~W}$ per channel. For this calculation, the ripple current value is taken to be $30 \%$ of the maximum output current, giving $\Delta i_{L}=1.26 \mathrm{~A}$. Assuming a switching frequency of $f_{o s c}=300 \mathrm{kHz}$, the critical inductance can be calculated as: 


$$
L=\frac{24 V *(48 V-24 V)}{48 V * 1.26 A * 300 k H z} \approx 32 \mu H
$$

The datasheet for the LT8619-5 Buck controller suggests a different method for calculating the inductor's critical value [15], shown in Equation 4-6.

$$
L=2 * \frac{V_{o u t}+V_{S W(B o t)}}{f_{o s c}}
$$

The critical inductance for the secondary Buck converter is found in Equation 4-7 using the bottom switch voltage drop value of $V_{S W(B o t)}=0.264 \mathrm{~V}$, a frequency of oscillation of $f_{o s c}=1.4 \mathrm{MHz}$, and an output voltage of $V_{\text {out }}=5 \mathrm{~V}$.

$$
L=2 * \frac{5 \mathrm{~V}+0.264 \mathrm{~V}}{1.4 \mathrm{MHz}} \approx 7.5 \mu \mathrm{H}
$$

When selecting inductors for this configuration, the inductance must be larger than the critical values calculated in Equations 4-5 and 4-7, as well as being rated to handle the maximum output current plus half of the ripple current. Two inductors with a saturation current of $11 \mathrm{~A}$ and an inductance of $33 \mu \mathrm{H}$ were selected for the primary Buck converter, while an inductor with a saturation current of $1 \mathrm{~A}$ and an inductance of $10 \mu \mathrm{H}$ was selected for the secondary Buck converter.

\subsection{Capacitor Sizing}

The Buck converter suffers from AC signal components on the input and output of the system, so capacitors are typically used to compensate and provide a more ideal DC signal. The input supply faces current pulses with very fast rise and fall times, and the input capacitor must be able to handle these large current spikes. The calculation for determining the input capacitor RMS current rating comes from [13], as shown in Equation 4-8. 


$$
I_{R M S}=\frac{I_{\max }}{V_{\text {in }}} \sqrt{V_{\text {out }} *\left(V_{\text {in }}-V_{\text {out }}\right)}
$$

The RMS current is maximized when the output is half of the input, occurring when $V_{\text {out }}=24 \mathrm{~V}$ on the primary Buck converter. Using the maximum average current of $I_{\max }=4.2 \mathrm{~A}$ at this operating point, the RMS current rating of the input capacitor for the primary Buck converter is $I_{R M S}=2.1 \mathrm{~A}$. For the secondary Buck converter with a maximum average output current of $I_{\max }=250 \mathrm{~mA}$, the RMS current rating needed is $I_{R M S}=75 \mathrm{~mA}$. Typical input capacitance values range from $5 \mu \mathrm{F}$ to $1005 \mu \mathrm{F}$, with multiple capacitors added in parallel to meet the RMS current rating. For the primary Buck converter, two parallel $22 \mu \mathrm{F}$ capacitors with RMS current ratings of $3 \mathrm{~A}$ were selected. For the secondary Buck converter, a $5 \mu \mathrm{F}$ capacitor with an RMS current rating of $250 \mathrm{~mA}$ was selected.

The output capacitor of a Buck converter helps smooth the noise at the output of the inductor and stores some energy to satisfy transient loads. The voltage ripple at the output is primarily controlled by the equivalent series resistance (ESR) of this capacitor, as shown in Equation 4-9 from [13].

$$
\Delta V_{\text {out }} \approx \Delta i_{L} *\left(E S R+\frac{1}{8 * f_{o s c} * C}\right)
$$

An output ripple voltage of less than $2.5 \%$ for the primary Buck converter is desired with the worst case occurring at an output value of $3 \mathrm{~V}$, creating an output voltage ripple of $\Delta V_{\text {out }} \leq 75 \mathrm{mV}$. The maximum ripple current occurs when the output voltage is half of the input, with $\Delta i_{L}=1.26 \mathrm{~A}$ as previously calculated. The process of finding a capacitor that satisfies this condition is iterative, but a set of three capacitors in parallel were chosen with two electrolytic capacitors featuring an ESR of $28 \mathrm{~m} \Omega$ and capacitance of $220 \mu \mathrm{F}$, 
and one ceramic capacitor rated at $10 \mu \mathrm{F}$ with a negligible ESR. Similar calculations were done for the secondary Buck converter, and a capacitor with an ESR of $30 \mathrm{~m} \Omega$ and capacitance of $22 \mu \mathrm{F}$ was selected.

\subsection{Current Sense Resistor Sizing}

The current being drawn by the load of each output channel of the primary Buck converter is calculated by measuring the voltage drop across a small resistor. The LTC3889 has a $75 \mathrm{mV}$ maximum range on the differential input, so the peak current going through the desired resistor should not generate a voltage larger than this. The desired resistance value can be calculated using Equation 4-10.

$$
R_{\text {sense }}=\frac{V_{\text {sense }(\max )}}{I_{\max }+\frac{\Delta i_{L}}{2}}
$$

Using $V_{\text {sense }(\max )}=75 \mathrm{mV}$, a maximum output current of $I_{\max }=6 \mathrm{~A}$, and a ripple current of $\Delta i_{L}=1.5 \mathrm{~A}$, the current sense resistors should be sized to $R_{\text {sense }}=10 \mathrm{~m} \Omega$. Two current sense resistors with a power rating of $1 \mathrm{~W}$ and a resistance of $10 \mathrm{~m} \Omega$ were selected for use with the primary Buck converter. The LT8619-5 monitors the output current internally, so no current sense resistor is necessary for this subsystem.

\subsection{Power Converter Simulation}

Unfortunately, there is no SPICE model available for the LTC3889 IC due to its digital interface, so no simulations could be performed using this IC. The component values chosen can still be verified using simulation, so a simulation was constructed using a different Buck controller. Specifically, the LTC3892 [17] was chosen as it was used in Liu's iteration of the smart DC wall outlet and met similar operating 
requirements. The simulation was configured as similar as possible to the LTC3889, using pulse skipping for increased efficiency and a switching frequency of $350 \mathrm{kHz}$, slightly higher than the specified $300 \mathrm{kHz}$. The schematic used in the simulations is shown in Figure 10.

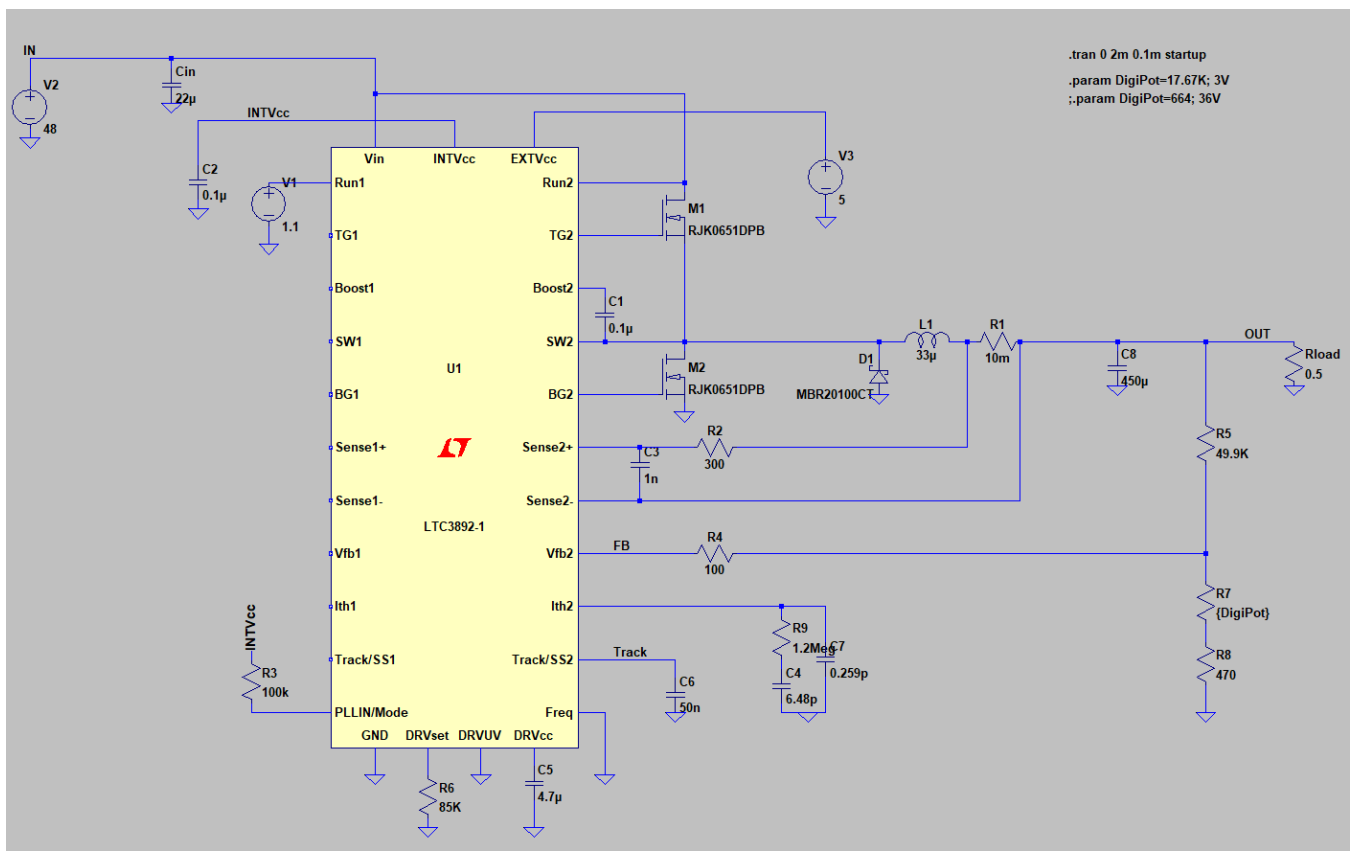

Figure 10: LTC3892 Simulation Schematic

The converter was simulated at the minimum and maximum output voltages of $3 \mathrm{~V}$ and $36 \mathrm{~V}$, each at the minimum and maximum load conditions. Figure 11 and Figure 12 show the transient waveform from start-up to steady state of the $3 \mathrm{~V}$ output at $0.25 \mathrm{~mA}$ and $6 \mathrm{~A}$ respectively. Figure 13 and Figure 14 show similar plots with a $36 \mathrm{~V}$ output at $0.25 \mathrm{~mA}$ and $2.78 \mathrm{~A}$ respectively. All four plots show that the ripple voltage and steady state error are within $2.5 \%$ of the nominal value, confirming that these component sizes are valid. Since the output capacitance is so large it can take more than $4 \mathrm{~ms}$ to reach high output voltages, but a fast response time is not crucial so this can be tolerated. 


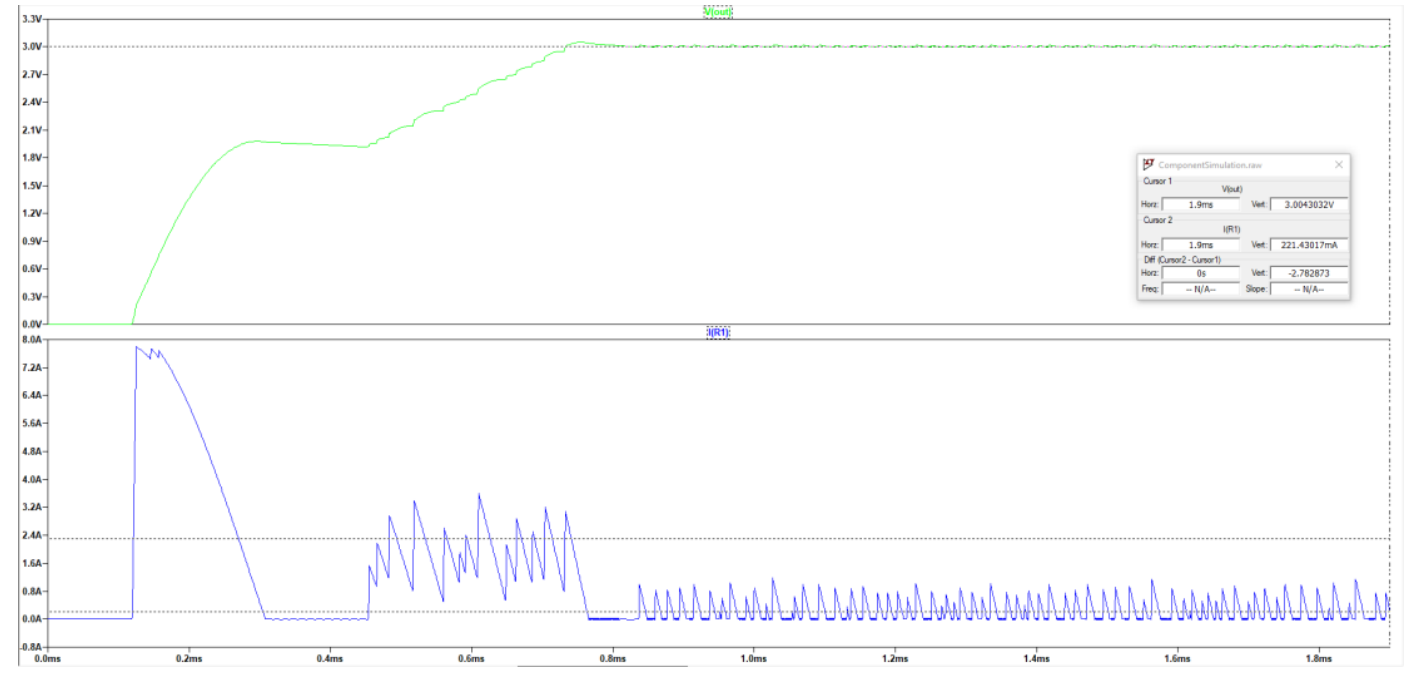

Figure 11: Simulated Output Voltage of 3V, Load Current of 250mA

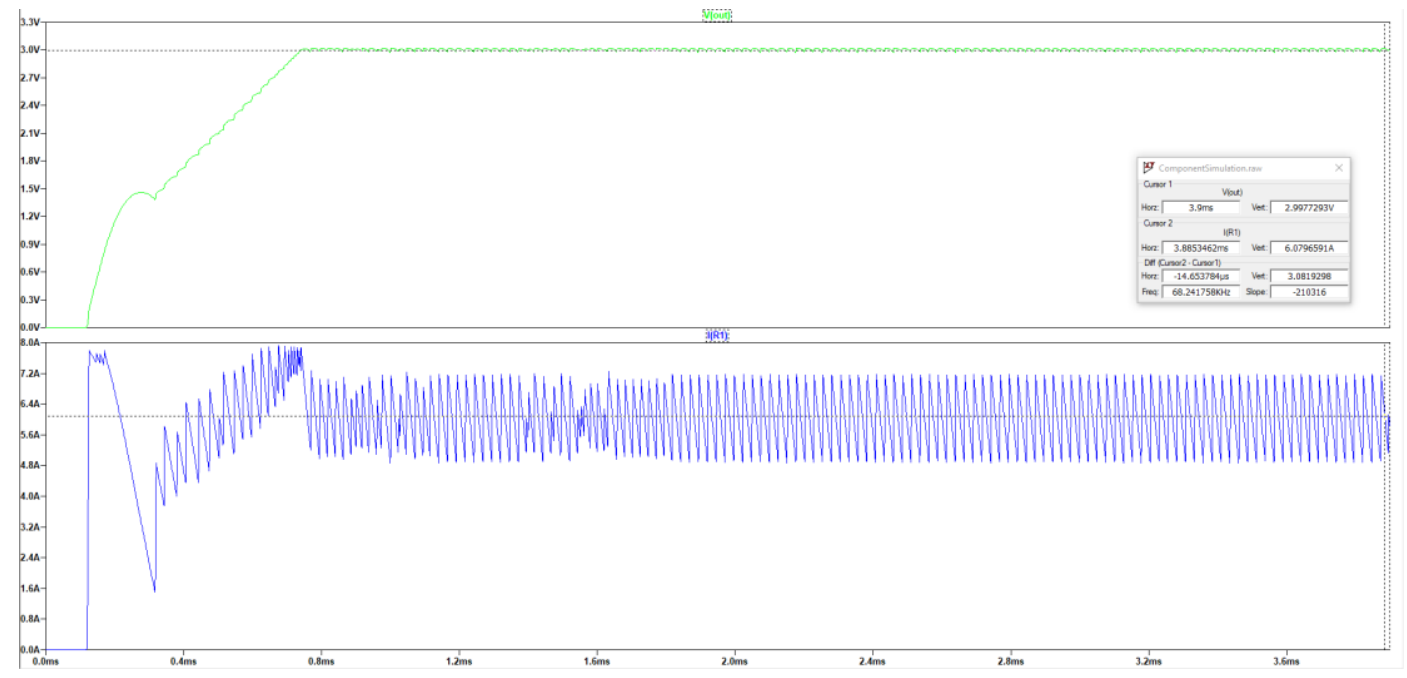

Figure 12: Simulated Output Voltage of 3V, Load Current of 6A 


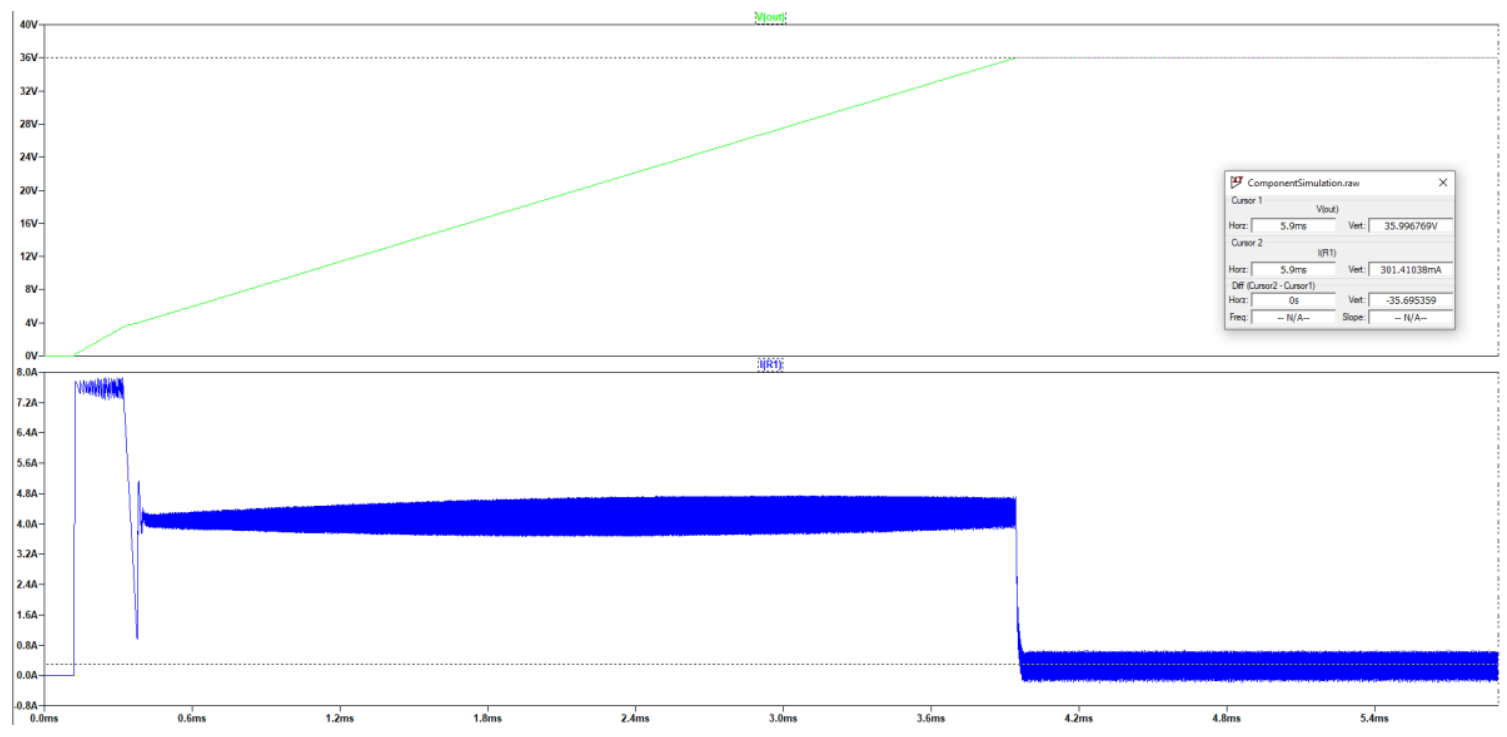

Figure 13: Simulated Output Voltage of 36V, Load Current of 250mA

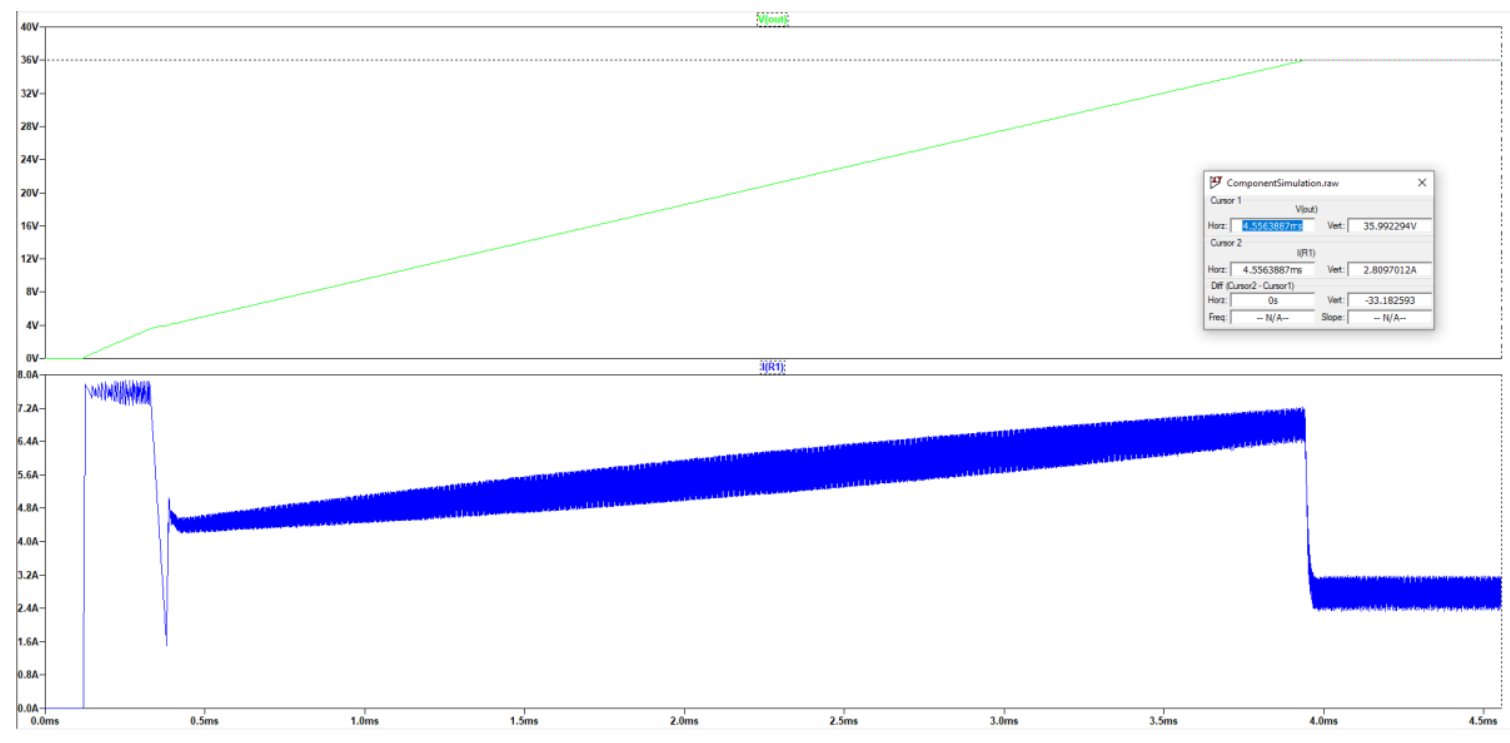

Figure 14: Simulated Output Voltage of 36V, Load Current of 2.78A 


\subsection{Schematic Design}

The schematic for the Smart DC Wall Outlet is shown in Figure 15. The two output channels of the primary Buck converter are shown symmetrically configured on the left and right of the LTC3889 IC. The secondary Buck converter is shown supplying auxiliary power to the ICs and status LEDs. The header connections to and from the board are shown with fuses, limiting the total current into the system to $5 \mathrm{~A}$ and the total current out of each channel to 8A. The Arduino Uno uses an internal logic level of 5V while the LTC3889 uses an internal logic level of 3.3V, so the I2C level shifters were included to allow the two devices to communicate directly. The status LEDs have been configured to turn on when the Arduino Uno applies 5V at the gate of the MOSFETs. 


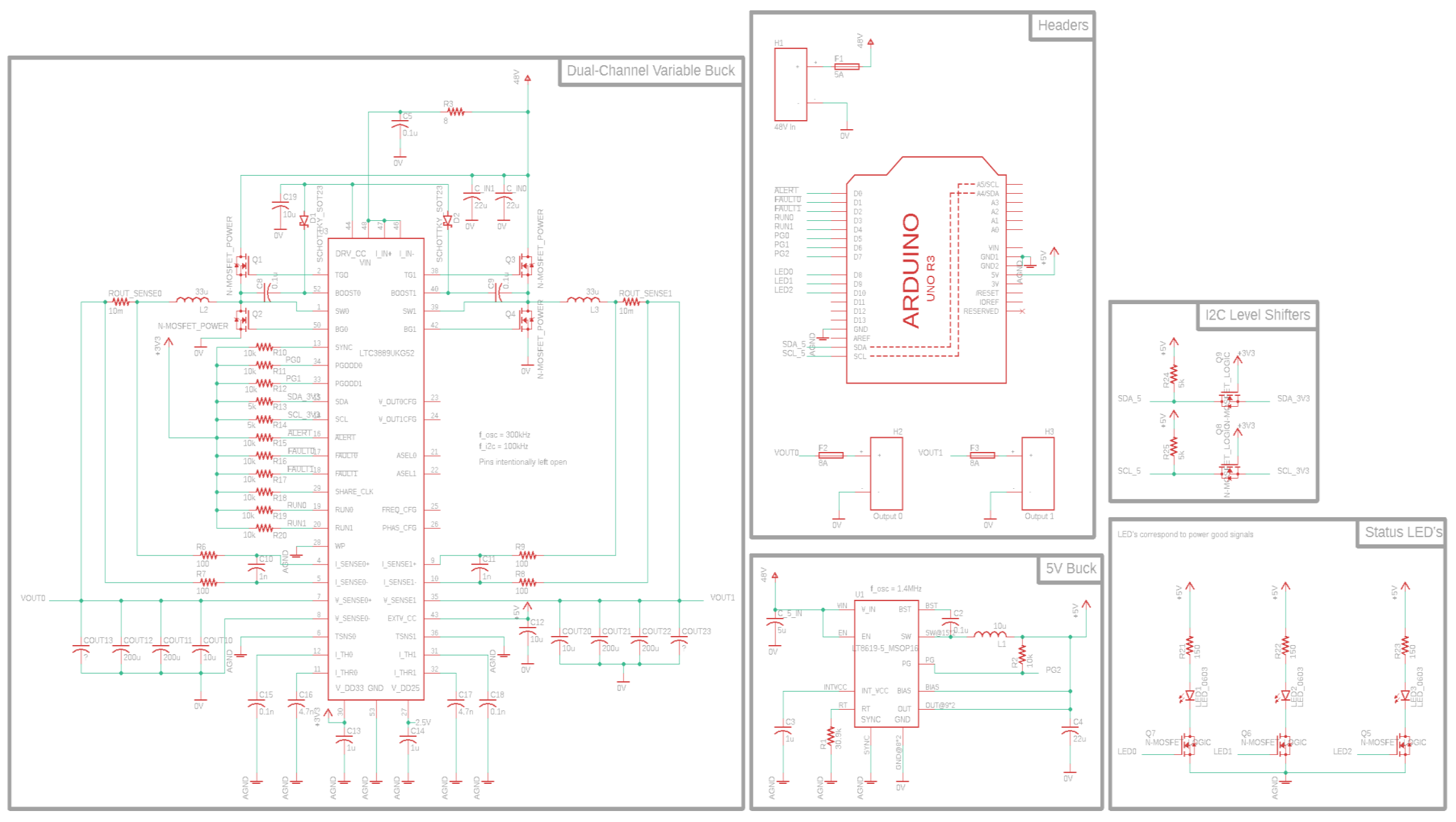

Figure 15: Smart DC Wall Outlet Schematic 


\subsection{Test Device Selection}

In order to develop a robust algorithm for detecting a load's nominal voltage, a wide range of DC devices must be studied. Devices that run on lithium ion batteries behave differently than those that run on alkaline batteries or are powered by USB. By gathering data from devices with different power sources, input voltages and load currents, trends that are common between all of them will become apparent. The major limiting factor for selecting devices to test was the financial cost, so most of the devices selected were inexpensive or free to use. Additionally, these devices must be able to be turned on just by applying an input voltage without any user interaction, so no devices with power toggle buttons were accepted. The devices selected for testing are listed in Table 3.

Table 3: Test Device Selection

\begin{tabular}{c|c|c|c} 
Device & Input Voltage & Load Current & Power Source \\
\hline Portable TV & $4.5 \mathrm{~V}$ & $450 \mathrm{~mA}$ & Alkaline Batteries \\
\hline Radio & $5 \mathrm{~V}$ & $250 \mathrm{~mA}$ & Lithium Ion Battery \\
\hline Raspberry Pi PC & $5 \mathrm{~V}$ & $300 \mathrm{~mA}$ & USB Cable \\
\hline Android Phone & $5 \mathrm{~V}$ & $450 \mathrm{~mA}$ & Lithium Ion Battery \\
\hline Windows Phone & $5 \mathrm{~V}$ & $475 \mathrm{~mA}$ & Lithium Ion Battery \\
\hline Computer Fans & $12 \mathrm{~V}$ & $125 \mathrm{~mA}$ & Power Adapter \\
\hline Speakers & $15 \mathrm{~V}$ & $70 \mathrm{~mA}$ & Power Adapter
\end{tabular}




\subsection{Data Analysis}

The turn-on characteristics of these devices were observed by sweeping the input voltage and recording the current draw at each step. The voltage sweep begins at $1 \mathrm{~V}$, then increases in steps of $0.1 \mathrm{~V}$ until at least $1 \mathrm{~V}$ after the nominal voltage. These raw voltage sweeps can be found in Appendix A. In general, these devices tend to use very little current at $1 \mathrm{~V}$, then feature a large spike in current around the voltage where the device first turns on. Since these plots tend to be noisy, a moving average with a window size of 5 samples can be used on the data to provide a clearer indication of trends. Additionally, since these plots feature large jumps in the rate at which the current is increasing per voltage step near the turn on voltage, the derivative of these plots could provide some additional information. The moving average and the derivative with respect to the current over the voltage were calculated for each test device, shown in Figure 16 through Figure 22. 

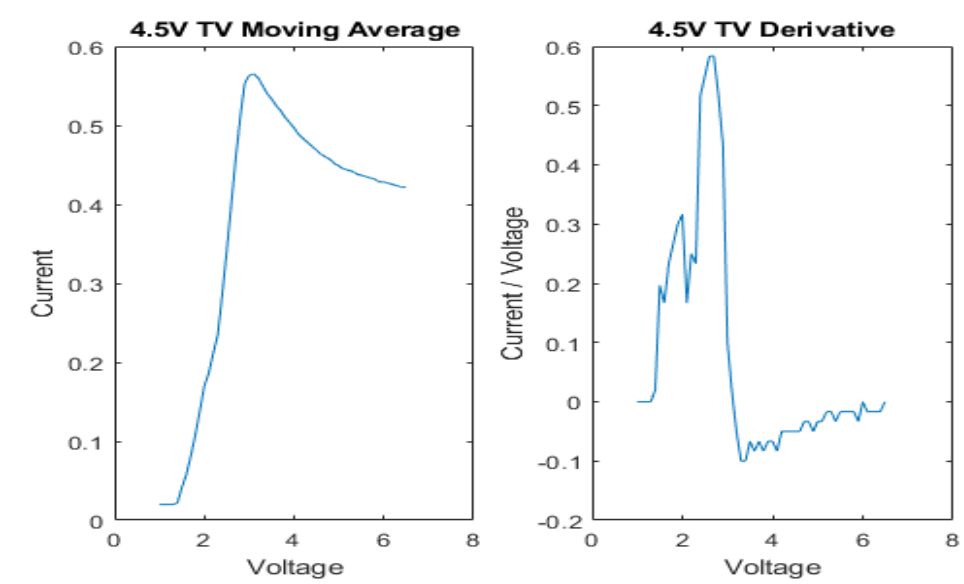

Figure 16: 4.5 TV Moving Average and Derivative
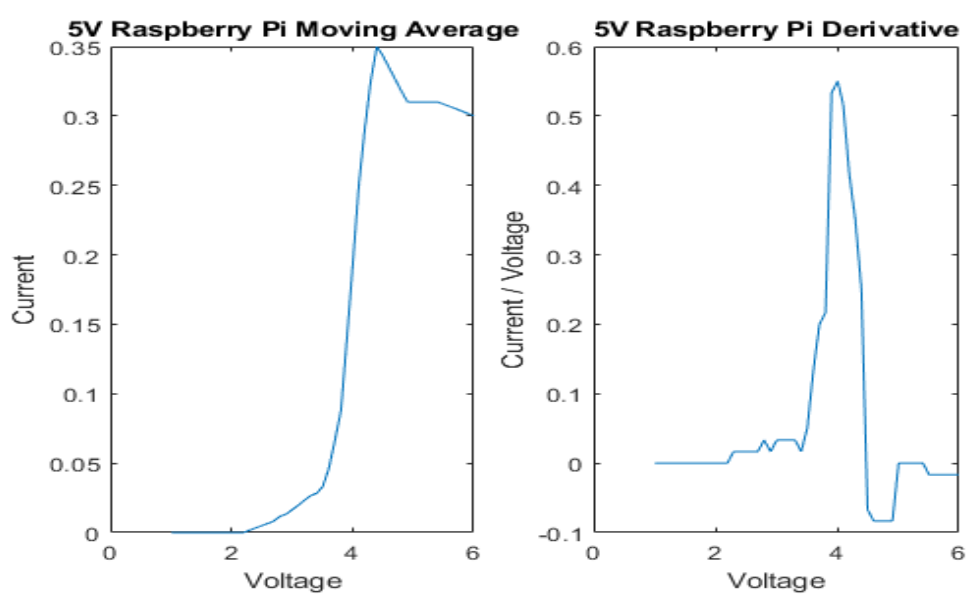

Figure 18: 5V Raspberry Pi Moving Average and Derivative
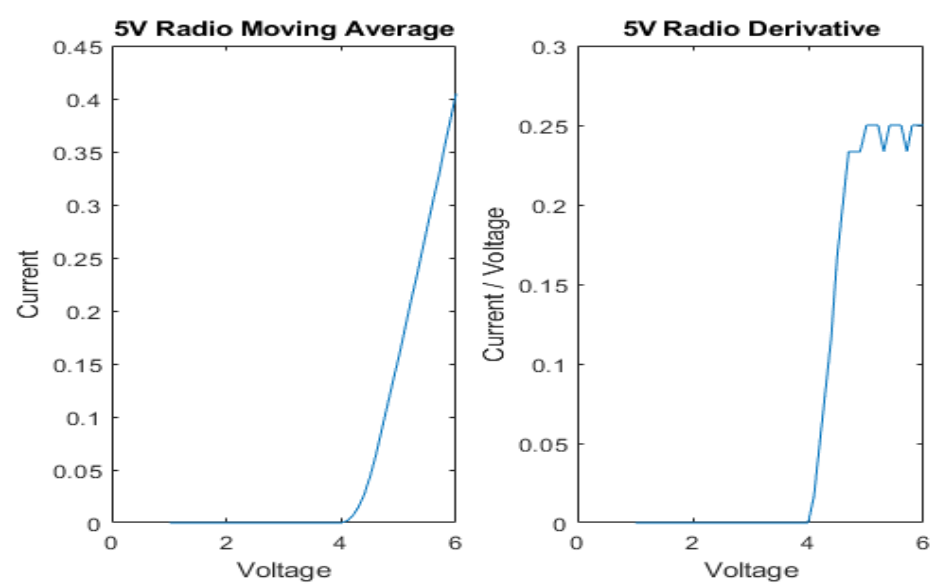

Figure 17: 5V Radio Moving Average and Derivative
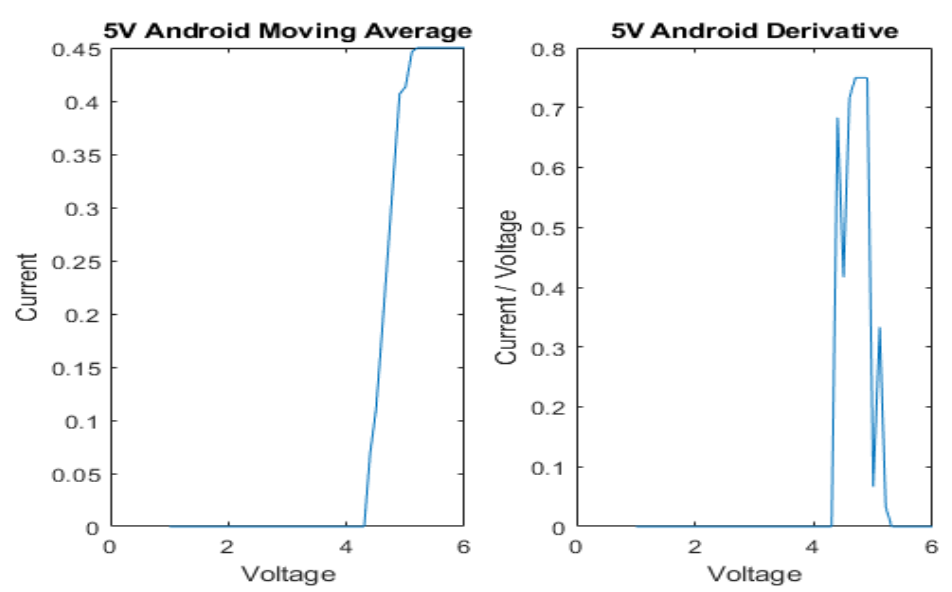

Figure 19: 5V Android Moving Average and Derivative 

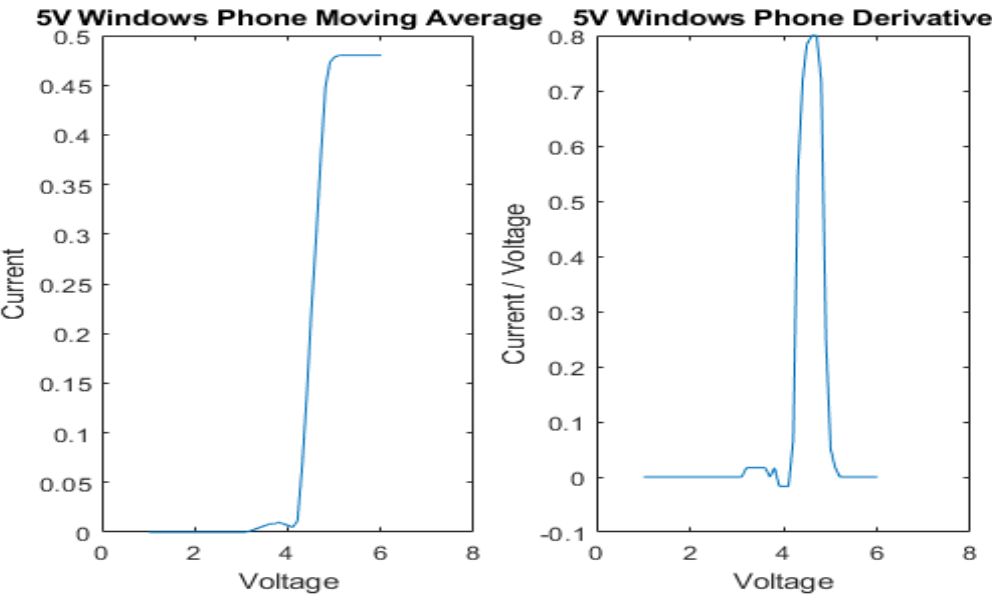

Figure 20: 5V Windows Phone Moving Average and Derivative
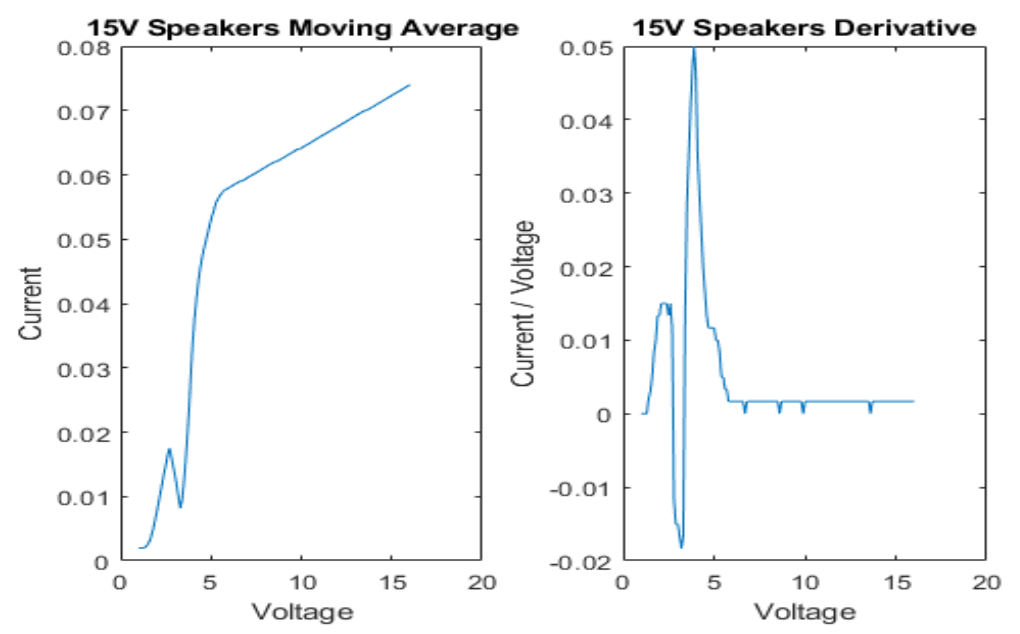

Figure 22: 15V Speakers Moving Average and Derivative
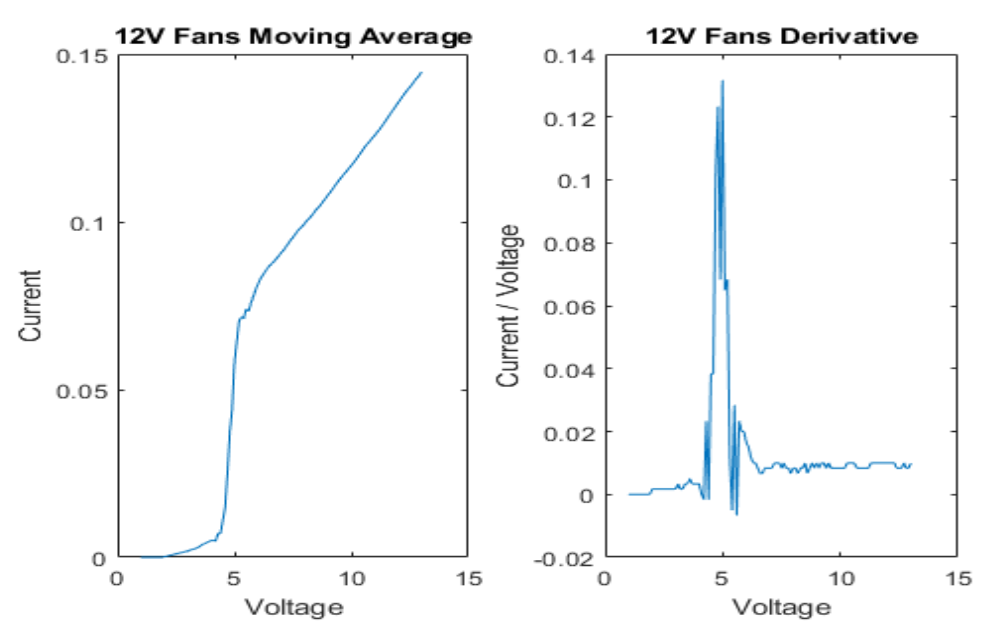

Figure 21: 12V Fans Moving Average and Derivative 
Analysis of these figures grants a few insights about the devices' nominal voltage. Primarily, the turn on voltage of every test device is directly indicated by the largest positive increase in current per voltage step. This is most clearly illustrated by Figure 20. The derivative of the current over voltage reaches its peak value at $4.7 \mathrm{~V}$, which is close to the nominal voltage of $5 \mathrm{~V}$. For most of the devices tested, this maximum derivative value is found just before the nominal voltage. The three devices that do not conform exactly to this pattern are the 5V Radio, the $12 \mathrm{~V}$ Fans and the $15 \mathrm{~V}$ Speakers.

The 5V Radio does feature a large step in the derivative value of the current over voltage, but this value is held constant unlike the other devices. This is because the $5 \mathrm{~V}$ Radio does not draw a large jump in current at the turn on voltage, but instead begins ramping up at a constant slope as seen in Figure 17. This is likely due to the simplistic lithium ion battery charging circuit within the 5V Radio. The voltage at which the device begins ramping up is close to the listed nominal voltage of the device, so this starting point can be used to trivially determine the nominal voltage.

The $12 \mathrm{~V}$ Fans and the 15V Speakers both present a maximum derivative between $4 \mathrm{~V}$ and $5 \mathrm{~V}$, but nominally require a voltage three times larger. The plots relating to the 12V Fans and 15V Speakers are shown in Figure 21 and Figure 22. Both devices function if they are provided a $5 \mathrm{~V}$ input voltage but may not perform optimally. The fans do not spin as fast as they normally would, and the speakers produce a much quieter sound. One characteristic differentiates the $12 \mathrm{~V}$ Fans and the $15 \mathrm{~V}$ Speakers from the other devices: the current per voltage step steadily increases after the tun on voltage. With the other devices being tested (except for the previously handled 5V Radio), the current draw after 
the turn on voltage either stagnates or begins to decrease. Unfortunately, neither of these devices exhibit any indication of what their nominal voltage might be. It is possible to infer that the nominal voltage is much higher than the turn on voltage for these devices, but just how much higher is left to speculation.

\subsection{Algorithm Development}

Using the turn on voltage characteristics previously identified, an algorithm can be developed to estimate the nominal voltage of a load device. A flowchart outlining the algorithm developed in MATLAB is shown in Figure 23. The process begins with sweeping the input voltage from $1 \mathrm{~V}$ to $3 \mathrm{~V}$, as nearly all DC devices can be assumed to handle this voltage range. The algorithm attempts to find a large spike in the current draw in this range to find the turn on voltage. If no spike is detected, the input voltage is increased in $1 \mathrm{~V}$ increments until one is detected. Once a peak in the current draw is detected, the peak needs to be verified. With some devices, like the $15 \mathrm{~V}$ speakers seen in Figure 22, there is a small initial jump in current usage followed by a much larger increase at the true turn on voltage. For all the devices tested, these false turn on voltage indicators appear within $1 \mathrm{~V}$ of the actual turn on voltage. By increasing the input voltage $1 \mathrm{~V}$ beyond the detected peak value, the current draw peak can either be confirmed as the true turn on voltage, or a new larger peak can be detected indicating that turn on voltage is likely higher. 


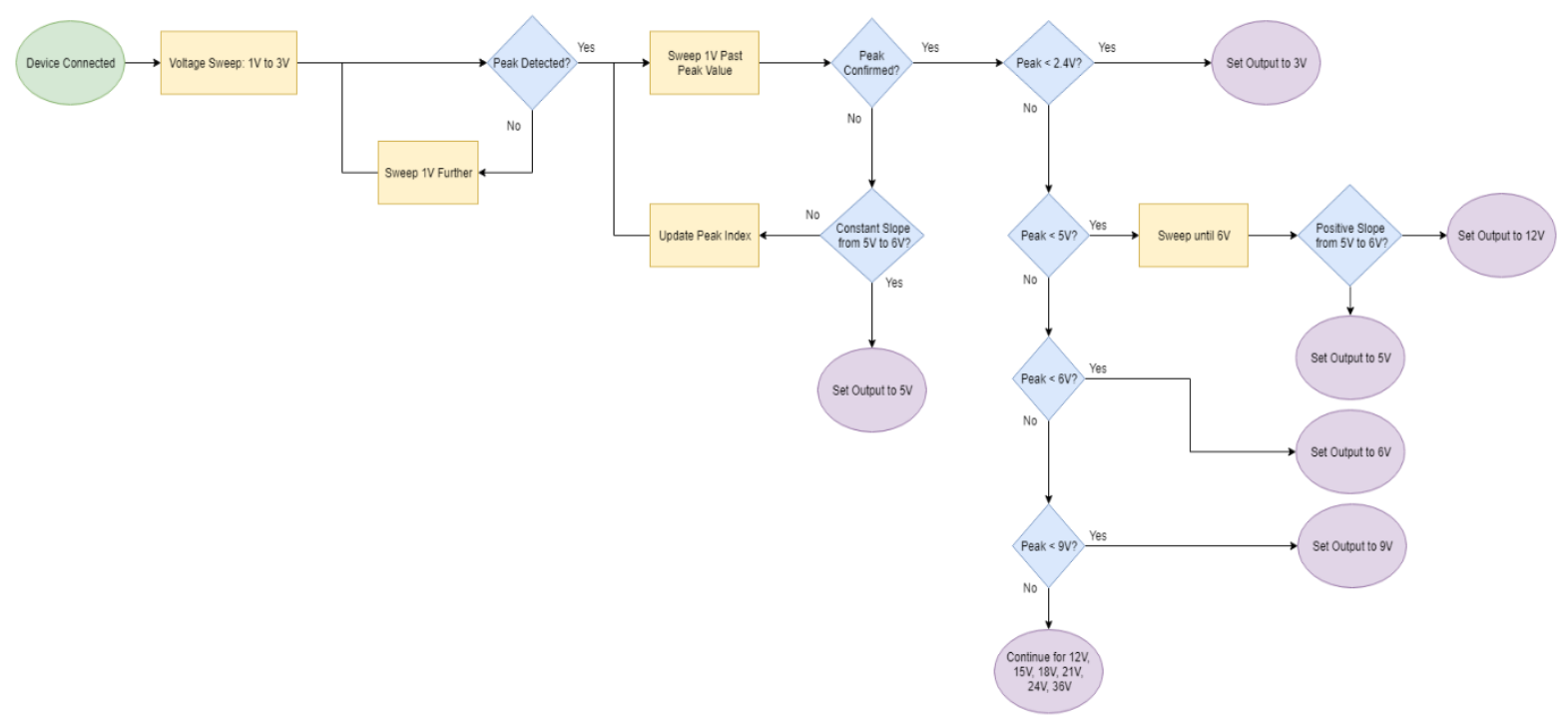

Figure 23: Nominal Voltage Detection Algorithm Flowchart

While attempting to confirm the peak in the current draw rate, the algorithm continues monitoring the maximum voltage being sent to the load device. Once the output voltage surpasses $6 \mathrm{~V}$, the algorithm looks to see if the device could be a battery charging device like the $5 \mathrm{~V}$ radio. If the current draw rate remains constant from $5 \mathrm{~V}$ to $6 \mathrm{~V}$ and the peak has yet to be confirmed, a battery charging device has been detected and the output is set to $5 \mathrm{~V}$. Otherwise, if the current draw rate is variable over this range, the device is likely not a battery charging device and the algorithm continues trying to confirm the peak current draw rate.

Once the peak is confirmed, the algorithm attempts to set the output voltage. If the peak value detected is below $2.4 \mathrm{~V}$, the output is set to $3 \mathrm{~V}$. Most $3 \mathrm{~V}$ devices are powered by alkaline batteries, which decrease their output voltage as they lose charge. These battery voltages can drop to less than $2 \mathrm{~V}$ total, which explains why a $3 \mathrm{~V}$ device would have a lower turn on voltage. Continuing, if the peak value detected is below $5 \mathrm{~V}$, the 
algorithm looks to see if the device might need more power. As found in the previous section, larger nominal voltage devices draw an increasing amount of current as the input voltage goes up. This is detected by finding the median current draw rate of the device from $5 \mathrm{~V}$ to $6 \mathrm{~V}$. If the median value is positive, it indicates that overall the device is drawing more current after its turn on voltage, implying a need for a larger input voltage. If the median value is close to 0 or negative, the device does not require a larger input voltage and the nominal voltage should be set close to the turn on voltage. The current draw rate was specifically investigated from $5 \mathrm{~V}$ to $6 \mathrm{~V}$ as most of the devices tested required $5 \mathrm{~V}$ or less. This was primarily done for safety, as all the devices tested would be able to handle being powered at $6 \mathrm{~V}$. Ideally, the current draw rate would be investigated 2 volts after the peak turn on voltage, not just from the $5 \mathrm{~V}$ to $6 \mathrm{~V}$ range. More testing would need to be done to see if most devices could handle an input voltage two volts higher than nominal.

If the device under test was identified as needing a higher input voltage, the voltage was set to $12 \mathrm{~V}$. As mentioned previously, there is currently no indicator for exactly what voltage a device requires, so the output is estimated at being $12 \mathrm{~V}$. In this case the two higher voltage devices being tested were able to be safely be powered by $12 \mathrm{~V}$, but further studies of DC devices would need to be conducted to identify a more general metric for finding the nominal voltage of a high input voltage device. If the device did not continue to draw an increasing amount of current after the turn on voltage, the device was set to the closest output voltage of $5 \mathrm{~V}$. For all devices with a larger detected turn on voltage, the output voltage was set to the next closest output voltage. These output voltages include $6 \mathrm{~V}, 9 \mathrm{~V}, 12 \mathrm{~V}, 15 \mathrm{~V}, 18 \mathrm{~V}, 21 \mathrm{~V}, 24 \mathrm{~V}$ and $36 \mathrm{~V}$. More output 
voltages can be added in the future, but these appeared to be the most common levels used commercially.

This algorithm was implemented in MATLAB and was successfully able to identify nominal voltages for the test devices. This algorithm will next be implemented on the microcontroller to be tested on the devices in real time. 


\section{HARDWARE CONSTRUCTION AND TESTING RESULTS}

\subsection{Bill of Materials}

The first step towards construction of the smart DC wall plug involved selecting physical parts for each of the components shown in the circuit schematic from Figure 15. All the components used in the smart DC wall outlet were purchased directly from DigiKey, except for the two Buck controllers which were obtained for free from Analog Devices. The main limiting factors for selecting components were size and cost. The total size of the board was limited by the physical dimensions listed in Table 2, requiring components to be small enough to fit on the board. Since the construction of the board was done by hand, the minimum package size for the resistors and capacitors was set to $16 \mathrm{~mm}$ by $8 \mathrm{~mm}$ to allow for easier manipulation. Other components such as the power MOSFETs and inductors needed to be larger to handle the large amounts of current passing through the system. With regards to cost, the cheapest possible components were chosen provided they satisfied the maximum current and voltage ratings and were reasonably sized. The finalized list of components chosen is shown in Figure 24. 


\begin{tabular}{|c|c|c|c|c|c|c|c|c|}
\hline Designators & Qty Needed Vafe & ty Value & Description & D Digikey PN & V Footprint & V Link & \multicolumn{2}{|c|}{ V Price/Unit V Total Price $\nabla$} \\
\hline C_5_IN & 1 & $15 u$ & 5V Buck Input Cap, I_RMS_MAX = 0.1A & 493-13293-1-ND & Radial Through Hole 1 & & $\$ 0.68$ & $\$ 0.68$ \\
\hline $\mathrm{C} 10, \mathrm{C} 11$ & 2 & $21 \mathrm{n}$ & Current Sense Low Pass Caps. Ceramic & 1276-1195-1-ND & 0603 (1608 Metric) & & $\$ 0.10$ & $\$ 0.20$ \\
\hline C12, C19, COUT10, COUT20 & 4 & $410 u$ & Output Caps, DRVcc Cap, EXTVcc Cap. Vmax $=20$ V. Ceramic & 490-12457-1-ND & 1206 (3216 Metric) & & $\$ 0.55$ & $\$ 2.20$ \\
\hline C15, C18 & 2 & $20.1 \mathrm{n}$ & I_TH Caps, used for control loop compensation. Vmax $=3.5$, Ceramic & 399-8980-1-ND & 0603 (1608 Metric) & & $\$ 0.18$ & $\$ 0.36$ \\
\hline C16, C17 & 2 & $24.7 n$ & I_THR Caps, Vmax $=3.5$, Ceramic & 490-9669-1-ND & 0603 (1608 Metric) & & $\$ 0.18$ & $\$ 0.36$ \\
\hline $\mathrm{C} 2, \mathrm{C} 5, \mathrm{C} 8, \mathrm{C} 9$ & 4 & $40.1 \mathrm{u}$ & Decoupling Caps. Vmax $=48 \mathrm{~V}$, Ceramic & 311-1523-1-ND & 0603 (1608 Metric) & . & $\$ 0.22$ & $\$ 0.88$ \\
\hline C3, C13, C14 & 3 & $31 \mathrm{u}$ & Decoupling Caps. Vmax $=3.3 \mathrm{~V}$. Ceramic & 1276-1036-1-ND & 0603 (1608 Metric) & & $\$ 0.10$ & $\$ 0.30$ \\
\hline C4, C_IN1, C_IN2 & 3 & $322 u$ & Input Cap and 5V Output Cap. Vmax $=48 \mathrm{~V}$. Electrolytic. Need 2 for input & P122450-ND & Radial Through Hole 1 & & $\$ 2.82$ & $\$ 8.46$ \\
\hline COUT11, COUT12, COUT21, COUT22 & 4 & $4200 u$ & Output Caps. Vmax = 40V, Electrolytic & 1572-1396-ND & Radial Through Hole 1 & & $\$ 2.88$ & $\$ 11.52$ \\
\hline COUT13, COUT23 & 2 & $2 ?$ & Extra space if another cap is needed & - & - & - & $\$ 0.00$ & $\$ 0.00$ \\
\hline D1, D2 & 2 & $2-$ & Schottky diode from DRVcc to Boost & 497-2529-1-ND & SOT-23-3 & & $\$ 0.45$ & $\$ 0.90$ \\
\hline F1 & $1^{\prime \prime}$ & $25 \mathrm{~A}$ & Fuse, $5 \mathrm{~A}$ & 507-1194-1-ND & 1206 (3216 Metric) & & $\$ 0.35$ & $\$ 0.70$ \\
\hline$F 2, F 3$ & $2^{\prime}$ & $48 \mathrm{~A}$ & Fuse, $8 \mathrm{~A}$ & 507-1056-1-ND & 2-SMD (Custom?) & & $\$ 0.41$ & $\$ 1.64$ \\
\hline $\mathrm{H} 1, \mathrm{H} 2, \mathrm{H} 3$ & 6 & 6 - & Input, Output Headers. Black and red banana plugs & BKCT3149-0-ND, BK & KCT Axial Through Hole & & $\$ 1.20$ & $\$ 7.20$ \\
\hline L1 & 1 & $110 u$ & $5 \mathrm{~V}$ Buck Inductor. Max Current of $1 \mathrm{~A}$ ? Maybe less. & 732-1025-1-ND & 1919 (4848 Metric) & & $\$ 1.45$ & $\$ 1.45$ \\
\hline L2, L3 & 2 & $233 u$ & Buck Inductors. Max Current of 10A? & 7732-2524-1-ND & Nonstandard & & $\$ 7.06$ & $\$ 14.12$ \\
\hline LED1, LED2, LED3 & 3 & $3-$ & 3 Green LED's & 160-1446-1-ND & 0603 (1608 Metric) & & $\$ 0.29$ & $\$ 0.87$ \\
\hline $\mathrm{Q} 1, \mathrm{Q} 2, \mathrm{Q} 3, \mathrm{Q} 4$ & 4 & 4. & Power Mosfets to handle main switching & SOJA68EP-T1_GE3CT & T-1 PowerPAK॰ SO-8 & 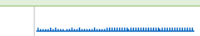 & $\$ 0.90$ & $\$ 3.60$ \\
\hline$Q 5, Q 6, Q 7, Q 8, Q 9$ & 5 & $5-$ & Used for LED's and I2C Level Shifting. Has body diode $I=0.2 \mathrm{~A}$ & SI1050X-T1-GE3DKR & R-N SC-89-6 & & $\$ 0.59$ & $\$ 2.95$ \\
\hline R1 & 1 & $130.9 \mathrm{k}$ & Used to set $5 \mathrm{~V}$ Buck freq. (1\%) & 541-30.9KHDKR-ND & 0603 (1608 Metric) & & $\$ 0.10$ & $\$ 0.10$ \\
\hline R13, R14, R24, R25 & 4 & $45 \mathrm{k}$ & Pull up resistors for the $12 \mathrm{C}$ lines. & YAG5090CT-ND & 1206 (3216 Metric) & & $\$ 0.56$ & $\$ 2.24$ \\
\hline R2, R10, R11, R12, R15, R16, R17, R18, R19, & 10 & $1010 \mathrm{k}$ & Pull Up resistors for buck. & RHM10KADCT-ND & 0603 (1608 Metric) & س. & $\$ 0.13$ & $\$ 1.26$ \\
\hline$R 21, R 22, R 23$ & $3^{\prime}$ & 10150 & Current Limiters for LED's & A129678CT-ND & 0603 (1608 Metric) & & $\$ 0.03$ & $\$ 0.33$ \\
\hline R3 & 1 & 18 & Used to filter Vin pin (1\%) & P8.2AICT-ND & 0603 (1608 Metric) & & $\$ 0.19$ & $\$ 0.19$ \\
\hline $\mathrm{R} 6, \mathrm{R7}, \mathrm{R} 8$, R9 & $4^{\prime}$ & 10100 & Isense Feedback RC network. & RMCF0603FT100RC & CT-10603 (1608 Metric) & & $\$ 0.02$ & $\$ 0.18$ \\
\hline ROUT_SENSEO, ROUT_SENSE1 & 2 & $210 \mathrm{~m}$ & Output Sesning Resistors, $10 \mathrm{mR}$ & 311-.010TCT-ND & 2512 (6432 Metric) & & $\$ 0.66$ & $\$ 1.32$ \\
\hline U1 & 1 & 1 LT8619-5 & Secondary buck controller & LT8619EMSE-5\#PBF- & E-N 16-MSOP-EP & & $\$ 6.00$ & $\$ 6.00$ \\
\hline U2 & $11^{\prime}$ & 2 ARDUINOR3 & Arduino Uno Rev. 3, Breakaway Headers & S1012EC-40-ND & $0.1 "$ Pitch & 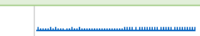 & $\$ 0.51$ & $\$ 1.02$ \\
\hline U3 & 1 & 1 LTC3889 & Primary buck controller & LTC3889IUKG\#PBF-1 & ND 52-QFN (7×8) & & $\$ 16.69$ & $\$ 16.69$ \\
\hline & & & & & & & Total Cost. & $\$ 8772$ \\
\hline
\end{tabular}

Figure 24: Bill of Materials 


\subsection{PCB Layout and Fabrication}

Once the components were selected, the footprints for each part had to be generated. Most of the resistors and capacitors used the standardized 0603 package size, which was readily available in the EAGLE footprint library. Most of the other components required custom footprints which needed to be made from scratch. Dimensions and tolerances for each of these parts were obtained from their respective datasheets. After generating footprints for every component, the parts were laid out and connected as shown in Figure 25 and Figure 26. The primary concerns for the board layout were to minimize the length of the power path and to isolate the small signal components from the power path. The power paths on the board are clearly illustrated in in Figure 25 as the wider traces on the left half. These traces were made to be $2.54 \mathrm{~mm}$, allowing a maximum temperature increase of $20^{\circ} \mathrm{C}$ as calculated from [18]. The power path connecting the input header to the output headers includes the switching MOSFETs, inductors, input and output capacitors, and the current sense resistors.

The remainder of the components were routed away from the noisy, high power components. The Arduino Uno header was placed on the right half of the board, oriented to allow the microcontroller to plug in from the bottom. Using the natural isolation that the Arduino Uno provided, the LTC3889 and its supporting components were placed in between the header pins. Not shown in Figure 25 and Figure 26 are two internal layers, consisting of ground planes that spanned the width of the board and a signal layer used to connect components to the 5V Buck regulator seen in the top right. Separate signal and power ground planes were used to improve isolation between sections of the board. 


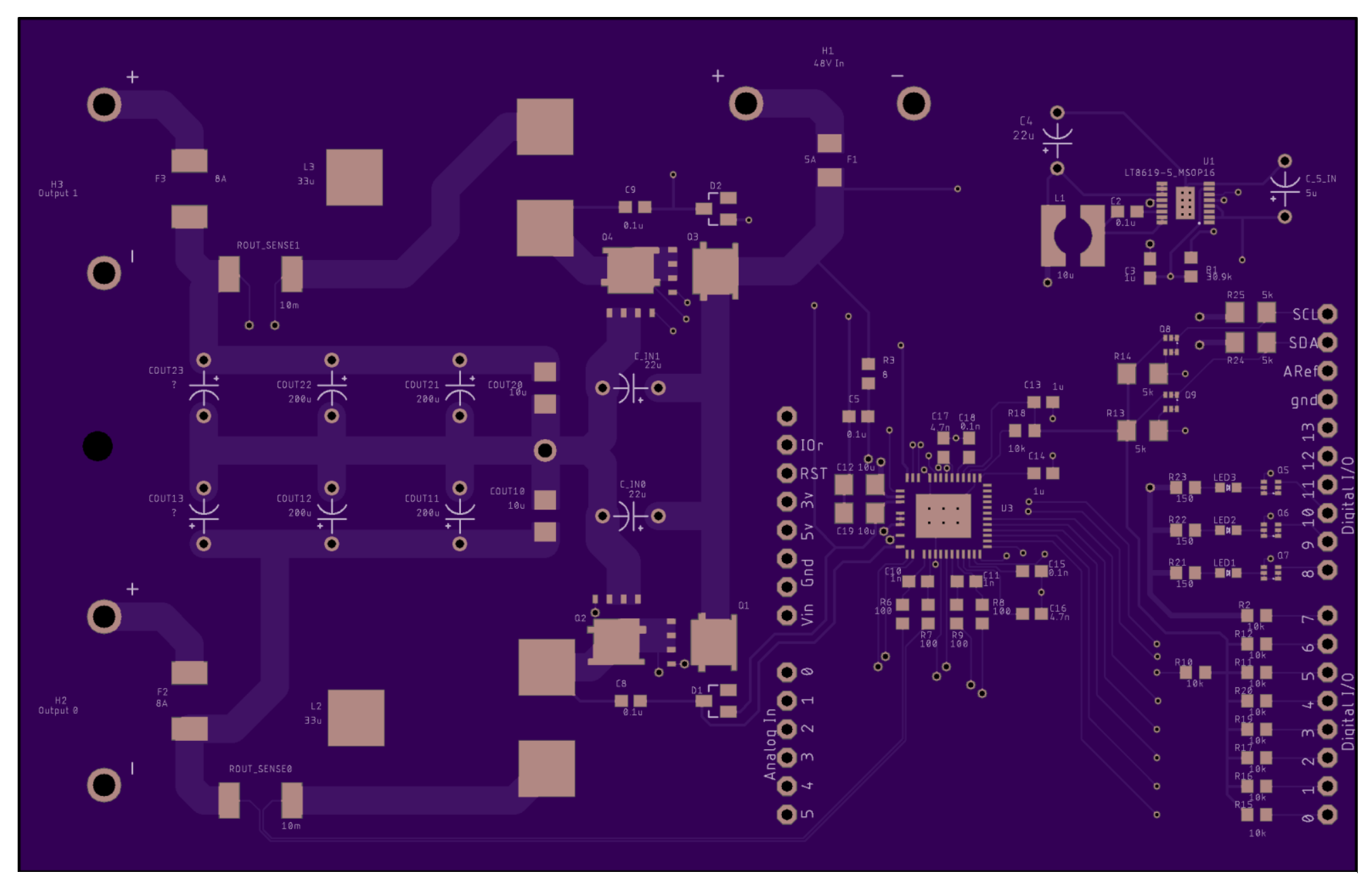

Figure 25: PCB Layout - Top 


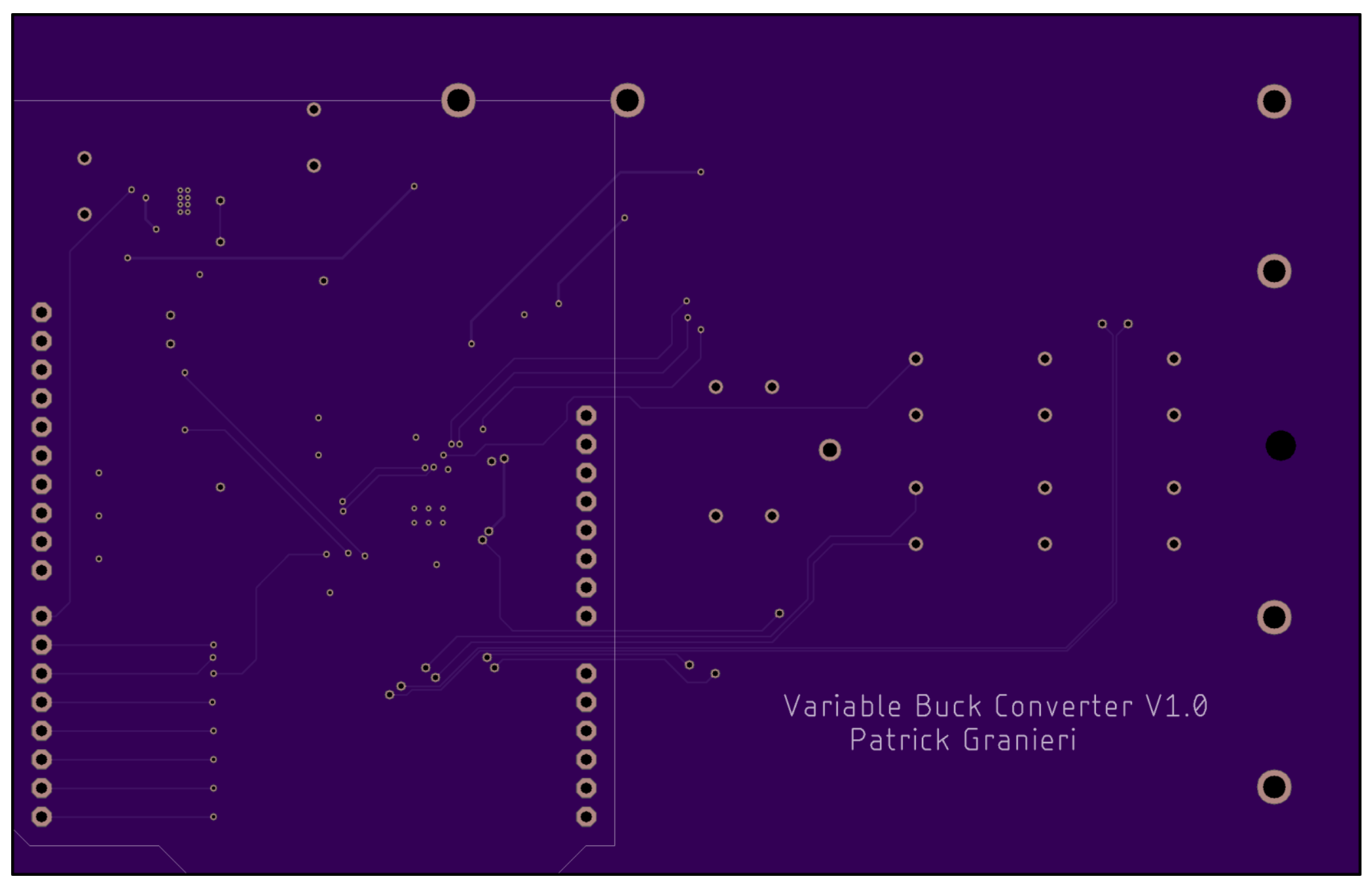

Figure 26: PCB Layout - Bottom 
After the PCB layout process was completed, the board was ready for fabrication. Oshpark was selected to print the board, as they offered a reasonable combination of cost and time-to-ship for a four-layer board.

\subsection{Board Assembly}

Upon receipt of the board, it was inspected for any possible defects. Before adding any components to the board, the surface mount component pads were lightly tinned with solder to prepare for use with the heat gun. Construction began by soldering the LTC3889 IC to the board, since this part controlled the rest of the board and needed to work before anything else could. Followed by soldering on the microcontroller pin headers, the I2C level shifters and a few configuration resistors, the Buck controller was connected to the Arduino Uno. The Uno was able to talk to and receive information from the LTC3889 using an I2C connection, so construction continued with the power path.

Next the input and output connectors were soldered on, followed by the current limiting fuses. Only one channel of the power path was soldered to start with, consisting of the power MOSFETs, the inductor, input and output capacitors, and the current sensing resistor. Additionally, the capacitors were added to the boost and gate drive pins of the LTC3889, along with the Schottky diode to assist in biasing the top N-channel MOSFET. After the assembly of one channel was complete, the Arduino Uno commanded the primary Buck controller to output a series of voltages on the output. Once these were successfully observed, the second power channel was soldered on in a similar fashion. 
Finally, the auxiliary systems were attached, consisting of the $5 \mathrm{~V}$ buck converter, the microcontroller pull-up resistors, and the status LEDs. The Arduino Uno was able to be powered by the board alone after these additions. After testing that the Uno could read information from the input pins and signal the status LEDs, the board was officially complete. The full assembly can be seen in Figure 27.

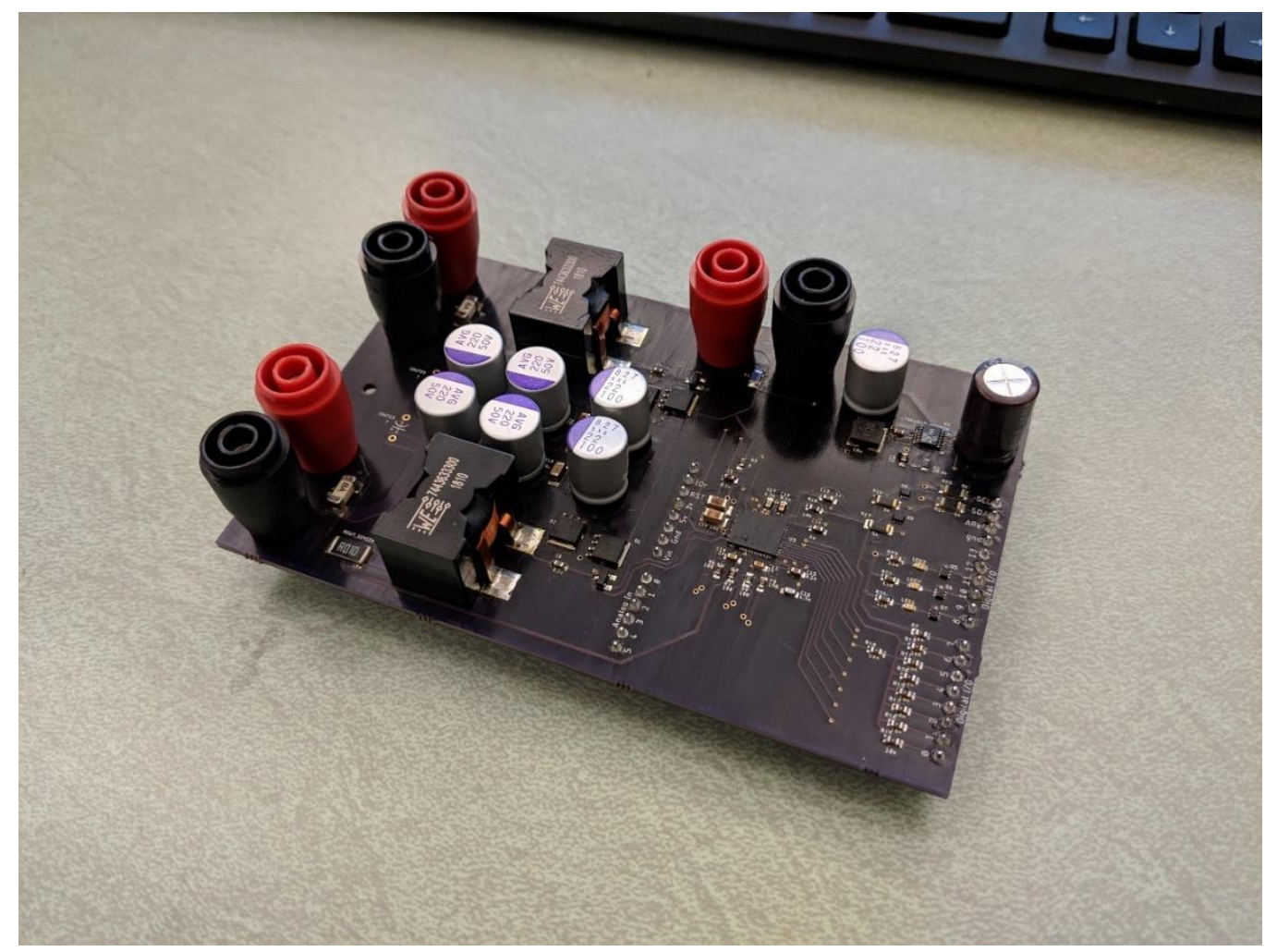

Figure 27: Fully Assembled Smart DC Wall Outlet

\subsection{Microcontroller Programming}

The algorithm developed in Section 4.11 was ported directly from MATLAB to C for use with the Arduino Uno. Though few changes were made to the algorithm, the Arduino Uno needed many new functions to interface with the LTC3889 properly. The 
entirety of the code used on the Arduino Uno can be found in Appendix C. The most basic additions include functions such as PMBUS_WRITE_WORD( ) or PMBUS_READ_BYTE(), which use the PMBUS interface to send data to and from the LTC3889 IC. Higher level functions include change_vout() and set_current_limit(), which use the PMBUS functions to send the many commands needed to safely set a new output voltage or current limit. Other functions that were present in MATLAB but not on the Arduino platform had to be reproduced, such as moving_avg( ) and the ability to find the median value of an array.

One significant change came in the form of a finite state machine in main(). The three states used enumerate the different statuses of the load. State ' 0 ' handles the disconnected case, and the program waits here for 10 seconds before moving to state ' 1 '. The program searches for the nominal voltage of the load device in state ' 1 ', as outlined previously. If no device is detected, the program is sent back to state ' 0 '. Otherwise, if a device is found and the nominal voltage is determined, the output voltage is updated accordingly and sent to state ' 2 '. State ' 2 ' maintains the current output voltage and monitors the current being used by the load. Once the device is disconnected and the output current goes to zero, the program is sent back to the disconnected state ' 0 '. This finite state machine is more clearly displayed in Figure 28. 


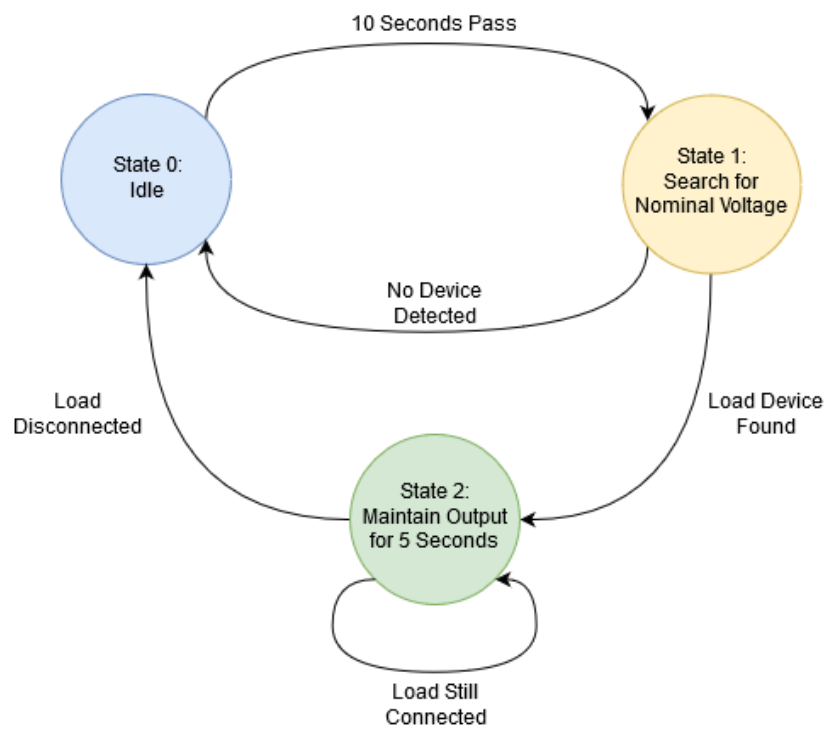

Figure 28: Arduino Uno Finite State Machine

While implementing the algorithm on the Arduino Uno, it was discovered that there was not enough RAM available on the device. The algorithm uses large arrays of floating-point numbers to gather data about the device, which use more than $2 \mathrm{~KB}$ of space in RAM alone. The Arduino Uno was replaced with an Arduino Mega, as it contains $8 \mathrm{~KB}$ of ram.

\subsection{Board Testing Results}

Before implementing the nominal voltage detection algorithm, the system was tested supplying power to the test devices. Unfortunately, while testing the smart DC wall outlet with the standard 48V input used by the DC House, a small pop was heard and the board stopped working. After thorough analysis of the board, it was determined that one of the diodes used in boosting the switching node voltage had failed. Likely due to an overcurrent condition, a diode with a higher current rating was obtained and installed on 
the board. Once the other failed components on the board were replaced, the system was tested again but starting at a $24 \mathrm{~V}$ DC supply instead of $48 \mathrm{~V}$.

Using this lower supply voltage, the system was recorded successfully powering devices and detecting nominal voltages. Following the collection of the necessary figures and data points, testing continued with the $48 \mathrm{~V}$ supply. It showed promising results at first, but after a few load devices had been connected a small pop was heard and the board failed once more. It is unclear why the board failed but it is likely related to the switching MOSFET gate drive subsystem where a short was located. This issue would have been further investigated if more time and funding were available, but thankfully the system was recorded operating from the lower supply voltage. All the following metrics and figures were collected using this $24 \mathrm{~V}$ supply.

First the output characteristics of the smart DC wall plug were verified against the electrical design specifications from Table 1. As previously mentioned, the input supply voltage used was $24 \mathrm{~V}$ instead of $48 \mathrm{~V}$, but this was still high enough to supply power to all the test devices. The efficiency, output voltage ripple and error were found for each test device as shown in Appendix B. Figure 29 is copied below from Appendix B for convenience. The output of the Buck converter suffers from $400 \mathrm{mV}$ peak to peak high frequency noise at the switching frequency of $300 \mathrm{kHz}$, likely due to resonance between the inductors and capacitors in the power path. To reduce this effect in the future, a capacitor with low ESR at the noise frequency could be added in parallel to the other output capacitors [19]. Ignoring this high frequency noise, the largest output voltage ripple stays below $25 \mathrm{mV}$ peak to peak, meeting the specification for every device tested. The output voltage ripple evaluations are shown in Table 6. 


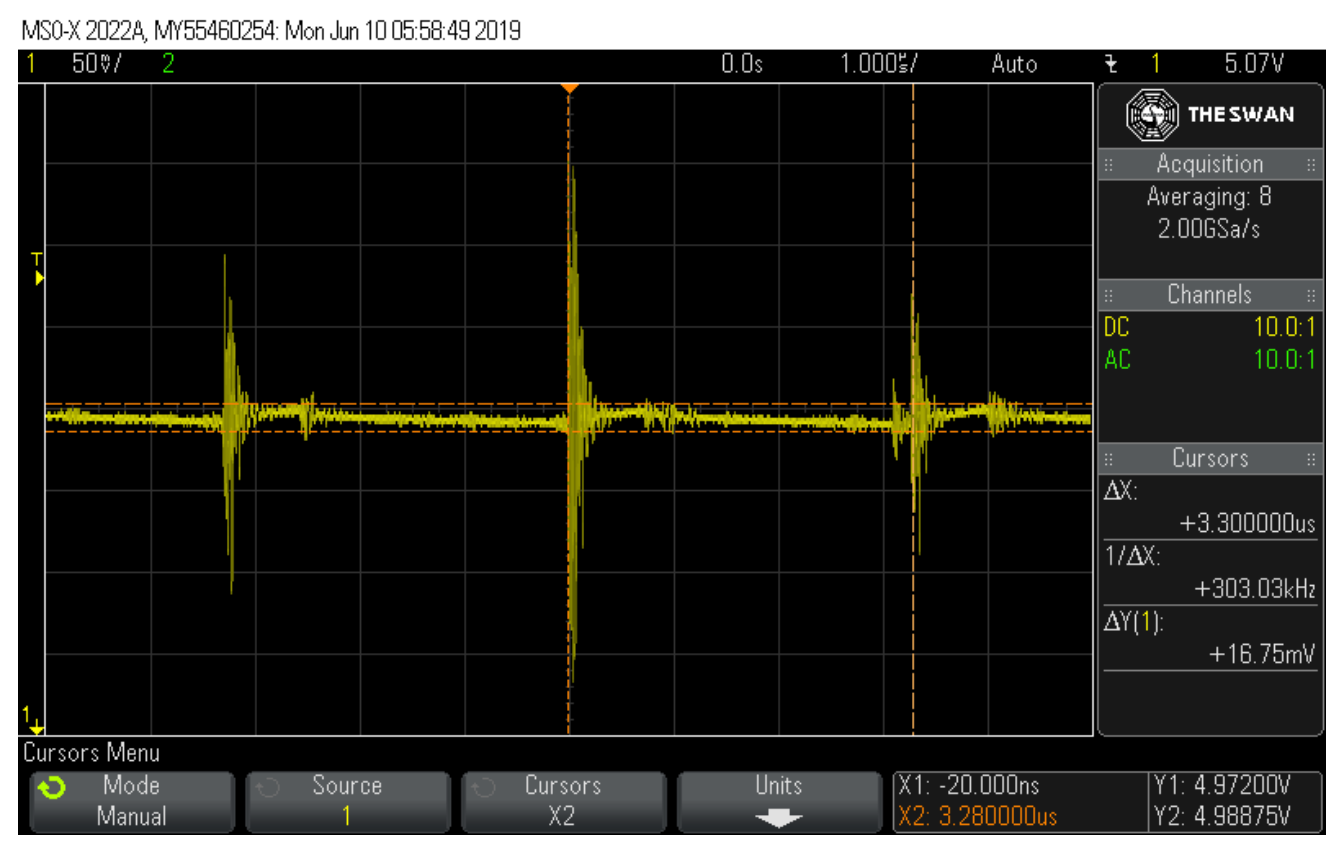

Figure 29: 5V TV Output Regulation

The efficiency and steady state voltage error were measured using the input power supply, the oscilloscope and the current sensing resistor of primary buck converter in tandem. The results of these measurements are listed in Table 4 and Table 5. Overall the steady state voltage error is within limits, but the system efficiency is below the desired $85 \%$. Without any load connected, the smart DC wall outlet consumes $20 \mathrm{~mA}$ from the $24 \mathrm{~V}$ supply, using almost half a watt just in standby. For load devices with low power requirements, this extra half watt of power usage is significant in the efficiency calculations. Figure 30 from the LTC3889 datasheet demonstrates how the efficiency of the system significantly increases as the load current increases. Due to the wide output current range, it is hard to find a buck converter that is efficient at low current conditions while also being able to handle large currents. 


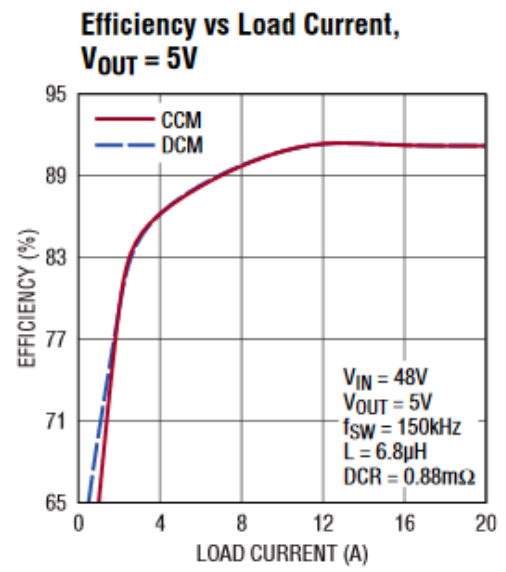

Figure 30: LTC3889 Efficiency Plot [13]

Table 4: Efficiency Evaluation

\begin{tabular}{l|r|r|r|r|r|r}
\multicolumn{1}{c|}{ Device } & $\begin{array}{c}\text { Input } \\
\text { Voltage }\end{array}$ & $\begin{array}{c}\text { Input } \\
\text { Current }\end{array}$ & $\begin{array}{c}\text { Output } \\
\text { Voltage }\end{array}$ & $\begin{array}{c}\text { Output } \\
\text { Current }\end{array}$ & Efficiency & $\begin{array}{c}\text { Target } \\
\text { Efficiency }\end{array}$ \\
\hline 4.5V TV & 24V & $0.12 \mathrm{~A}$ & $4.98 \mathrm{~V}$ & $0.44 \mathrm{~A}$ & $76.1 \%$ & $\geq 85 \%$ \\
\hline 5V Android Phone & $24 \mathrm{~V}$ & $0.12 \mathrm{~A}$ & $4.98 \mathrm{~V}$ & $0.45 \mathrm{~A}$ & $77.8 \%$ & $\geq 85 \%$ \\
\hline 5V Windows Phone & $24 \mathrm{~V}$ & $0.13 \mathrm{~A}$ & $4.98 \mathrm{~V}$ & $0.48 \mathrm{~A}$ & $76.6 \%$ & $\geq 85 \%$ \\
\hline 5V Raspberry Pi & $24 \mathrm{~V}$ & $0.09 \mathrm{~A}$ & $4.98 \mathrm{~V}$ & $0.35 \mathrm{~A}$ & $80.7 \%$ & $\geq 85 \%$ \\
\hline 5V Radio & $24 \mathrm{~V}$ & $0.07 \mathrm{~A}$ & $4.98 \mathrm{~V}$ & $0.23 \mathrm{~A}$ & $68.2 \%$ & $\geq 85 \%$ \\
\hline 12V Fans & 24V & $0.10 \mathrm{~A}$ & $12.01 \mathrm{~V}$ & $0.15 \mathrm{~A}$ & $75.1 \%$ & $\geq 85 \%$ \\
\hline 15V Speakers & 24V & $0.07 \mathrm{~A}$ & $15.00 \mathrm{~V}$ & $0.07 \mathrm{~A}$ & $62.5 \%$ & $\geq 85 \%$
\end{tabular}

Table 5: Output Voltage Percent Error Evaluation

\begin{tabular}{l|r|r|r|r}
\multicolumn{1}{c|}{ Device } & Output Voltage & Target Voltage & Percent Error & \multicolumn{1}{c}{ Target Error } \\
\hline $4.5 \mathrm{~V} \mathrm{TV}$ & $4.98 \mathrm{~V}$ & $5 \mathrm{~V}$ & $0.4 \%$ & $\leq 2.5 \%$ \\
\hline 5V Android Phone & $4.98 \mathrm{~V}$ & $5 \mathrm{~V}$ & $0.4 \%$ & $\leq 2.5 \%$ \\
\hline 5V Windows Phone & $4.98 \mathrm{~V}$ & $5 \mathrm{~V}$ & $0.4 \%$ & $\leq 2.5 \%$ \\
\hline 5V Raspberry Pi & $4.98 \mathrm{~V}$ & $5 \mathrm{~V}$ & $0.4 \%$ & $\leq 2.5 \%$ \\
\hline 5V Radio & $4.98 \mathrm{~V}$ & $5 \mathrm{~V}$ & $0.4 \%$ & $\leq 2.5 \%$ \\
\hline 12V Fans & $12.01 \mathrm{~V}$ & $12 \mathrm{~V}$ & $0.1 \%$ & $\leq 2.5 \%$ \\
\hline 15V Speakers & $15.00 \mathrm{~V}$ & $15 \mathrm{~V}$ & $0 \%$ & $\leq 2.5 \%$
\end{tabular}


Table 6: Output Voltage Ripple Evaluation

\begin{tabular}{l|r|r|r|r}
\multicolumn{1}{c|}{ Device } & Output Voltage & $\begin{array}{c}\text { Output Voltage } \\
\text { Ripple }\end{array}$ & $\begin{array}{c}\text { Output Voltage } \\
\text { Ripple Percent }\end{array}$ & $\begin{array}{c}\text { Target Ripple } \\
\text { Percent }\end{array}$ \\
\hline 4.5V TV & $4.98 \mathrm{~V}$ & $16.75 \mathrm{mV}$ & $0.3 \%$ & $\leq 2.5 \%$ \\
\hline 5V Android Phone & $4.98 \mathrm{~V}$ & $10.50 \mathrm{mV}$ & $0.2 \%$ & $\leq 2.5 \%$ \\
\hline 5V Windows Phone & $4.98 \mathrm{~V}$ & $10.00 \mathrm{mV}$ & $0.2 \%$ & $\leq 2.5 \%$ \\
\hline 5V Raspberry Pi & $4.98 \mathrm{~V}$ & $14.50 \mathrm{mV}$ & $0.3 \%$ & $\leq 2.5 \%$ \\
\hline 5V Radio & $4.98 \mathrm{~V}$ & $9.25 \mathrm{mV}$ & $0.2 \%$ & $\leq 2.5 \%$ \\
\hline 12V Fans & $12.01 \mathrm{~V}$ & $21.75 \mathrm{mV}$ & $0.2 \%$ & $\leq 2.5 \%$ \\
\hline 15V Speakers & $15.00 \mathrm{~V}$ & $15.00 \mathrm{mV}$ & $0.1 \%$ & $\leq 2.5 \%$
\end{tabular}

\subsection{Algorithm Testing Results}

The nominal voltage detection algorithm was first tested with the $5 \mathrm{~V}$ devices. The algorithm successfully determined the nominal output voltage of the $4.5 \mathrm{~V} \mathrm{TV}$, the $5 \mathrm{~V}$ Android Phone, the 5V Windows Phone and the 5V Raspberry Pi. A plot depicting the algorithm successfully finding the nominal voltage during this process is shown in Figure 31.

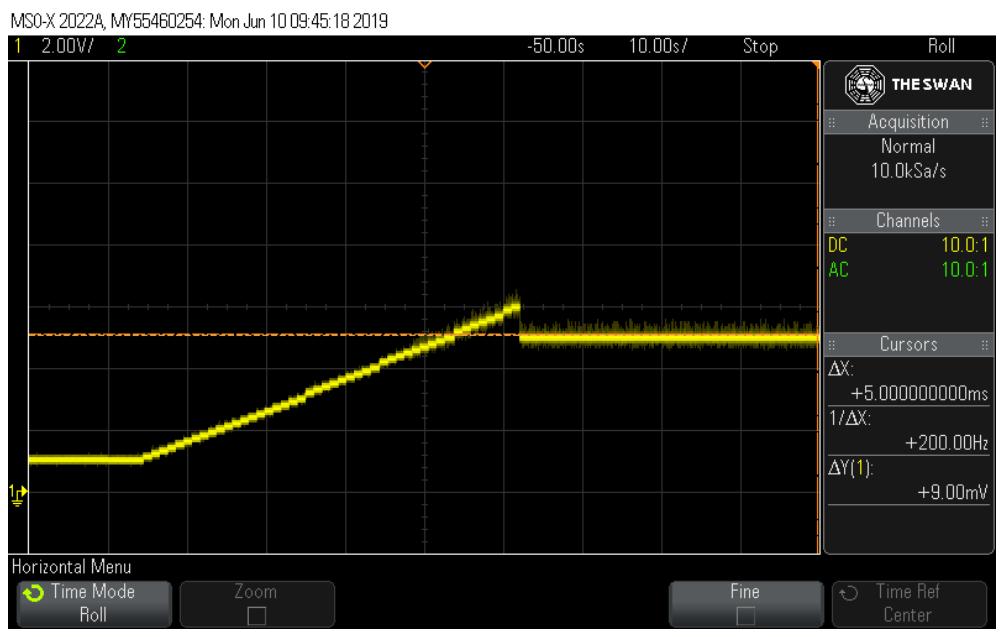

Figure 31: 5V Android Algorithm Success 
The algorithm faced some issues when trying to discern the nominal voltage of the 5V Radio. Figure 32 shows the algorithm sweeping the output voltage to just above $6 \mathrm{~V}$, then setting the output voltage to $6 \mathrm{~V}$ rather than the desired $5 \mathrm{~V}$. This indicates that a current peak was confirmed after $5 \mathrm{~V}$, rather than identifying that the current draw rate remained constant after the turn on voltage. The experimental load current draw was recorded from the smart DC wall outlet in Figure 33. This plot clearly shows that the current draw did not remain constant as previously assumed and instead featured dips around the $5 \mathrm{~V}$ and $6 \mathrm{~V}$ mark. These dips likely caused the algorithm to mistakenly confirm the peak current draw rates.

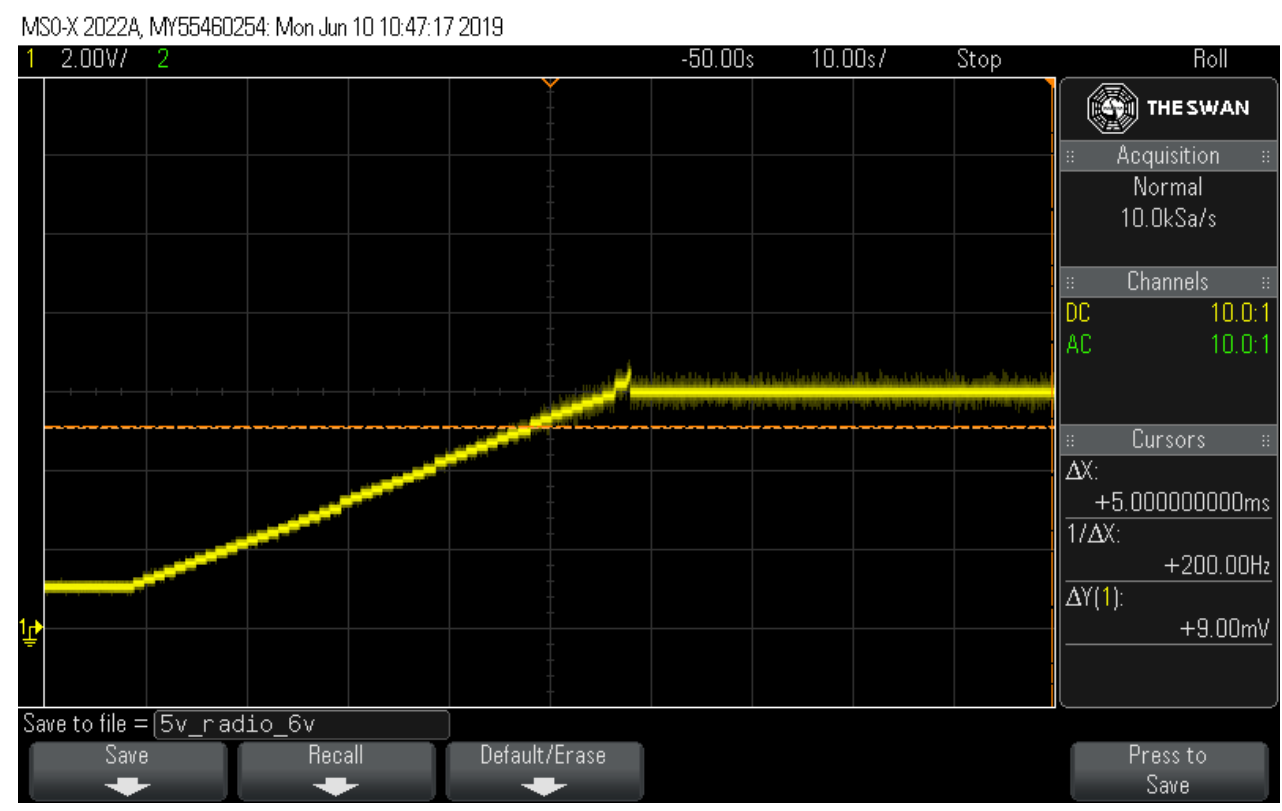

Figure 32: 5V Radio Algorithm Failure 


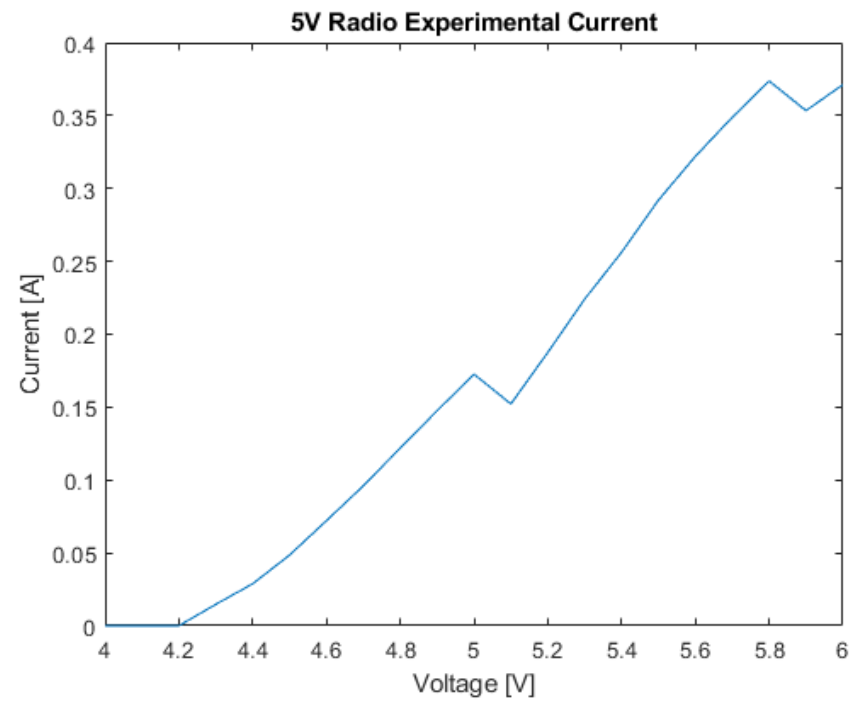

Figure 33: 5V Radio Experimental Current Draw

Testing continued with the $12 \mathrm{~V}$ Fans and the $15 \mathrm{~V}$ Speakers. The algorithm is shown correctly determining the output voltage of the $12 \mathrm{~V}$ Fans in Figure 34 . The $15 \mathrm{~V}$ speakers were mistakenly classified as a 5V device, as seen in Figure 35. After analyzing the system's current readings from the 15V Speaker, it was discovered that the algorithm correctly identified the turn on voltage of the device as being below $5 \mathrm{~V}$ but failed to identify the slope after the turn on voltage as being positive. Since the $15 \mathrm{~V}$ Speakers only draw $70 \mathrm{~mA}$, the current draw rate calculated for the critical region was positive but failed to pass the minimum threshold. The algorithm could be further tuned to use a smaller threshold for this calculation, but this would make the system more susceptible to noise. 


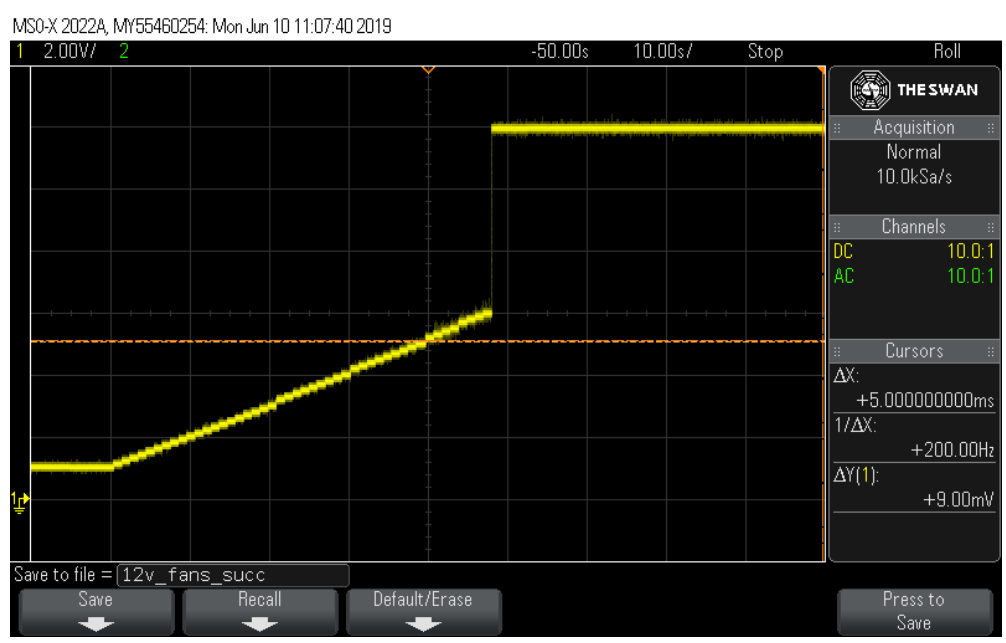

Figure 34: 12V Fans Algorithm Success

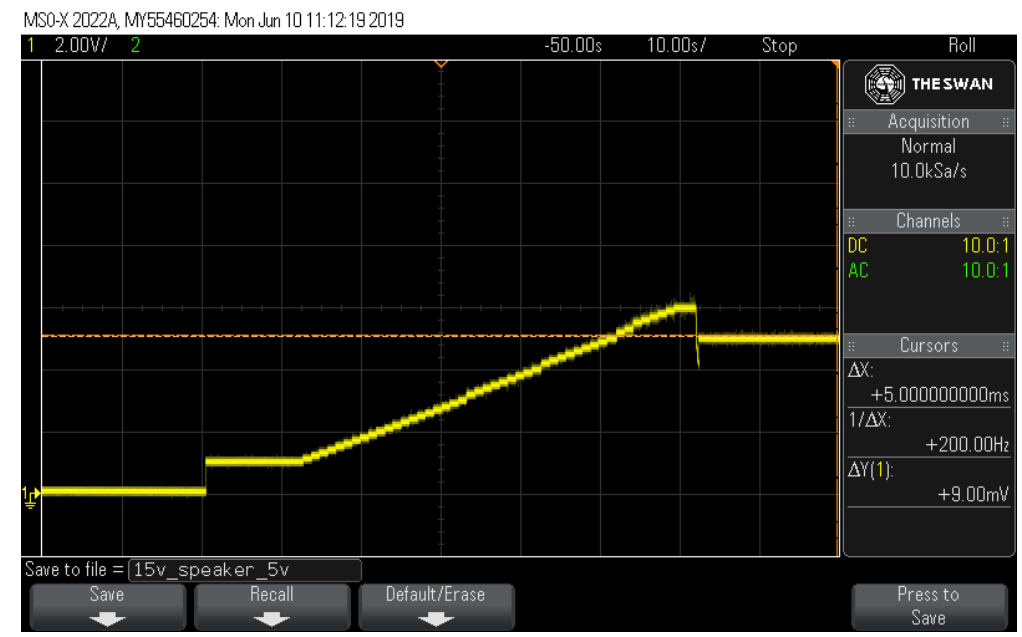

Figure 35: 15V Speakers Algorithm Failure

In total, the nominal voltage detection algorithm was successfully able to classify five out of the seven test devices. With further tuning this could likely be improved, but it is hard to know if the algorithm would be able to generalize to other devices that have not yet been tested. The turn on characteristics of DC devices vary significantly between themselves, and it is difficult to design a process that handles every case. 


\section{CONCLUSION}

The Smart DC Wall Outlet presented in thesis extracts power from the DC House power supply and automatically converts it to an appropriate output DC voltage. This project eliminates energy losses created by converting between AC and DC power systems by supplying DC power directly to DC devices. The Smart DC Wall Outlet features two output channels capable of providing $100 \mathrm{~W}$ of power each, with a theoretical output range from $1 \mathrm{~V}$ to $40 \mathrm{~V}$. The power conversion efficiency of the system features a minimum of $70 \%$ for low load currents around $250 \mathrm{~mA}$ and increases proportionally as the output current rises. Both the output voltage ripple and percent error are less than $0.4 \%$ of the target value, surpassing the $2.5 \%$ design specification.

The two primary improvements for this iteration of the Smart DC Wall Outlet are the digital interface and the improved voltage finding algorithm. Previous designs for this project utilized potentiometers and current sources to set the output voltage of the DC to DC converter, leading to issues with accuracy and general system complexity. This system uses an improved Buck controller, the LTC3889, to digitally monitor and manage the output voltage of the system. Using this chip, a microcontroller can communicate with the Buck controller directly to change the output as needed instead of manipulating components in the feedback path.

Earlier version of the nominal voltage detection algorithm set the output voltage as either $3 \mathrm{~V}, 6 \mathrm{~V}$ or $12 \mathrm{~V}$ depending only on the amount of current being drawn by the load. The algorithm implemented in this iteration finds the turn on voltage of the device by finding the voltage that creates the largest increase in current draw. Following this, it observes the rate of current draw after the turn on voltage, and classifies the device as 
being a high power or low power device. Using the turn on voltage and the power classification, the output voltage is set appropriately to one of the following values: $3 \mathrm{~V}$, $5 \mathrm{~V}, 6 \mathrm{~V}, 9 \mathrm{~V}, 12 \mathrm{~V}, 15 \mathrm{~V}, 18 \mathrm{~V}, 21 \mathrm{~V}, 24 \mathrm{~V}$ and $36 \mathrm{~V}$. This was found to work with five out of the seven devices tested, with the possibility to improve the results with further testing.

The Smart DC Wall Outlet contains a few areas that could use further improvement, with the worst area being the nominal voltage detection process. The algorithm used in this project only works on devices that can be turned on by applying power to the input and cannot be used on devices that implement a toggle button. Additionally, the turn on characteristics of DC devices vary significantly, and it is near impossible to design a ruleset that could handle every case. The ideal method for detecting the output voltage would involve digitally communicating with the load device, like how USB-C negotiates what voltage to supply. Alternatively, a reinforcement learning network could be trained on a wide set of DC devices and used to predict what output voltage would suit a load device best. Other minor improvements that could be made involve shrinking the physical size of the system. The PCB used for this project was sized to house a full Arduino Uno header, and this could be drastically reduced if only the microcontroller IC was placed on the board. Finally, the efficiency of the system could be further improved for small current loads, as this system was only able to achieve $70 \%$ efficiency when the target was $80 \%$. 


\section{BIBLIOGRAPHY}

[1] Edison Tech Center, "Arc Lamps," 2016. [Online]. Available: http://edisontechcenter.org/ArcLamps.html. [Accessed 4 April 2018].

[2] C. L. Sulzberger, "Triumph of AC - from Pearl Street to Niagra," IEEE Power and Energy Magazine, vol. 99, no. 3, pp. 64-67, 2003.

[3] Taufik, Introduction to Power Electronics, 2018, pp. 35-36.

[4] Taufik, "The DC House Project," 13 September 2010. [Online]. Available: https://web.calpoly.edu/ taufik/dchouse/. [Accessed 4 April 2018].

[5] Taufik and M. Muscarella, "Development of DC house prototypes as demonstration sites for an alternate solution to rural electrification," in 2016 6th International Annual Engineering Seminar, 2016.

[6] C. K. Alexander and M. N. O. Sadiku, "6.4 Inductors," in Fundamentals of Electric Circuits, New York, McGraw-Hill, 2013, p. 226.

[7] M. Detmers and T. Blauvelt, "Variable DC Voltage Wall Outlet for The DC House Project," San Luis Obispo, 2011.

[8] E. Sibal, "Smart Wall Plug Design For The DC House Project," San Luis Obispo, 2012.

[9] K. Mendoza, "Smart Wall Outlet Design and Implementation for the DC House Project," San Luis Obispo, 2014. 
[10] R. Liu, "Smart DC/DC Wall Plug Design for the DC House Project," San Luis Obispo, 2017.

[11] D. Ngo, "USB Type-C and Thunderbolt 3: One port to connect them all," CNET, 26 October 2016. [Online]. Available: https://www.cnet.com/how-to/usb-type-cthunderbolt-3-one-cable-to-connect-them-all/. [Accessed 12 April 2019].

[12] NEMA, "Wiring Devices - Dimensional Specifications," 14 April 2016. [Online]. Available: https://www.nema.org/standards/pages/wiring-devices-dimensionalspecifications.aspx?key=67ri900e6rt5af. [Accessed 12 April 2019].

[13] Analog Devices, Inc., "LTC3889 Datasheet and Product Info," 2019. [Online]. Available: https://www.analog.com/en/products/ltc3889.html. [Accessed 2 June 2019].

[14] SMIF, Inc., "PMBus Power Management Defined," 28 March 2005. [Online]. Available: http://pmbus.org/Home. [Accessed 2 June 2019].

[15] Analog Devices, Inc., "LT8619-5 Datasheet and Product Overview," 2019. [Online]. Available: https://www.analog.com/en/products/lt8619.html. [Accessed 2 June 2019].

[16] Arduino, "Arduino - Board," 2019. [Online]. Available: https://www.arduino.cc/en/reference/board. [Accessed 2 June 2019].

[17] Analog Devices, Inc., "LTC3892 Datasheet and Product Info," 2015. [Online]. Available: https://www.analog.com/en/products/ltc3892.html. [Accessed 4 June 2019]. 
[18] B. Suppanz, "Trace Width Calculator," 2018. [Online]. Available: https://www.4pcb.com/trace-width-calculator.html. [Accessed 9 June 2019].

[19] Crane Aerospace \& Electronics, "Measurement and Filtering of Output Noise of DCDC Converters," 2016. [Online]. Available: http://www.interpoint.com/product_documents/DC_DC_Converters_Output_Noise.pdf. [Accessed 10 June 2019]. 
A. Test Device Voltage Sweeps

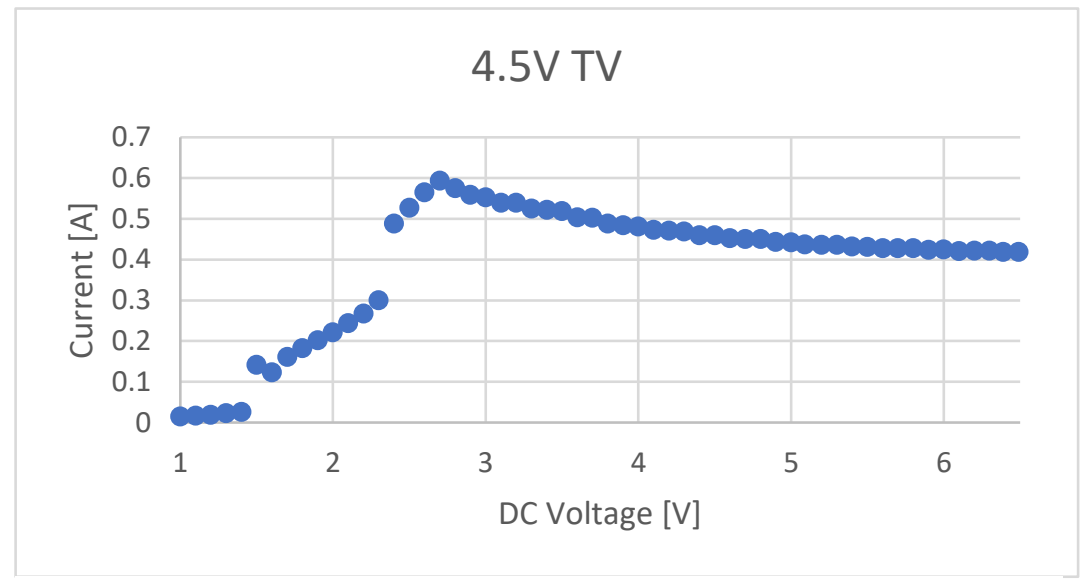

Figure 36: 4.5V TV Voltage Sweep

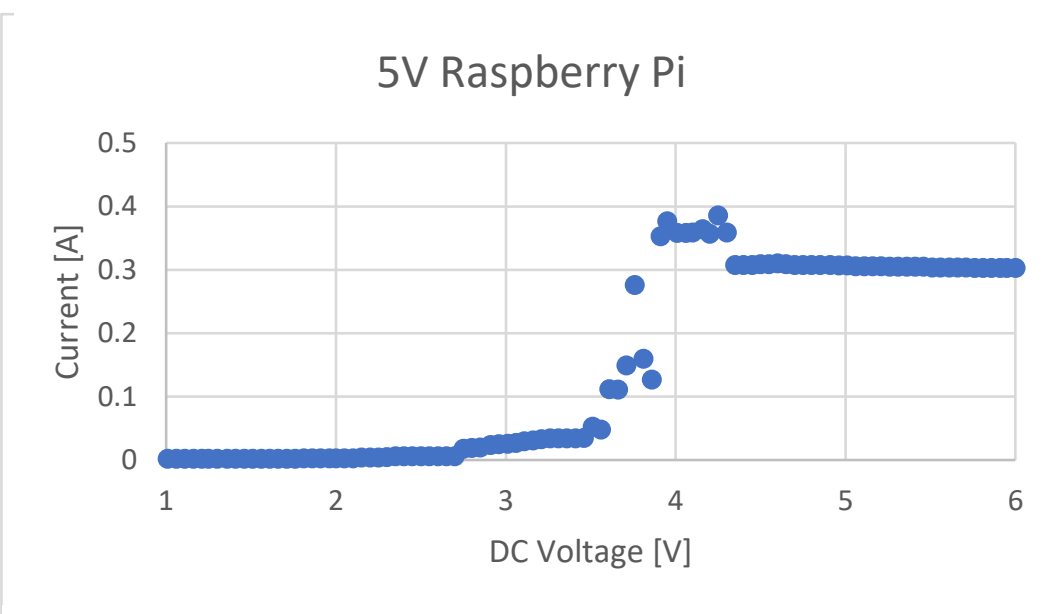

Figure 38: 5V Raspberry Pi Voltage Sweep

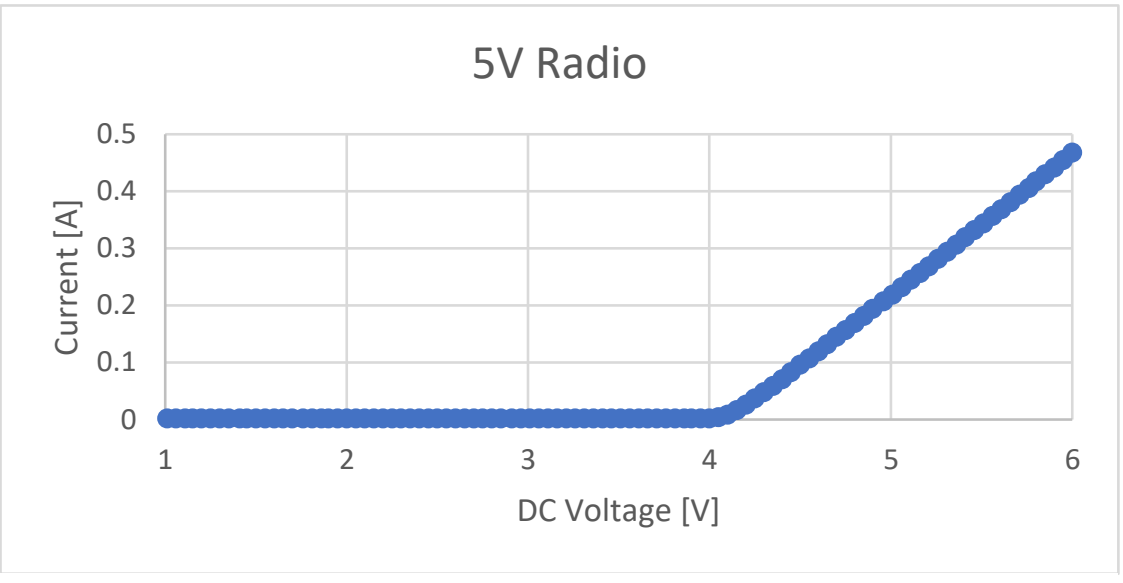

Figure 37: 5V Radio Voltage Sweep

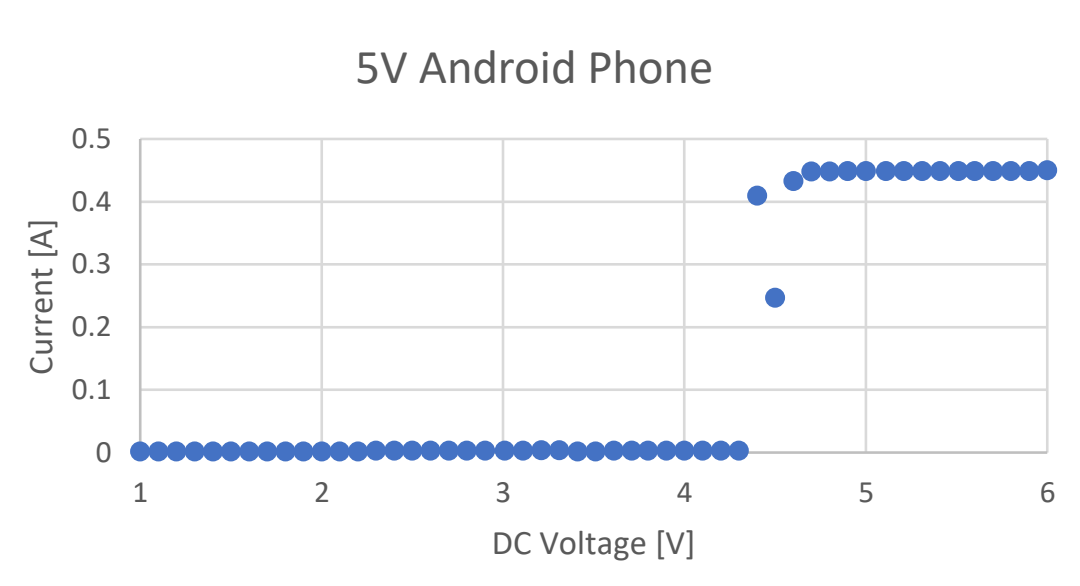

Figure 39: 5V Android Phone Voltage Sweep 


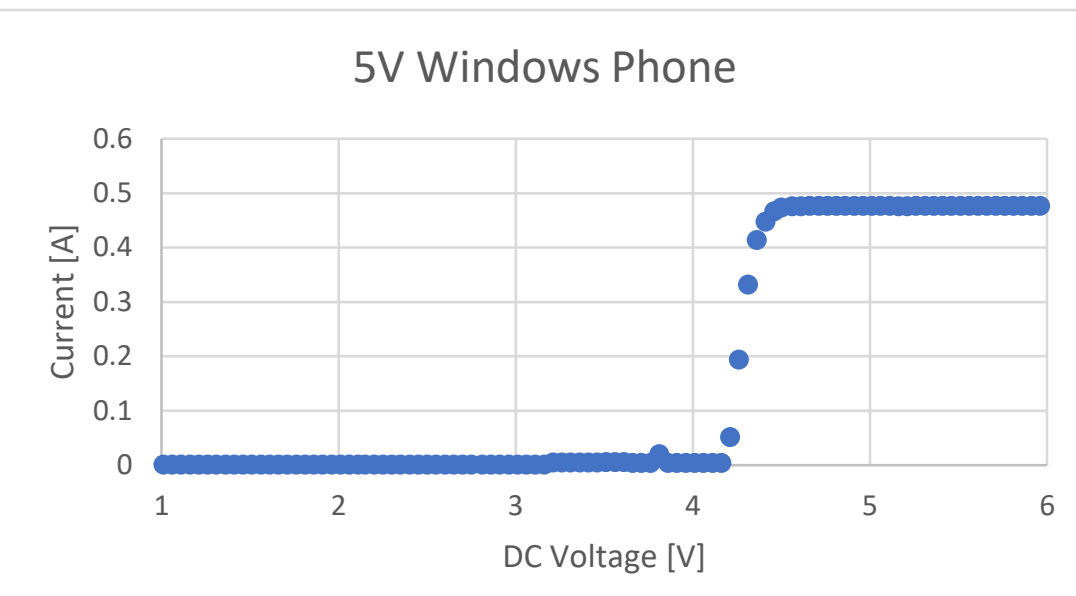

Figure 40: 5V Windows Phone Voltage Sweep

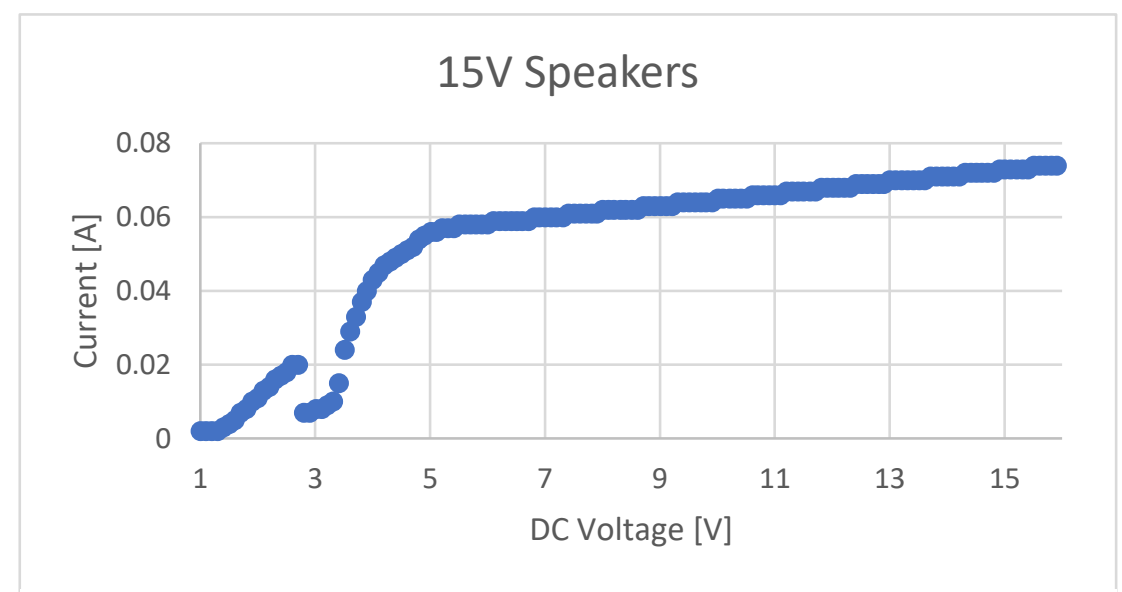

Figure 42: 15V Speakers Voltage Sweep

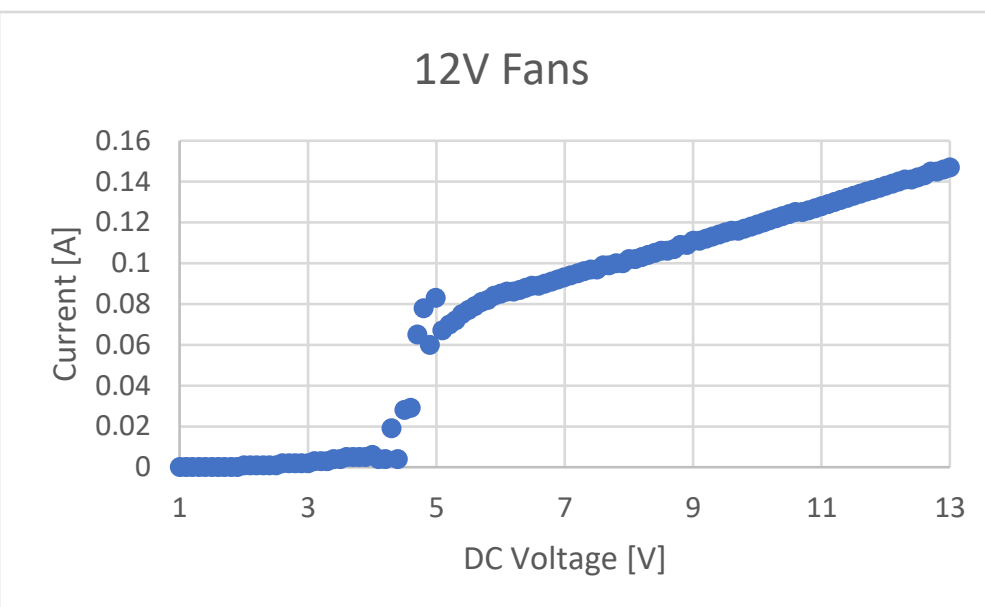

Figure 41: 12V Fans Voltage Sweep 


\section{B. Output Regulation}

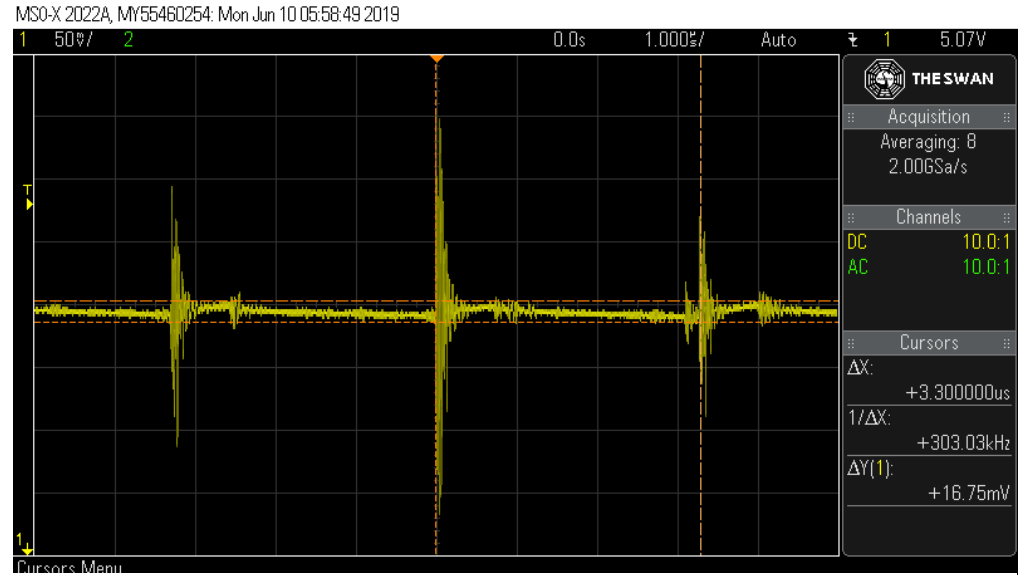

Figure 43: 4.5V TV Output Regulation

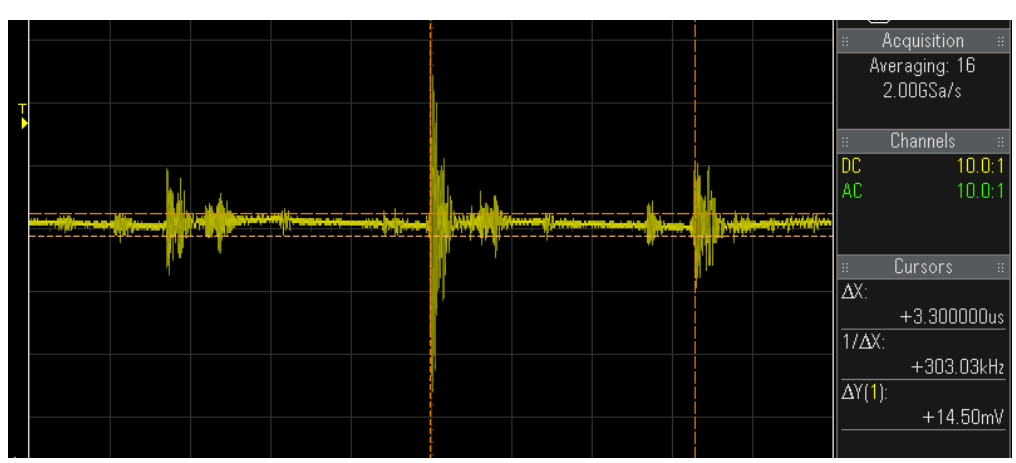

Figure 45: 5V Raspberry Pi Output Regulation

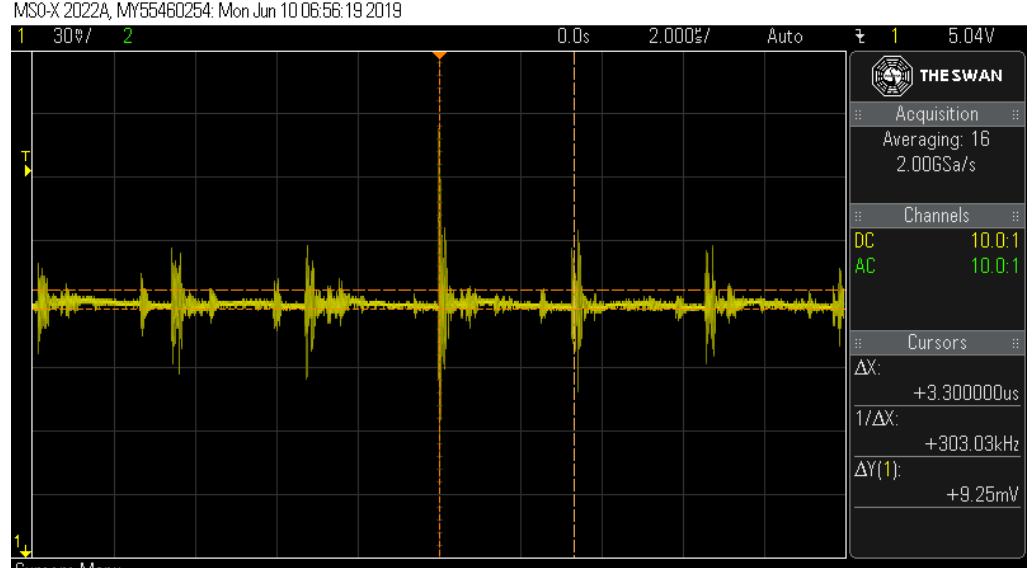

Figure 44: 5V Radio Output Regulation

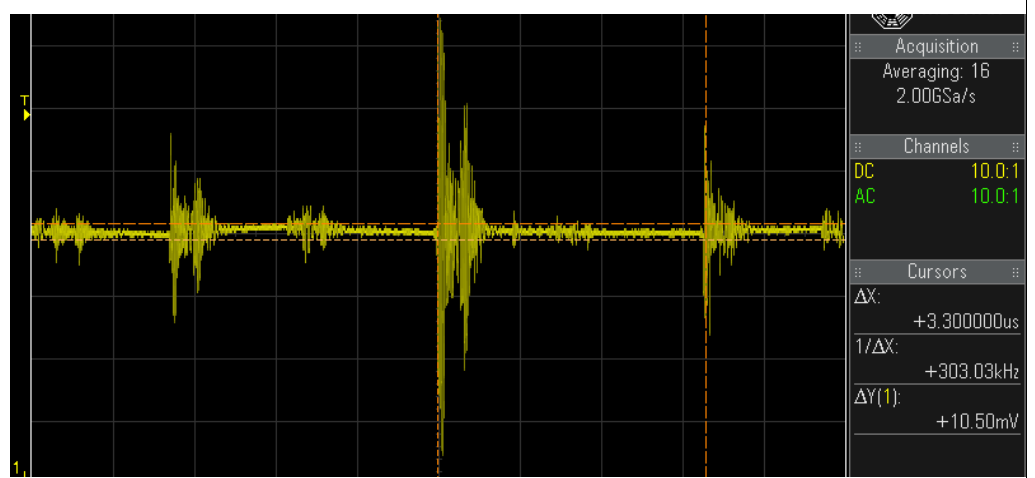

Figure 46: 5V Android Phone Output Regulation 


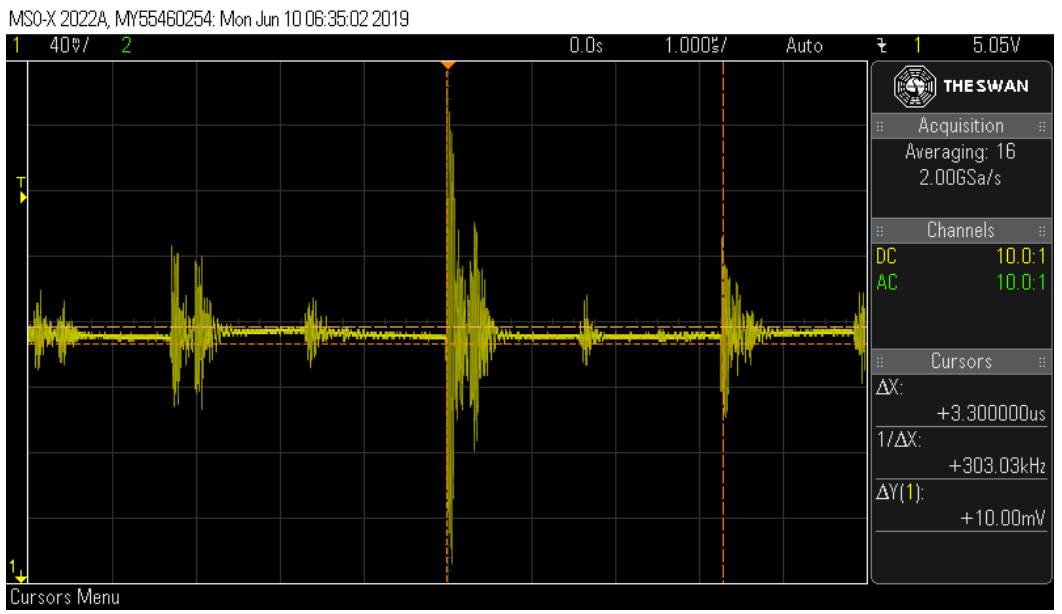

Figure 47: 5V Windows Phone Output Regulation

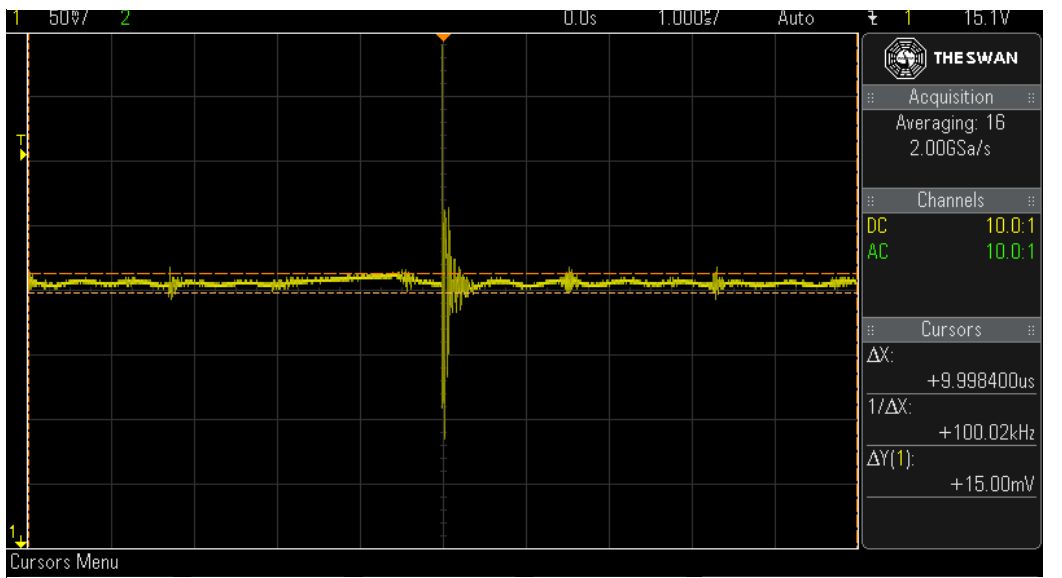

Figure 49: 15V Speakers Output Regulation

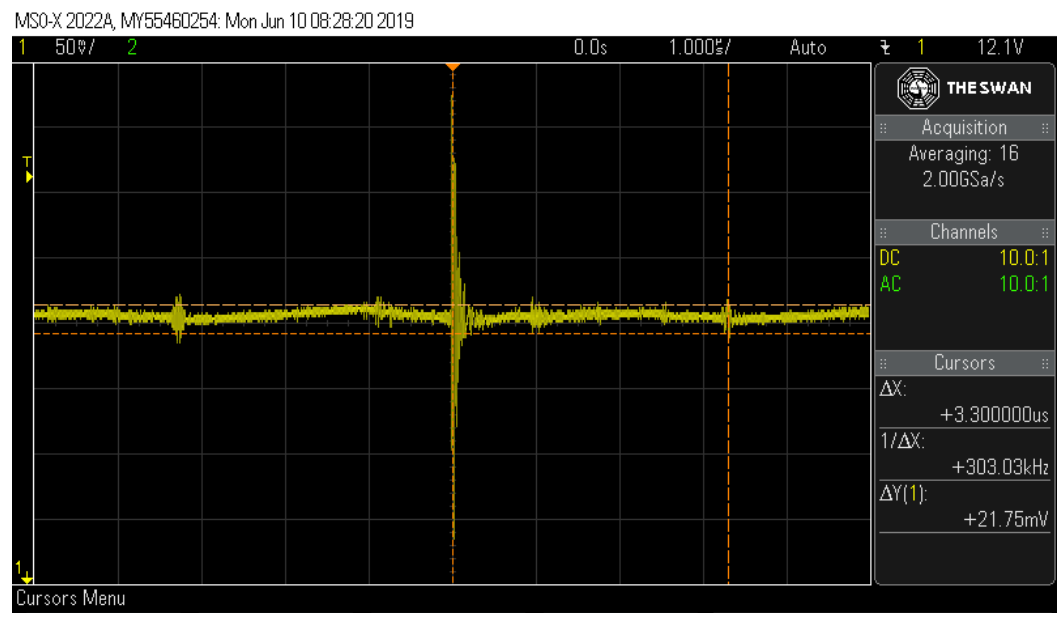

Figure 48: 12V Fans Output Regulation 


\section{Microcontroller Code}

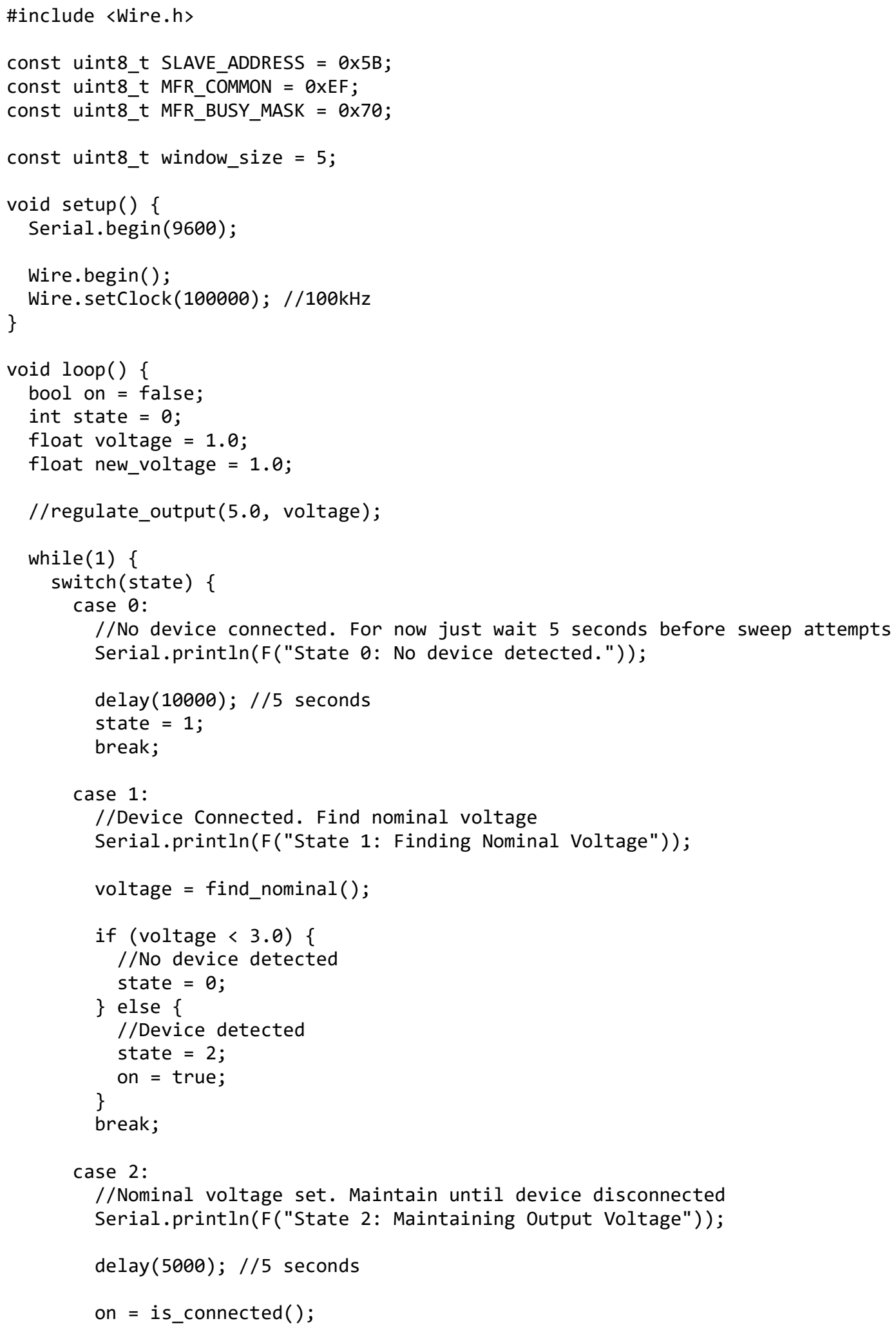




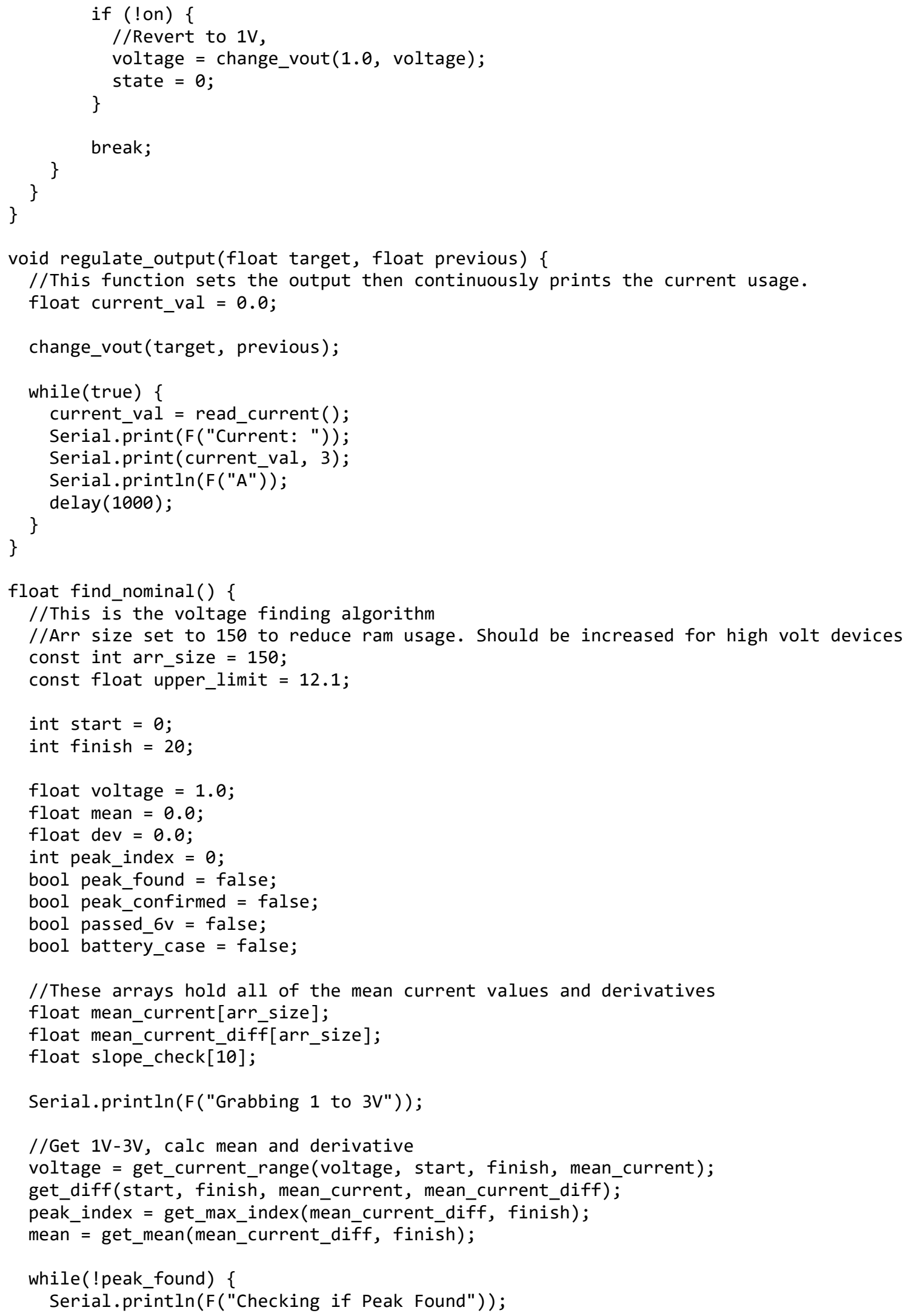


//Peak found when value is > $180 \%$ of mean $0.02))\{$

if ((mean_current_diff[peak_index] > $1.8 *$ mean) \&\& (mean_current[peak_index] >=

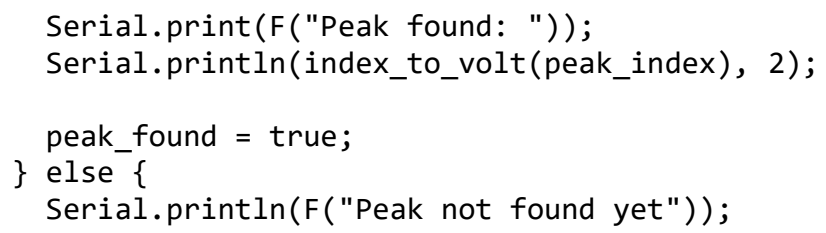




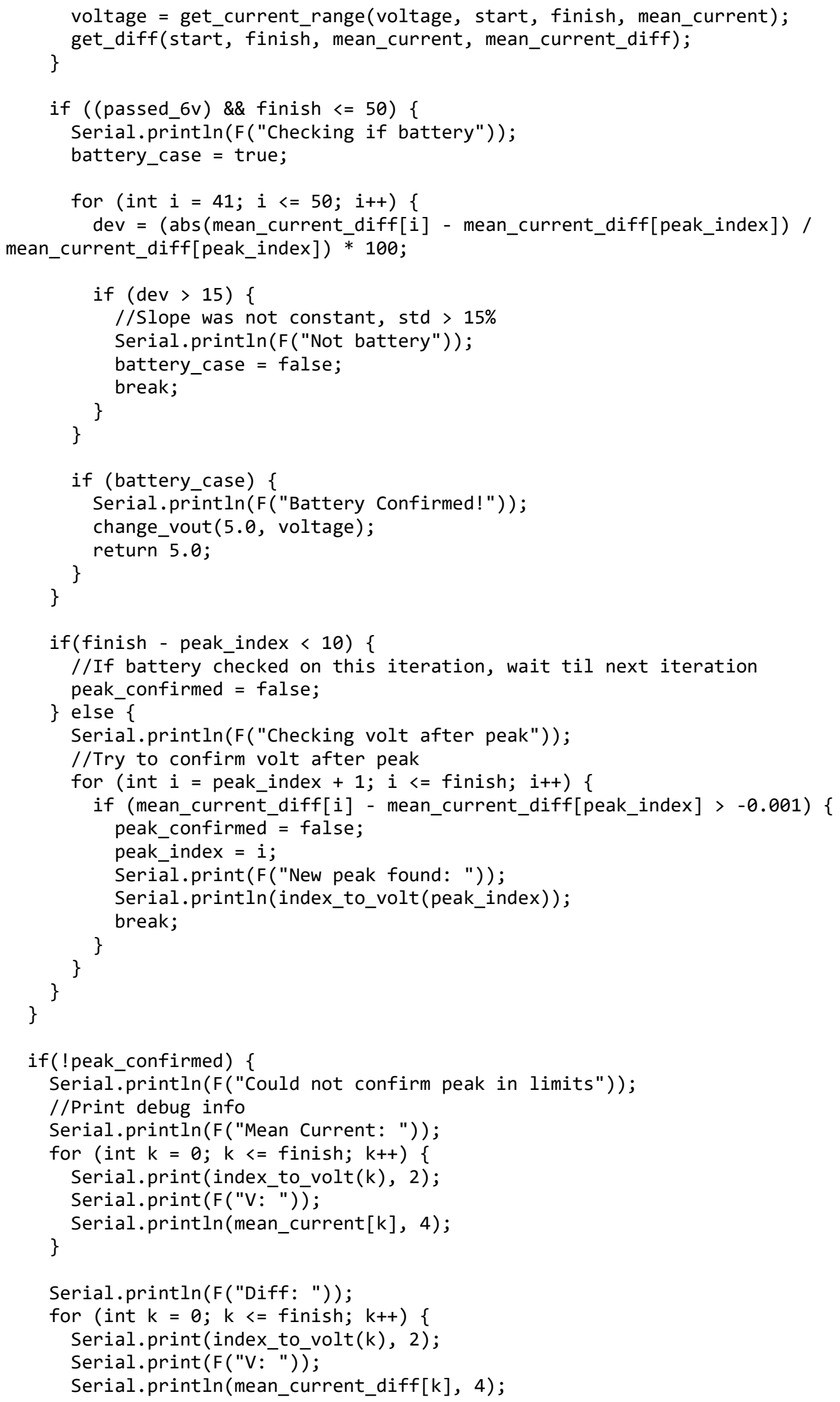




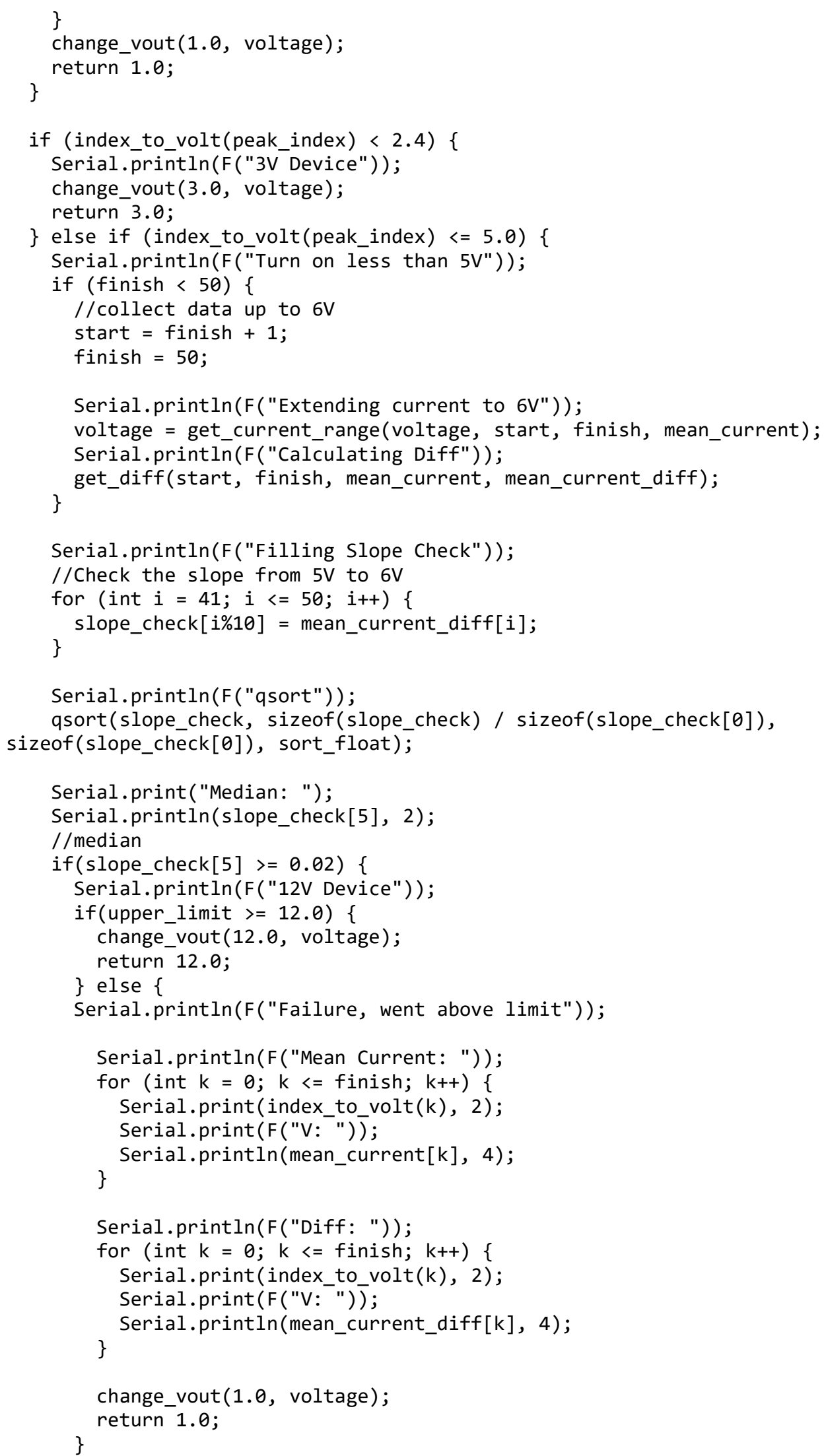




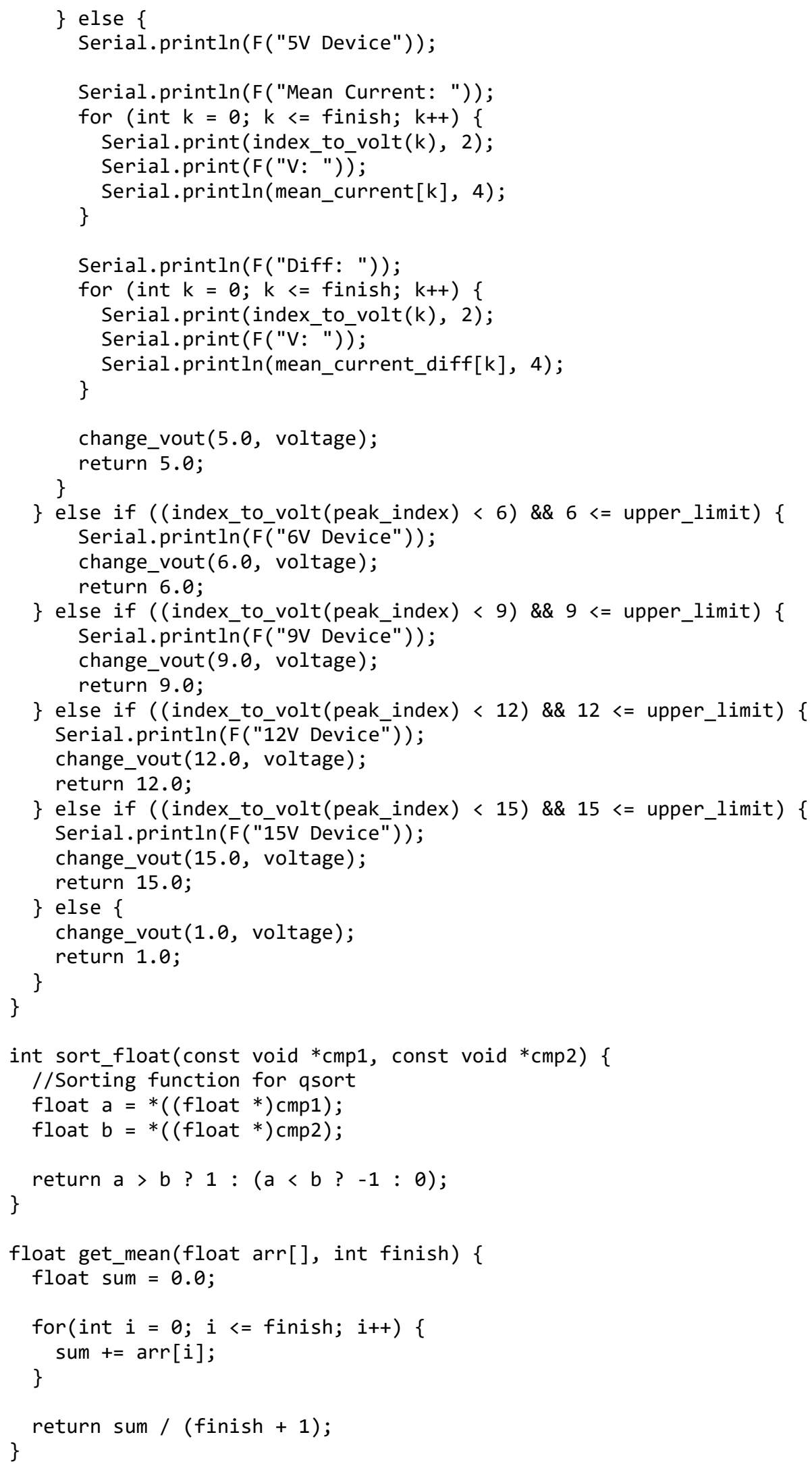




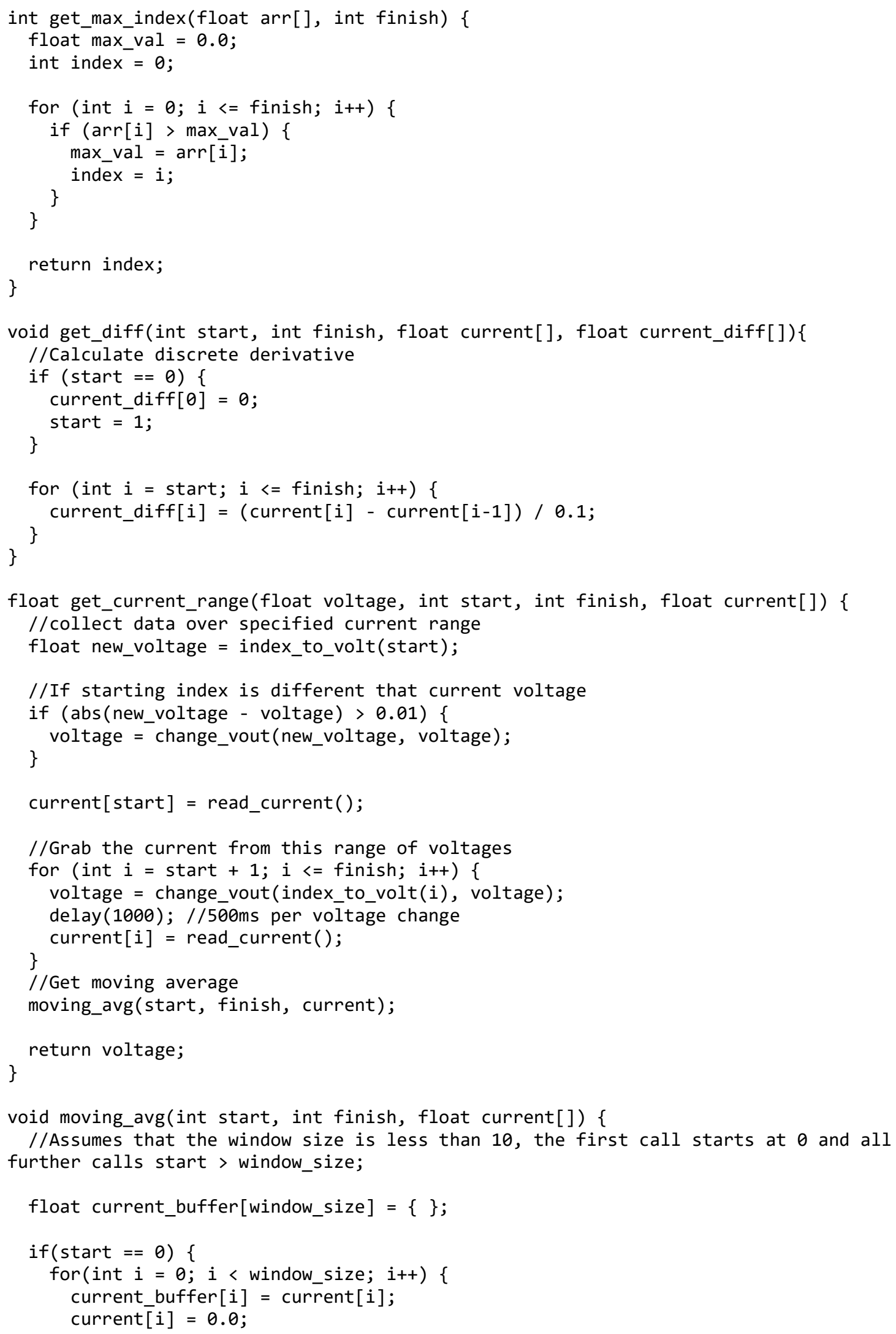




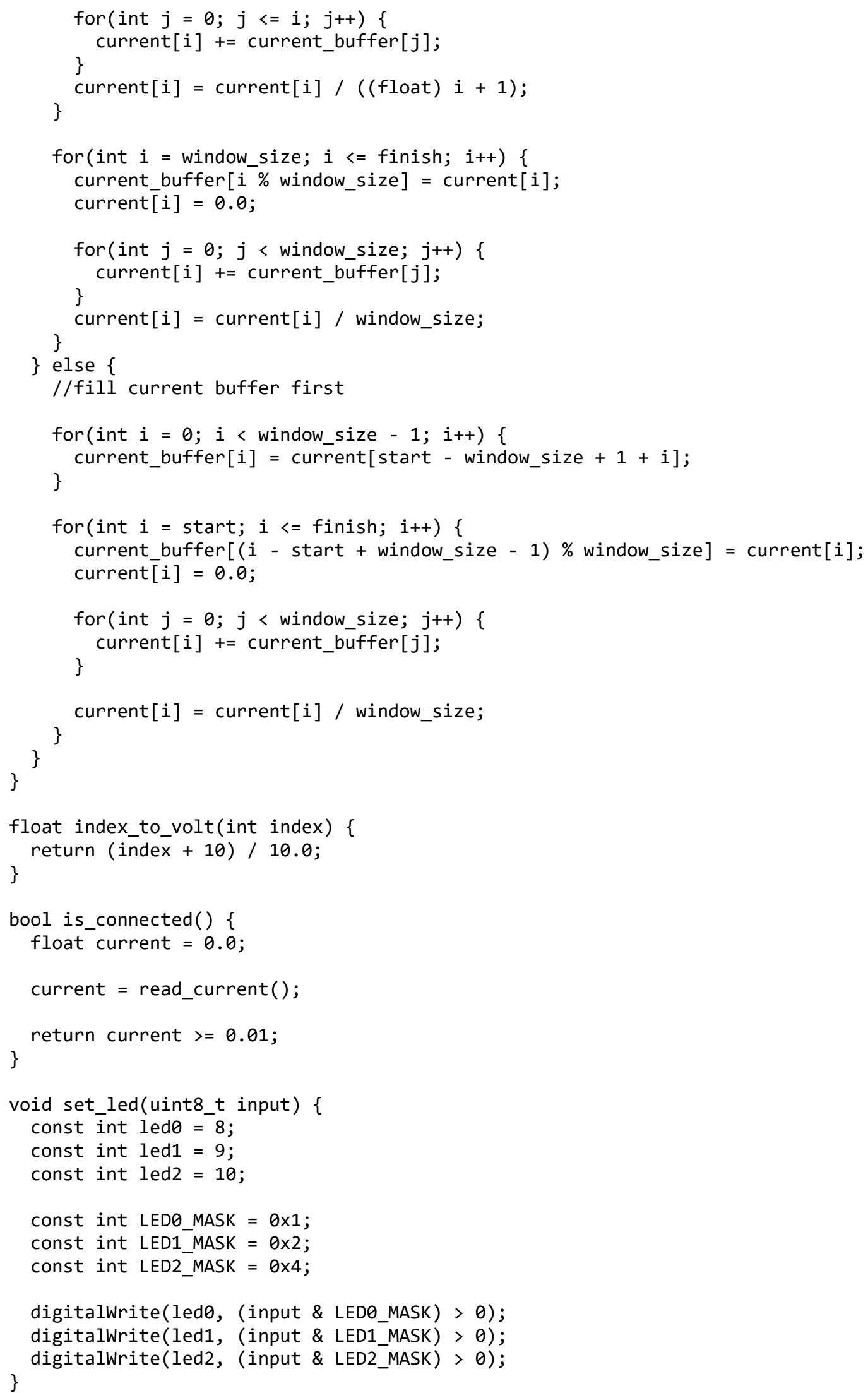




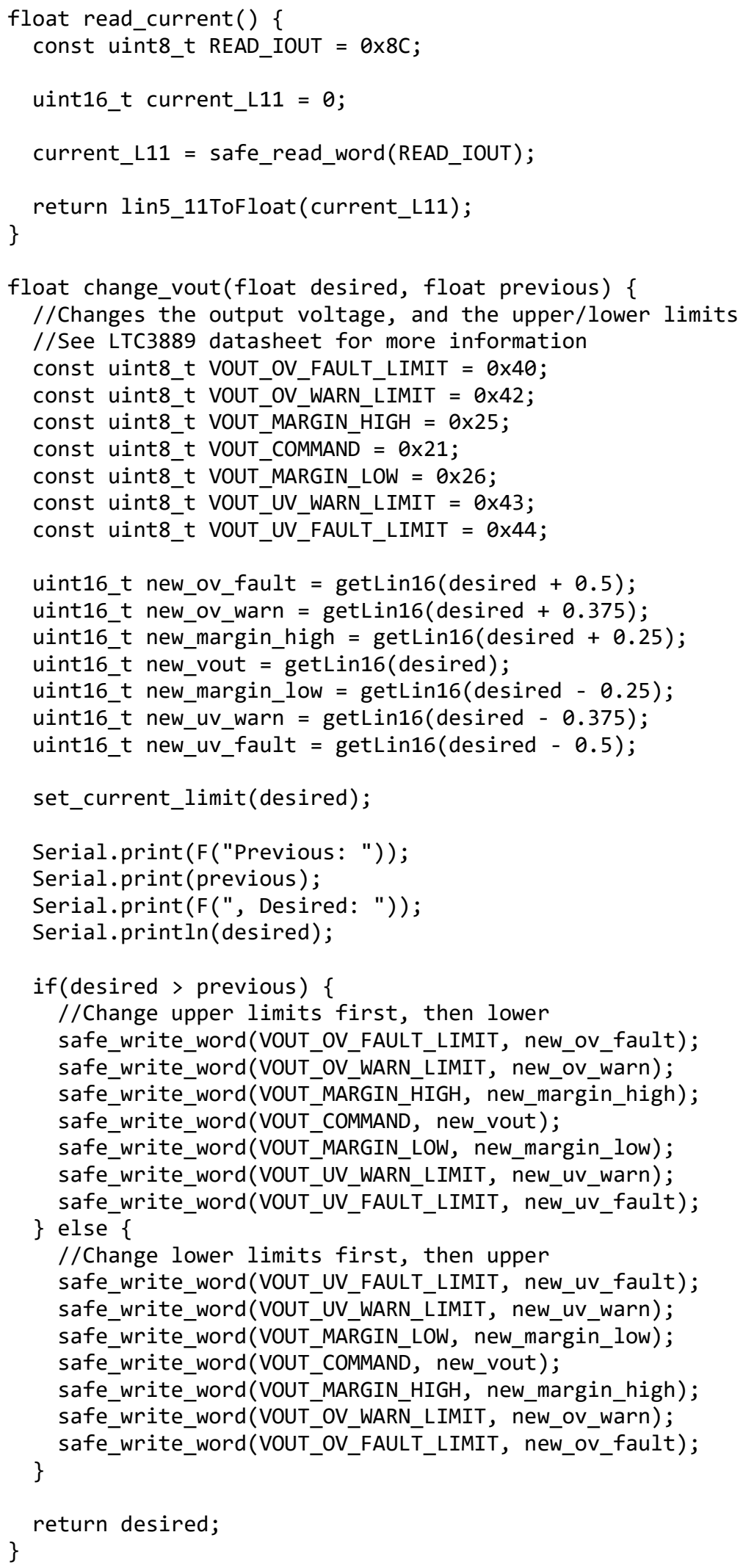




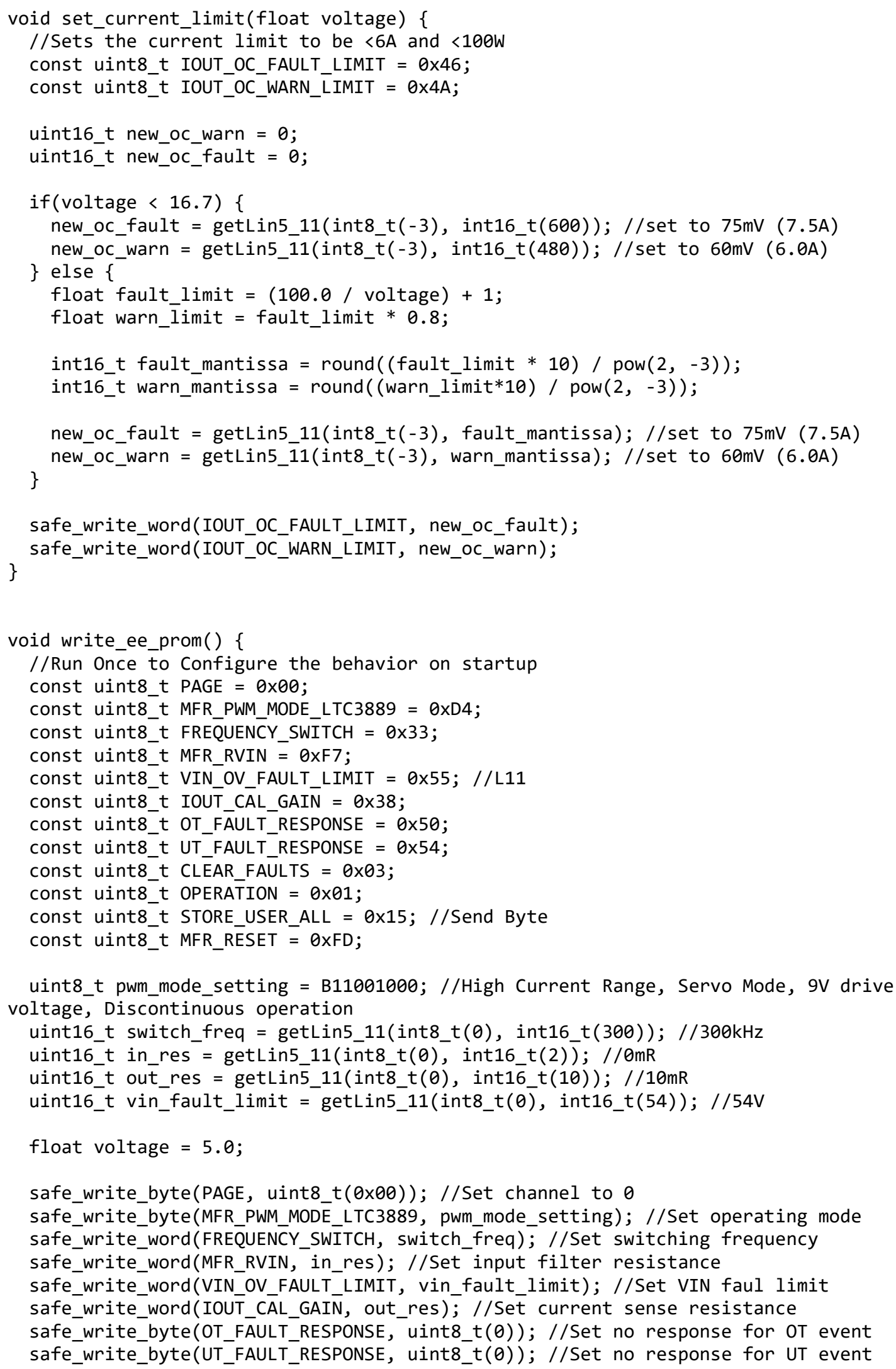




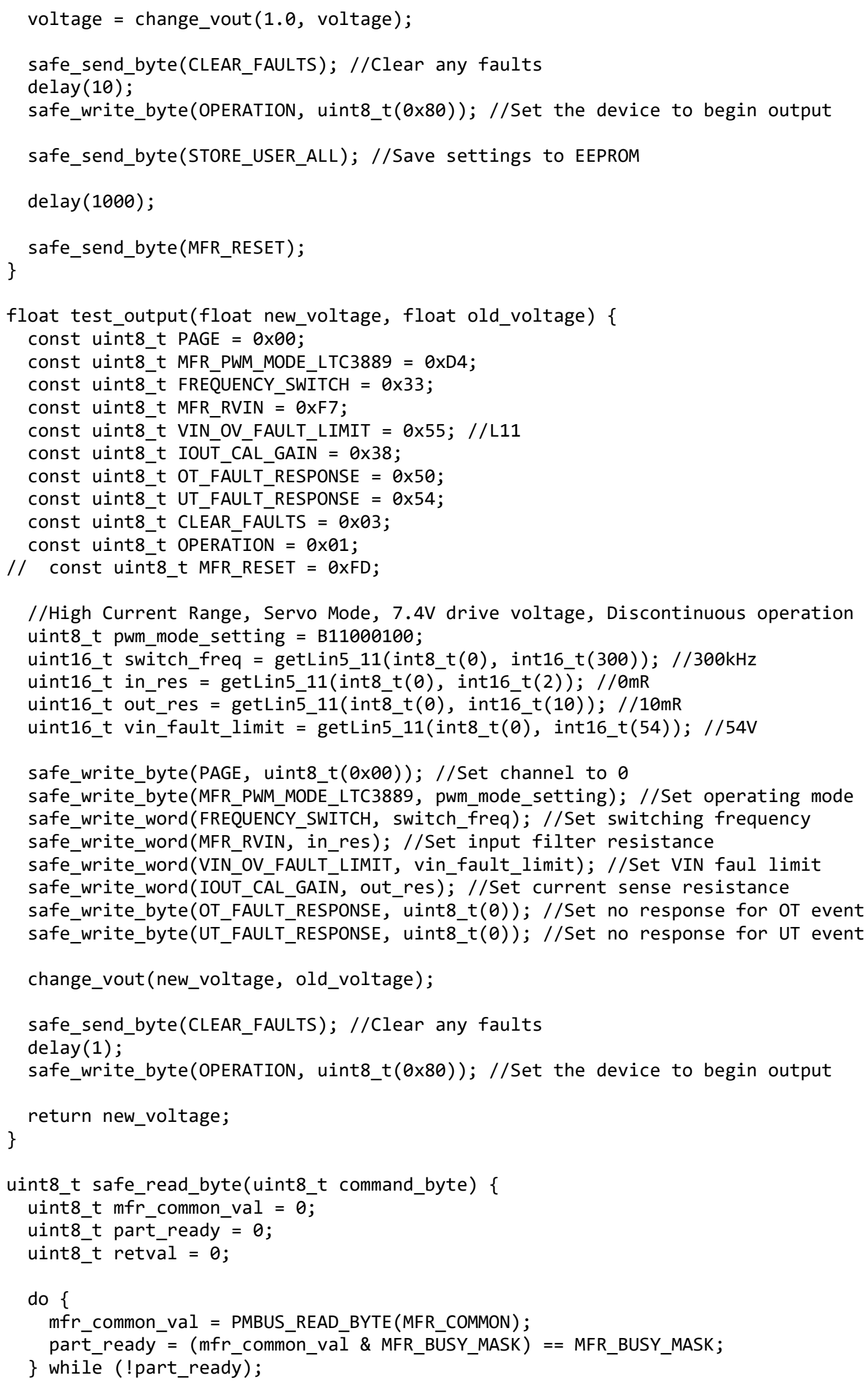




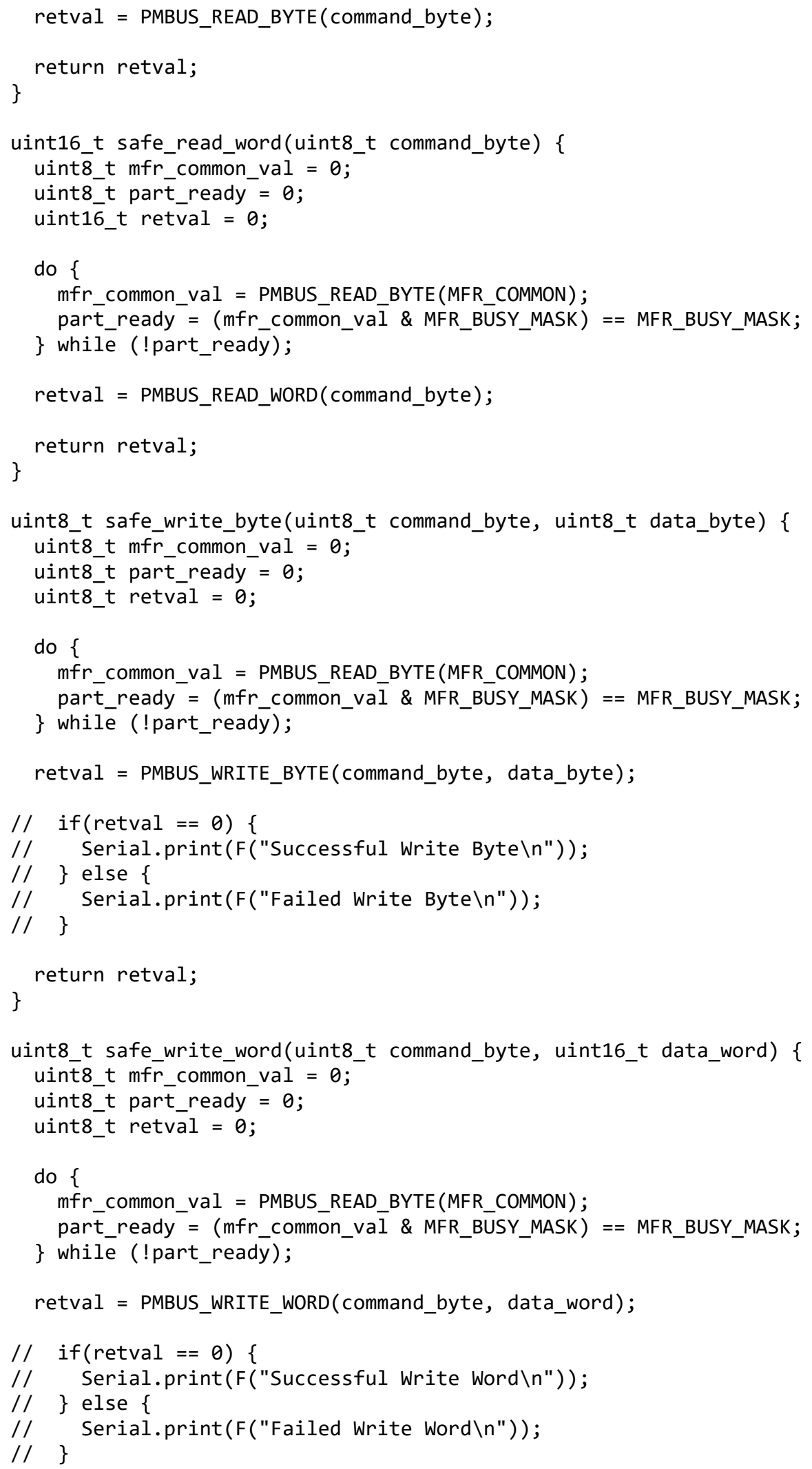




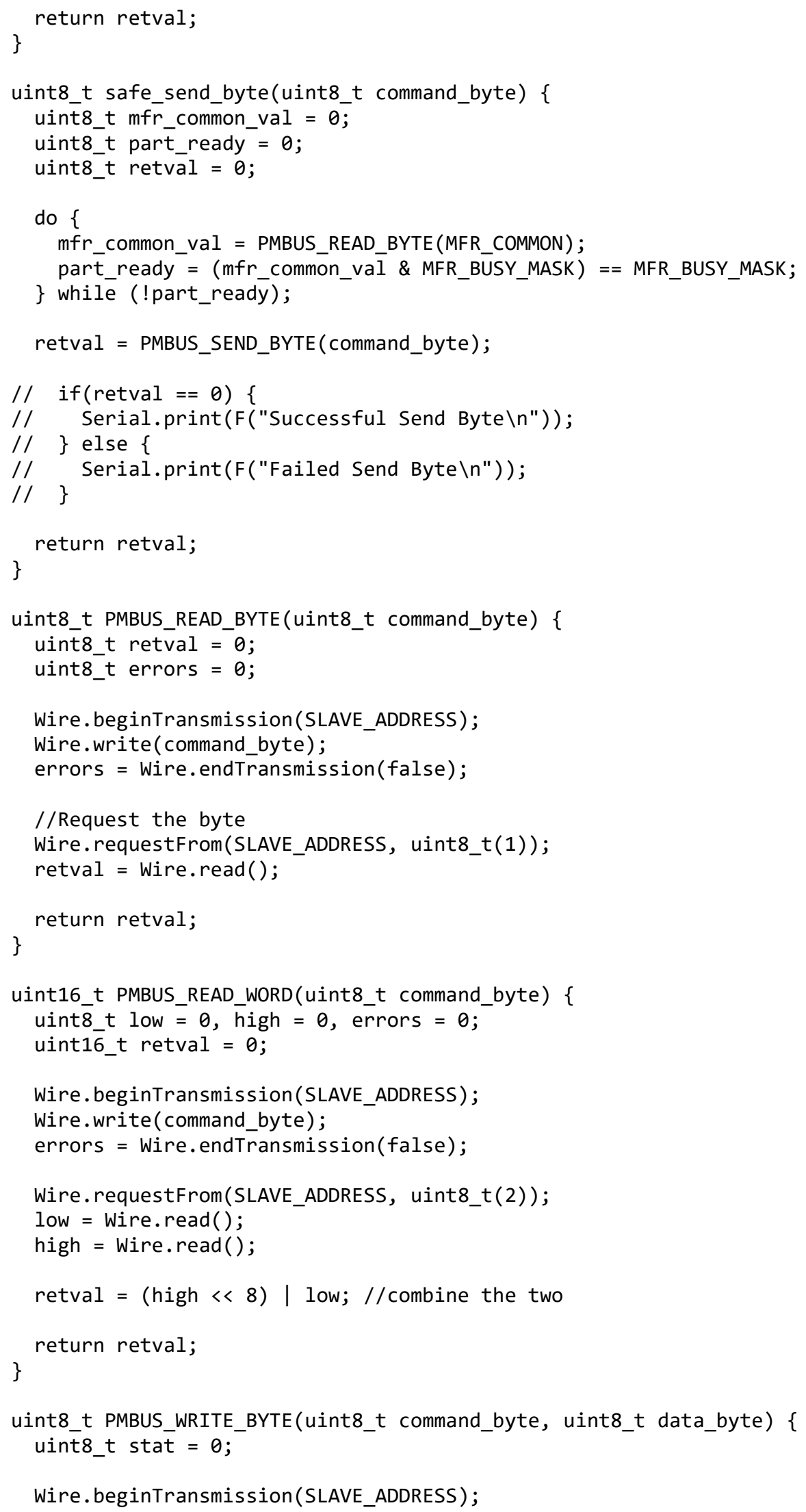




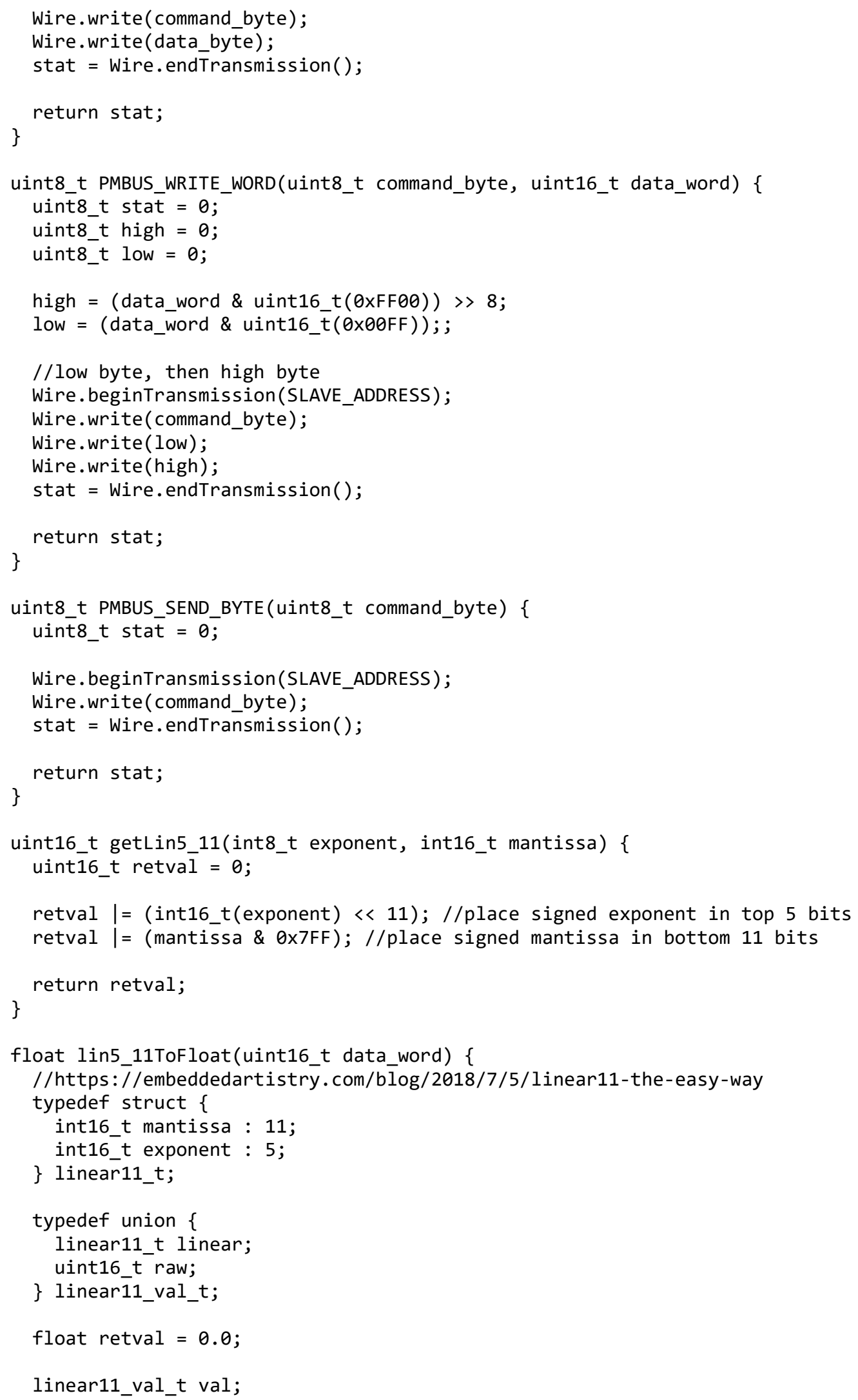




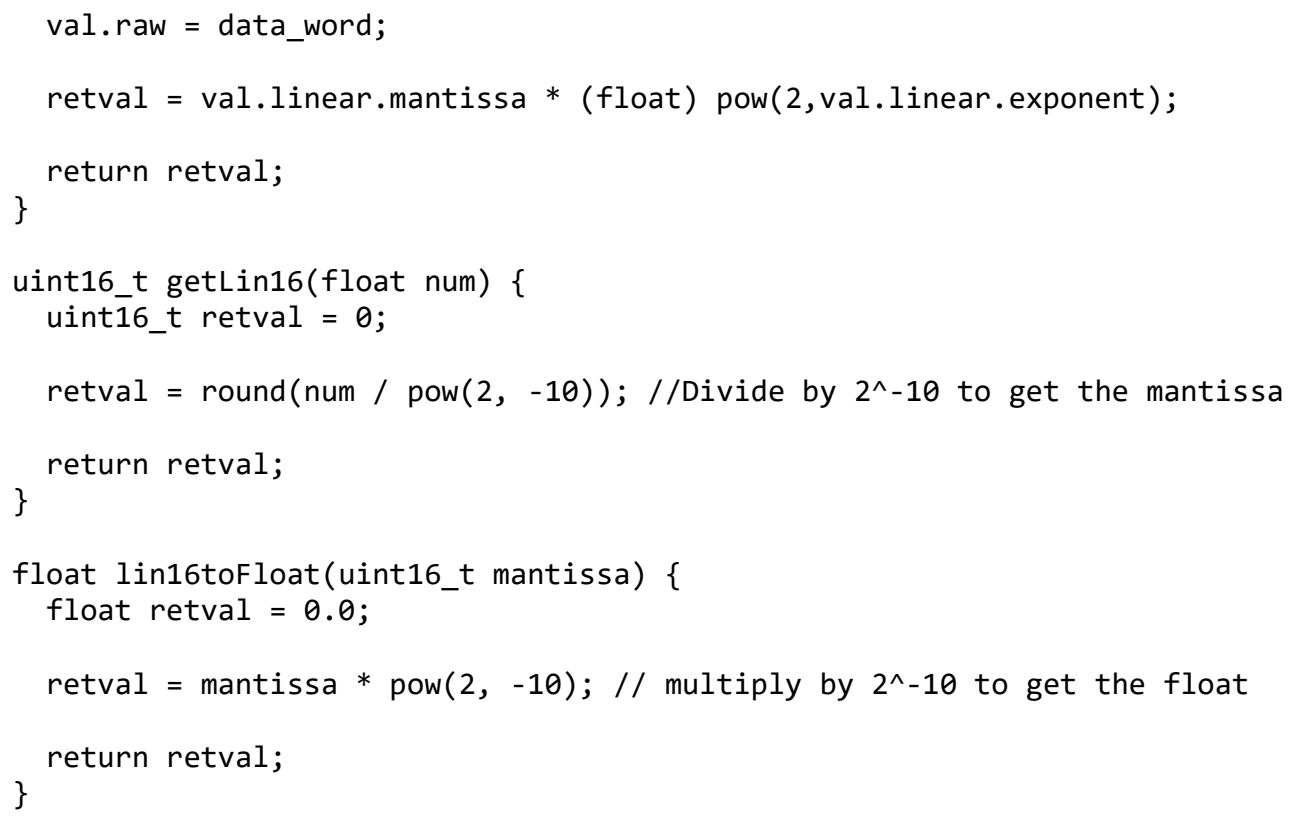

